Pre-print, peer-reviewed version of the article published in Applied Geochemistry:

Rees, F., Quideau, S., Dyck, M., Hernandez, G., \& Yarmuch, M. (2020). Water and nutrient retention in coarsetextured soil profiles from the Athabasca oil sand region. Applied Geochemistry, 104526. https://doi.org/10.1016/j.apgeochem.2020.104526

\title{
Water and nutrient retention in coarse-textured soil profiles from the Athabasca Oil Sand Region
}

Frédéric Rees ${ }^{1,2}$, Sylvie Quideau ${ }^{1, *}$, Miles Dyck $^{1}$, Guillermo Hernandez $^{1}$, Marty Yarmuch $^{3}$

${ }^{1}$ University of Alberta, Department of Renewable Resources, Edmonton, AB, Canada

${ }^{2}$ Current address: UMR ECOSYS, INRAE, AgroParisTech, Université Paris-Saclay, Thiverval-Grignon, France

${ }^{3}$ Mine Closure Research, Syncrude Canada Ltd., Edmonton, AB, Canada

*Corresponding author: Frédéric Rees, frederic.rees@inrae.fr 


\section{HIGHLIGHTS}

- The stock of nutrients was comparable between reclaimed and natural soils

- $\quad \mathrm{N}$ leaching depended on the design of soil cover and on the underlying substrate

- The downward movement of $\mathrm{N}$ was slower than the movement of water

- Fertilizer-N remained in the top $20 \mathrm{~cm}$ after an intense rainfall 


\section{ABSTRACT}

Post-mining land reclamation of Athabasca Oil Sands (AB, Canada) involves the reconstruction of soil profiles able to support a mosaic of boreal forest communities. However, the use of coarse-textured reclamation materials to recreate forest ecosystems represents a challenge in terms of soil water and nutrient availability. This work aimed to quantify nutrient leaching in reclaimed coarse-textured soils constructed with two coversoils (peat mineral mix and forest floor mineral mix) underlain by mineral materials, including a blended B/C subsoil reclamation material, lean oil sand overburden substrate, and tailing sand. Water retention and conductivity curves were estimated for each material, and their retention capacity for inorganic $\mathrm{N}$ and $\mathrm{P}$ was measured in sorption isotherm experiments. The redistribution of water, inorganic $\mathrm{N}$ and $\mathrm{P}$ five days after an intense rain event was evaluated in six different reclaimed soil profiles using a laboratory-controlled leaching experiment in 1.2-meter deep columns. The redistribution of fertilizer nutrients was also measured following the addition of ${ }^{15} \mathrm{~N}$-labelled ammonium and phosphate over the top $10 \mathrm{~cm}$ of the columns. In addition, a 25-day incubation experiment with the two coversoils enabled us to estimate the timing of $\mathrm{N}$ immobilization and nitrification processes. Our results show that, depending on the combination of materials used for land reclamation, the soil profiles may provide equal or higher amounts of inorganic $\mathrm{N}$ and $\mathrm{P}$ in the rooting zone compared to natural, coarse-textured soils of the region. Following the simulated intense rainfall, the peat-mineral mix was able to retain $44 \%$ of its initial inorganic $\mathrm{N}$ within the top $20 \mathrm{~cm}$ of the reclaimed soil profiles, while $84 \%$ of the inorganic $\mathrm{N}$ present in the forest floor mineral mix was leached down. Compared to the movement of water, the leaching of $\mathrm{N}$ down the soil profiles was slower and partly restricted by the presence of lean oil sand, and to a lesser degree tailing sand. Most of the introduced fertilizer- $\mathrm{N}$ remained in the first $20 \mathrm{~cm}$ of the soil profiles under the form of nitrate, although the incubation experiment suggested that nitrification only occurred after the simulated rainfall event. Based on our experimental data and on additional simulations of water and nutrient transport, we conclude that nutrient leaching in reclaimed soils can be significant if specific materials such as forest floor mineral material and coarse-textured subsoil are combined and when an intense rainfall occurs at a period coinciding with a high concentration of nitrate- $\mathrm{N}$ in the topsoil.

Keywords: Nutrient leaching, sorption, HYDRUS-1D, land reclamation, Technosol, Anthroposol 


\section{INTRODUCTION}

Controlling soil water and nutrient availability is a critical point in the reclamation of mining sites, particularly with coarse-textured soils. In the boreal region of Canada, Brunisolic and Podzolic soils are mostly coarse-textured and are therefore particularly susceptible to nutrient depletions (Maynard et al., 2014). In northeastern Alberta, Canada, coarse-textured soils (i.e., sandy loam and coarser) support a relatively wide range of forest productivity levels and species types, from nutrient-poor, low-productivity jack pine dominated stands to more productive trembling aspen and white spruce ecosystems (Beckingham and Archibald, 1996). Because these ecosystems are limited by soil moisture and nutrient availability, slight variations in soil texture may have a dramatic effect on forest productivity through a modification of water and/or nutrient availability (Barnes et al., 2018; Zettl et al., 2011). Such modification can in turn directly determine the composition and structure of the forest ecosystems which have developed on these soils (Barnes et al., 2018).

In the Athabasca Oil Sands Region (AOSR) of Alberta, open-pit mining implies complete removal of the existing vegetation, surface soils, overburden and the oil sand ore body that results in an excavation depth up to 75 meters (Alberta Environment, 2010). Once mining has been completed, land reclamation is done by reconstructing soil profiles with surface soil materials salvaged during the mining operations. In the specific context of oil sands mine operations in the AOSR, suitable soil materials for reclamation correspond to either coversoil or subsoil. Suitable coversoil materials include peat or peat-mineral mix salvaged from wetlands (e.g., bogs and fens), and forest floor mineral material (i.e., litter layer, A horizon and potentially a portion of the B horizon) from upland forest environments. The mineral material remaining after the removal of coversoil comprises the subsoil for reclamation; the maximum salvage depth of subsoil varies depending on the quality of the material and volume required for reclamation activities. The salvaged soil materials are used for land reclamation of a number of substrates which includes lean oil sand (i.e., overburden containing appreciable amount of naturally-occurring bitumen but not high enough for economical extraction) and tailing sand (i.e., sand component of tailings product that remain after bitumen extraction). A significant extent of the closure landforms consisting of lean oil sand and tailing sand substrate will be primarily upland forest environments that are moderately well to well drained. Reestablishment of common upland boreal forest species is required for this landscape to achieve equivalent land capability to pre-disturbance levels (Alberta Environment, 2010). Evaluation and establishment of an appropriate soil cover design (i.e., appropriate soil reclamation materials and capping depth thickness) is therefore essential for re-establishing a soil moisture and nutrient regime able to sustain the growth of natural upland boreal forest 
species in the reclaimed landscape. This is beneficial to reclamation practitioners who are developing and validating strategies to attain a sustainable boreal community within a reasonable timeframe and cost, relative to risk.

The amount of soil nutrients available to plants results from a complex balance between nutrient inputs by fertilizer or atmospheric deposition, soil organic matter mineralization, nutrient immobilization by microorganisms or sorption on soil organic and mineral phases, and nutrient losses by volatilization or leaching. While several studies have investigated how soil reclamation profiles and materials may release nutrients over time (Kwak et al., 2015; MacKenzie and Quideau, 2012; McMillan et al., 2007; Quideau et al., 2017), and how fertilizer addition to reclaimed soils may benefit plant growth, little is known regarding nutrient leaching in coarse-textured reclaimed soils of the AOSR. The leaching of inorganic $\mathrm{N}$ in a Luvisol from this region was estimated to be very low $(<7$ $\mathrm{mgN} \mathrm{m} \mathrm{yr}^{-1}$ ) below $45 \mathrm{~cm}$, because of the combined effect of low precipitation, low permeability of the illuviated B horizon and fast immobilization of $\mathrm{N}$ in the upper horizon (Jung and Chang, 2012). However, it is reasonable to suggest that there may be more leaching with coarser-textured soils, because of their higher rate of water percolation (Sitthaphanit et al., 2009). In such situations, the potential for nutrient leaching may depend on the water retention capacity and hydraulic conductivity of the soil profile and underlying substrate, rather than on mineralization or immobilization processes. Recently, a 325-day incubation experiment showed that the amount of phosphorus released from the two capping materials directly depended on the volume of water that percolated, whereas the release of nitrate was limited by the rate of soil organic matter mineralization and did not depend on the frequency of water inputs (Quideau et al., 2017).

The objective of this study was to investigate the potential for nutrient losses from a range of soil reclamation materials, soil cover designs and substrates following intense rainfalls, which typically occur in this region over summer. We investigated the movement of the initial pool of available nutrients generated from the soil by organic matter mineralization or abiotic release and the fate of external inorganic nutrients after fertilizer addition. Our working hypothesis was that the nutrient leaching potential in these soil reclamation profiles that contained coarsetextured soil materials would mainly depend on water dynamics, and could therefore be predicted from water retention and conductivity measurements. From a practical perspective, we also aimed to determine the soil cover designs that would be most suitable to recreate a soil moisture and nutrient regime similar to the coarse-textured, natural upland boreal forests in the local region. 


\section{MATERIALS \& METHODS}

\subsection{Description of the reclaimed soil profiles}

Five materials from oil sands mining and reclamation activities in the AOSR were investigated. The soil reclamation materials consisted of peat mineral mix (PMM) and forest floor mineral mix (FFM) coversoils, and a loamy sand textured, blended B, BC and C horizon subsoil (SUB). Two substrates were included in the investigation, overburden containing naturally-occurring bitumen and classified as lean oil sand (LOS), and tailing sand (TS), i.e. the sand fraction of the tailings product from the extraction of bitumen from the oil sand ore body. The materials for the study were collected at the Syncrude Aurora North mine $\left(57^{\circ} 19^{\prime} 20 \mathrm{~N}, 111^{\circ} 30^{\prime} 24 \mathrm{~W}\right)$ in northern Alberta. The soil reclamation materials and LOS substrate were collected from the Aurora Soil Capping Study (ASCS), while the tailing sand (TS) was collected at a tailings storage facility. The ASCS is a large-scale field trial to test a number of soil cover designs and capping depths to reclaim LOS overburden landforms. The experimental plots were constructed in 2011 according to various soil designs, and were planted to a mixture of trembling aspen (Populus tremuloides Michx.), white spruce (Picea glauca (Moench) Voss), and jack pine (Pinus banksiana Lamb.) in May of 2012. PMM, FFM, SUB and LOS were sampled from the plots of the Capping Study in November 2014, and TS in August 2016. Samples of each material were taken from different positions from the plots and stored in 20-1 buckets. Each material was then homogenized using a cement mixer and kept at $4^{\circ} \mathrm{C}$ in the dark until further use. A representative sample of each material was air-dried for four days, and then sieved to $2 \mathrm{~mm}$.

Six reclaimed soil profiles were tested in this work, using PMM or FFM in the 0-20 cm horizon, SUB in the 20$50 \mathrm{~cm}$ horizon, and either SUB, TS or LOS in the 50-120 cm horizon (Fig.1). The bulk density of each horizon was set according to field measurements of the experimental plots of the ASCS (Alberta Innovates, 2013) when possible, or what was practically achievable in the soil columns: $0.50 \mathrm{~g} \mathrm{~cm}^{-3}$ for PMM, $1.36 \mathrm{~g} \mathrm{~cm}^{-3}$ for FFM, 1.49 $\mathrm{g} \mathrm{cm}^{-3}$ for SUB, $1.42 \mathrm{~g} \mathrm{~cm}^{-3}$ for LOS, and $1.43 \mathrm{~g} \mathrm{~cm}^{-3}$ for TS. In our experimental work, the bulk density of LOS and TS were lower than field bulk densities that are generally in the range of $1.6 \mathrm{~g} \mathrm{~cm}^{-3}$ (Alberta Innovates, 2013; Yarmuch, 2003).

Peer-reviewed, unedited version of the manuscript of Rees et al. (2020) published by Applied Geochemistry: 
Fig. 1: Description of the reclaimed (R1-R6) and natural (N1 and N2) soil profiles. PMM: peat-mineral mix; FFM: forest floor mineral material; SUB: blended B/C horizons of sandy subsoil; TS: tailing sand; LOS: lean oil sand. For an easier comparison, soil horizons in the natural profiles N1 and N2 were simplified to match the 10$\mathrm{cm}$ increments used in the description of the reclaimed soil profiles.

\begin{tabular}{|c|c|c|c|c|c|c|}
\hline & $R 1$ & $R 2$ & $R 3$ & $R 4$ & $R 5$ & $R 6$ \\
\hline$\frac{0-10 \mathrm{~cm}}{10-20 \mathrm{~cm}}$ & $P M M$ & $F F M$ & $P M M$ & $F F M$ & $P M M$ & $F F M$ \\
\hline $20-30 \mathrm{~cm}$ & \multirow{10}{*}{$S U B$} & \multirow{10}{*}{$S U B$} & & & & \\
\hline $30-40 \mathrm{~cm}$ & & & $S U B$ & $S U B$ & $S U B$ & $S U B$ \\
\hline $40-50 \mathrm{~cm}$ & & & & & & \\
\hline $50-60 \mathrm{~cm}$ & & & \multirow{7}{*}{$T S$} & \multirow{7}{*}{$T S$} & \multirow{7}{*}{ LOS } & \multirow{7}{*}{ LOS } \\
\hline $60-70 \mathrm{~cm}$ & & & & & & \\
\hline $70-80 \mathrm{~cm}$ & & & & & & \\
\hline $80-90 \mathrm{~cm}$ & & & & & & \\
\hline $90-100 \mathrm{~cm}$ & & & & & & \\
\hline $100-110 \mathrm{~cm}$ & & & & & & \\
\hline $110-120 \mathrm{~cm}$ & & & & & & \\
\hline
\end{tabular}

\begin{tabular}{|c|c|c|}
\hline & $N 1$ & N2 \\
\hline $0-10 \mathrm{~cm}$ & $L F H / A e$ & $L F H$ \\
\hline $10-20 \mathrm{~cm}$ & \multirow{4}{*}{$B m 1$} & $\mathrm{Ae}$ \\
\hline $20-30 \mathrm{~cm}$ & & \multirow{3}{*}{$B m$} \\
\hline $30-40 \mathrm{~cm}$ & & \\
\hline $40-50 \mathrm{~cm}$ & & \\
\hline $50-60 \mathrm{~cm}$ & \multirow{3}{*}{$B m 2$} & \multirow{2}{*}{$B C$} \\
\hline $60-70 \mathrm{~cm}$ & & \\
\hline $70-80 \mathrm{~cm}$ & & \multirow{2}{*}{ IIC } \\
\hline $80-90 \mathrm{~cm}$ & \multirow{4}{*}{$B C$} & \\
\hline $90-100 \mathrm{~cm}$ & & \multirow{3}{*}{ IIIC } \\
\hline $100-110 \mathrm{~cm}$ & & \\
\hline $110-120 \mathrm{~cm}$ & & \\
\hline
\end{tabular}

\subsection{Characterization of the reclamation materials}

To determine the different sand fractions, each of the five air-dried materials was passed through a set of five different sieves (ASTM Nr. 18, 35, 60, 140 and 270) using automatic shaking for 5 minutes. Particle size distribution of FFM, SUB, LOS and TS was measured on air-dried soil $<2 \mathrm{~mm}$ based on the method described by Bouyoucos (1962) using a hydrometer (ASTM Soil Hydrometer 152H - Temp. 68 F), after removal of carbonate with $\mathrm{HCl}$ treatment and organic matter with $30 \% \mathrm{H}_{2} \mathrm{O}_{2}$.

The water content of each air-dried material (sieved to $2 \mathrm{~mm}$ ) was determined at a water pressure of $-10 \mathrm{kPa}$ and $-1500 \mathrm{kPa}$, which were assumed to represent the field capacity and the wilting point, respectively, using a pressure plate extractor (Soil Moisture Equipments Corp.). The gravimetric water content of each sample was then calculated from the weight loss after drying for $24 \mathrm{~h}$ at $105{ }^{\circ} \mathrm{C}$. The lower points of the water retention curve with water tension higher than $1500 \mathrm{kPa}$ were assessed using a Dewpoint PotentioMeter WP4-T (Decagon Devices Inc., Pullman, WA, USA), based on the measurement of water tension using the chilled mirror dewpoint technique. The water retention and hydraulic conductivity curves were also measured using HYPROP equipment (UMS GmbH, Munich, Germany), based on the evaporation method (Schindler et al., 2010). HYPROP measurements were made on soil cylinders taken from a bucket filled with field-moist material that was compacted to reach the required bulk density. For each of these techniques, three replicates of each material were used. Hydraulic 
conductivity at saturation was also measured in duplicates according to the falling head method (Klute and Dirksen, 1986). All these measurements were used to model the water retention curve and the hydraulic conductivity curve with the bimodal constrained van Genuchten model (Durner, 1994) using the HYPROP Data Evaluation Software (see the detailed equations in Supporting material 1).

The hydrophobicity of each material, either air-dried and sieved to $2 \mathrm{~mm}$ or field-moist and not sieved, was assessed with water drop penetration tests adapted from previous works (Doerr, 1998; Flores-Mangual et al., 2011). Between 50 and $100 \mathrm{~g}$ of each material were placed into a 1-cm high aluminum cup. A drop of deionized water $(\sim 0.05 \mathrm{ml})$ was placed on the flattened surface, using a hypodermic syringe. The penetration time of the drop was defined as the maximal time until no visible water films could be seen on the surface of the material. Aluminum cups were covered with a glass beaker to minimize water evaporation.

The $\mathrm{pH}$ value of each material was measured in deionized water or $0.01 \mathrm{M} \mathrm{CaCl}_{2}$ using an Accumet XL200 $\mathrm{pH}$ (1:5 vol. ratio) according to the international norm ISO 10390 (2005). Total carbon, organic carbon and nitrogen contents were measured by dry combustion at the Natural Resources Analytical Laboratory (NRAL) of the University of Alberta on finely ground samples using flash combustion and analysis on a Costech 4010 Elemental Analyzer System (Costech Analytical Technologies Inc., Valencia, CA, USA). In addition, organic matter content was estimated by loss of ignition after $4 \mathrm{~h}$ at $550^{\circ} \mathrm{C}$. Total inorganic $\mathrm{P}$ was determined by measuring $\mathrm{P}$ concentrations in $0.5 \mathrm{~mol} \mathrm{l}^{-1} \mathrm{H}_{2} \mathrm{SO}_{4}$ extracts (1:10 soil to solution ratio). Total organic $\mathrm{P}$ was estimated by the difference of inorganic $\mathrm{P}$ measured in one ignited sample $\left(550^{\circ} \mathrm{C}\right.$ for $\left.4 \mathrm{~h}\right)$ and an un-ignited sample (O’Halloran and Cade-Menun, 2008). Extractable P was measured by extraction with either $\mathrm{NaHCO}_{3}(\mathrm{Olsen}, 1954), 0.5 \mathrm{M}$ $\mathrm{K}_{2} \mathrm{SO}_{4}$ or according to the modified Kelowna method (Quideau et al., 2017), and analyzed by ICP-OES on a Thermo iCAP6300 Duo (Thermo Fisher Corp., Cambridge, UK). Inorganic N was extracted by 0.5M K $\mathrm{SO}_{4}(1: 10$ m:v ratio), and analyzed by NRAL as $\mathrm{NH}_{4}-\mathrm{N}$ and $\mathrm{NO}_{3}-\mathrm{N}$ on a SmartChem 200 (Westco Scientific Ltd., Brookfield, CT, USA). Cation exchange capacity (CEC) was measured at NRAL using exchange with ammonium acetate (Metson, 1956).

\subsection{Comparison with natural analog soils}

In order to compare the water retention capacity and nutrient availability in the reclaimed soil profiles with those from natural forest soils of the region, two coarse-textured analog soils were sampled and used as a reference. Both soils were selected based on the work of Barnes et al. (2018), who investigated a range of natural coarse-textured 
soils in the area to establish a possible link between soil properties and forest ecosystem characteristics. Natural soil N1 was sampled under a jack pine (Pinus banksiana) dominated forest, and natural soil N2 under an aspen (Populus tremuloides) dominated forest. N1 and N2 were selected as representative of the range of forest ecosystems (overstory and understory) present on coarse-textured soils in this region. Both N1 and N2 were classified as Eluviated Dystric Brunisols and corresponded to sites \#118-2 and \#177 described in Barnes et al. (2018). Soil samples were taken from each horizon (Fig. 1) and analyzed separately for plant-available water (difference in soil water contents at a water tension of $-10 \mathrm{kPa}$ and $-1500 \mathrm{kPa}$ ), total organic $\mathrm{C}$, total $\mathrm{N}$ and $\mathrm{P}$, and $0.5 \mathrm{M} \mathrm{K}_{2} \mathrm{SO}_{4}$ extractable inorganic $\mathrm{N}$ and $\mathrm{P}$ using the same procedures described above for the reclamation materials.

\subsection{Nutrient sorption experiment}

A sorption-desorption procedure was used to assess the chemical retention capacity of each material for ammonium-N, nitrate-N and phosphate-P. For the sorption step, $5 \mathrm{~g}$ of air-dried material $(<2 \mathrm{~mm})$ was added to a $50-\mathrm{ml}$ centrifugation tube, and $50 \mathrm{ml}$ of a $0.1 \mathrm{M} \mathrm{KCl}$ solution containing varying concentrations of $\mathrm{NH}_{4} \mathrm{NO}_{3}$ and $\mathrm{KH}_{2} \mathrm{PO}_{4}$ was added. The initial concentrations of $\mathrm{NH}_{4}-\mathrm{N}$ and $\mathrm{NO}_{3}-\mathrm{N}$ in the tubes corresponded to $0,0.5,1,5$ or $10 \mathrm{mmol} \mathrm{l}^{-1}$, and the corresponding initial concentration of $\mathrm{H}_{2} \mathrm{PO}_{4}-\mathrm{P}$ were $0,0.05,0.1,0.5$ and $1 \mathrm{mmol} \mathrm{l}^{-1} .0 .1 \mathrm{M}$ $\mathrm{KCl}$ was used as a background electrolyte to maintain a relatively constant ionic force $\left(0.101-0.115 \mathrm{~mol}^{-1}\right)$ despite the variations in nutrient concentrations. Tubes were shaken for $20 \mathrm{~h}$ on a mechanical shaker at $200 \mathrm{rpm}$, and then centrifuged for $10 \mathrm{~min}$ at $4000 \mathrm{rpm} .35 \mathrm{ml}$ of the supernatant was sampled and filtered to $0.45 \mu \mathrm{m}$, and two 15 -ml subsamples were stored in glass vials at $-20{ }^{\circ} \mathrm{C}$ before analysis. For the desorption step, $35 \mathrm{ml}$ of pure $0.1 \mathrm{M} \mathrm{KCl}$ without nutrients was added to the suspensions remaining in each tube, so that the new initial nutrient concentration in the tube corresponded to $30 \%$ of the previous sorption equilibrium concentration. Tubes were shaken again for $20 \mathrm{~h}$, centrifuged for $10 \mathrm{~min}$ at $4000 \mathrm{rpm}$, and two $15-\mathrm{ml}$ subsamples were stored in glass vials at $-20{ }^{\circ} \mathrm{C}$ before analysis. Each treatment was repeated in triplicate. Ammonium, nitrate and phosphate concentrations in the $0.1 \mathrm{M}$ $\mathrm{KCl}$ extracts were analyzed colorimetrically by reaction with sodium salicylate, vanadium cocktail and malachite green, respectively (Quideau et al., 2017), using a BioTek Synergy HT multi-detection microplate reader. Results from this experiment were used to calculate nutrient sorption parameters for each materials, based on Langmuir or Freundlich models (Rees et al., 2014). As we assumed that the net immobilization of nutrients over this short period would mainly occur through abiotic processes (i.e. sorption, ion exchange or precipitation), no attempt was made to impose sterile conditions by treating the materials or adding a biocide in solution. The results obtained 
from control tubes containing nutrient solutions without materials, or materials without nutrient addition and stored at $4{ }^{\circ} \mathrm{C}$ or shaken at $22^{\circ} \mathrm{C}$, suggested that biological activity did not significantly affect the net amount of inorganic $\mathrm{N}$ and $\mathrm{P}$ remaining in solution after $20 \mathrm{~h}$ (data not shown).

\subsection{Column leaching experiment}

A 6-day column leaching experiment took place in our laboratory at a temperature of $20 \pm 2{ }^{\circ} \mathrm{C}$, using acrylonitrile butadiene styrene (ABS) pipes (7.6 cm diam.) cut in 10-cm segments and then sealed with silicone glue (Fig. S1). A small pipe $(0.5 \mathrm{~cm}$ diam. $)$ was installed at the bottom of the column to allow free drainage. A rain simulator based on the principle of a Mariotte's bottle was installed on the top of each column. Columns were filled with non-sieved, field-moist reclamation materials at the desired bulk density in order to reproduce the $120-\mathrm{cm}$ reclaimed soil profiles (Fig. 1). Following a resting period of 16-20 $\mathrm{h}$ after filling the columns, an identical amount of deionized water was applied simultaneously at the top of each column through the rain simulators at a constant

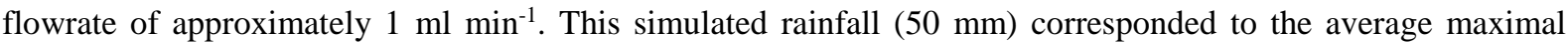
rainfall observed each summer in Fort McMurray (AB, Canada) from 2001 to 2015 (Table S1). The water was however added to the column at a constant rate 10 times faster than the average of an intense rainfall event for the region (i.e. within $3.5 \mathrm{~h}$ instead of $35 \mathrm{~h}$ ). At the end of the watering period, the rain simulators were removed, and the columns were covered by a plastic lid to limit water evaporation from the soil. Five days after, the columns were dismantled and soil samples were taken in each $10-\mathrm{cm}$ segment.

The experiment was done in triplicate, using two successive runs with 12 columns at a time. Besides the use of the 6 reclaimed soil profiles detailed in Fig. 1 (treatment 1 to 6), two additional treatments (treatments 7 and 8) were tested on soil profiles R5 and R6 by adding fertilizer on the top $10 \mathrm{~cm}$ prior to the leaching experiment. A concentrated solution containing $21.4 \mathrm{~g} \mathrm{l}^{-1}$ of $\left(\mathrm{NH}_{4}\right)_{2} \mathrm{SO}_{4}$ and $19.9 \mathrm{~g} \mathrm{l}^{-1}$ of $\mathrm{KH}_{2} \mathrm{PO}_{4}$ was prepared, with the ammonium solution containing $0.5 \%$ of $98 \%$-pure ${ }^{15} \mathrm{~N}$-ammonium sulfate solution. A few minutes prior to the filling of columns, the exact mass of PMM or FFM intended to fill the $0-10 \mathrm{~cm}$ segment received $5 \mathrm{ml}$ of the nutrient solution, and was then homogenized by hand mixing before being packed into the column. As each material was air-dried for a few hours prior to this operation, the water content of PMM or FFM after the addition of the nutrient solution was similar to the water content of PMM or FFM without fertilizer in the other treatments. The addition of fertilizer corresponded to an input of $50 \mathrm{~kg}_{\mathrm{N}} \mathrm{ha}^{-1}$ and $50 \mathrm{~kg}_{\mathrm{P}} \mathrm{ha}^{-1}$, which was chosen according to past common practices in the reclamation of oil sand soils (Lanoue, 2003; McMillan et al., 2007; Pinno et al., 2012).

Peer-reviewed, unedited version of the manuscript of Rees et al. (2020) published by Applied Geochemistry: https://doi.org/10.1016/j.apgeochem.2020.104526 
Soil samples were taken at the beginning of the experiment from the same batch from which columns were filled, and at the end of the experiment in each 10-cm segment when columns were dismantled. An aliquot of soil was used to measure the average soil gravimetric water content in each 10-cm segment. A mass of moist material equivalent to $4 \mathrm{~g}$ of dry material was added to $40 \mathrm{ml}$ of a $0.5 \mathrm{M} \mathrm{K} \mathrm{SO}_{4}$ solution in a 50 -ml polypropylene centrifugation tube, and the suspension was shaken for 30 min using a mechanical shaker at $200 \mathrm{rpm}$. Tubes were then centrifuged at $4000 \mathrm{rpm}$ for $10 \mathrm{~min}$, and the supernatant was sampled and filtered to $0.45 \mu \mathrm{m}$. The extracts were kept frozen at $-18^{\circ} \mathrm{C}$ until analysis. Total ammonium-N, nitrate-N, and total $\mathrm{P}$ in these extracts were measured by NRAL using the methods described above. The isotopic composition of nitrate- $\mathrm{N}$ was measured in the extracts from treatments 5, 6, 7 and 8 by the Isotope Science Lab of University of Calgary using the denitrifier method (Rock and Ellert, 2007). In this leaching experiment, $0.5 \mathrm{M} \mathrm{K}_{2} \mathrm{SO}_{4}$ was chosen as the extracting solution instead of $0.1 \mathrm{M} \mathrm{KCl}$, which was previously used in the sorption experiment, so that technical problems of $\mathrm{KCl}$ interference with the analysis of $\mathrm{N}$ could be avoided. The $0.5 \mathrm{M} \mathrm{K}_{2} \mathrm{SO}_{4}$ extraction procedure was adapted from the protocol of soil microbial biomass $\mathrm{N}$ determination (Brookes et al., 1985).

\subsection{Incubation experiment}

An incubation experiment was conducted to better monitor the release of nutrients from the two capping materials used in the column experiment. Field-moist PMM and FFM (equivalent to $20 \mathrm{~g}$ in dry weight) sieved to $4 \mathrm{~mm}$ were introduced in 250-ml glass jars and compacted to reach the desired bulk density. Prior to compaction, the soil in each jar was thoroughly mixed with a rod, with 0 or $451 \mu$ of the same fertilizer solution used in the column experiment containing ${ }^{15} \mathrm{~N}$-labelled ammonium sulfate and potassium phosphate. Because a similar dry mass (not volume) of each material was compared in this experiment, the fertilizer addition in the incubation experiment was equivalent to a theoretical input of $50 \mathrm{~kg} \mathrm{ha}^{-1}$ of $\mathrm{N}$ and $50 \mathrm{~kg} \mathrm{ha}^{-1}$ of $\mathrm{P}$ on $10 \mathrm{~cm}$ of PMM, as done in the column experiment, and to $136 \mathrm{~kg} \mathrm{ha}^{-1}$ of $\mathrm{N}$ and $136 \mathrm{~kg} \mathrm{ha}^{-1}$ of $\mathrm{P}$ on the first $10 \mathrm{~cm}$ of FFM, which corresponded to an input of $\mathrm{N}$ and $\mathrm{P} 2.7$ times higher than in the column experiments. Four jars per treatment were incubated in the dark at $23^{\circ} \mathrm{C}$, with a constant moisture content equivalent to a water potential of $-10 \mathrm{kPa}$ (field capacity).

The air inside the sealed jars was renewed at least every 3 days; calculations showed that the decrease in oxygen content caused by soil microbial respiration between two air renewal operations could not have limited the rate of mineralization of soil organic matter. The $\mathrm{CO}_{2}$ accumulated in the jars was measured at 1, 2, 5, 10, 15, 20 and 25 days. For each measurement, 20-ml gas sample was taken from the headspace of the jars and analyzed for $\mathrm{CO}_{2}$ 
concentration on a Hewlett Packard 5890 Series II gas chromatograph. $\mathrm{N}_{2} \mathrm{O}$ emissions and soil extractable nutrients were measured after 1 day, 5 days and 25 days on 3 separated series of runs. Instantaneous emissions of total $\mathrm{N}_{2} \mathrm{O}$ and ${ }^{15} \mathrm{~N}_{2} \mathrm{O}$ were measured by circulating air between the headspace of the jar and an Aerodyne QC TILDAS Gas Monitor for 5 minutes in a closed loop. Once $\mathrm{N}_{2} \mathrm{O}$ emissions were measured, soils were destructively sampled and extracted with $0.5 \mathrm{M} \mathrm{K}_{2} \mathrm{SO}_{4}$ to measure extractable inorganic $\mathrm{N}$ and $\mathrm{P}$ using a similar protocol as in the column experiment: a mass of moist material equivalent to $8 \mathrm{~g}$ of dry material was added to $50 \mathrm{ml}$ of a $0.5 \mathrm{M} \mathrm{K}_{2} \mathrm{SO}_{4}$ solution in a 50-ml polypropylene centrifugation tube, and the suspension was shaken for 30 min using a mechanical shaker at $200 \mathrm{rpm}$. Tubes were then centrifuged at $4000 \mathrm{rpm}$ for $10 \mathrm{~min}$, and the supernatant was sampled and filtered to $0.45 \mu \mathrm{m}$ using syringe filters. Total ammonium-N, nitrate- $\mathrm{N}$, and total $\mathrm{P}$ in these extracts were measured by NRAL using the methods described above.

\subsection{Modelling the movement of water and nutrients}

The vertical movement of water, $\mathrm{NH}_{4}-\mathrm{N}, \mathrm{NO}_{3}-\mathrm{N}$ and $\mathrm{P}$ within the different reclaimed soil profiles were modelled using the HYDRUS-1D (v.4.16.0110) software package (Šimůnek et al., 2008), from the start of the rainfall event until the end of the experiment 5 days later. The dynamics of water was simulated according to the water retention curves and the hydraulic curves determined for each material and to their initial water content prior to the rainfall event. The initial nutrient concentration in the liquid phase in contact with the solid phase was calculated by assuming that the amount of $0.5 \mathrm{M} \mathrm{K}_{2} \mathrm{SO}_{4}$ extractable nutrients measured at the beginning of the column experiment was only present in the liquid phase. Three types of simulations were used (Table S2). In Simulation 1, no possibility of nutrient exchange between the liquid phase and the solid phase was considered. In Simulation 2 , sorption parameters from the Freundlich desorption curves determined in the nutrient sorption experiment were used. In Simulation 3, the results from the incubation experiment were used to mimic the mobilization/immobilization dynamics of nutrients in the capping materials PMM and FFM, without considering sorption parameters (see details in Supplementary material 3).

Peer-reviewed, unedited version of the manuscript of Rees et al. (2020) published by Applied Geochemistry: 


\section{RESULTS}

\subsection{Chemical and physical properties of the reclamation materials}

The main properties of the five reclamation materials are indicated in Table 1. All materials were neutral or slightly alkaline. Among the two organic materials used as topsoil, PMM contained about 10 times more organic C and total $\mathrm{N}$ than FFM on a dry weight basis. The lean oil sand (LOS) also had a high content of organic C (3.7\%), due to the presence of the naturally occurring petroleum hydrocarbons, but a low $\mathrm{N}$ content. Comparatively, the blended B/C horizon (SUB) and the tailing sand (TS) had a very low content of $\mathrm{C}$ and $\mathrm{N}$. The fraction of total organic $\mathrm{P}$ was larger in PMM, while the fraction of extractable P (Olsen method) was the highest in the FFM and SUB materials. PMM, FFM, SUB and TS were coarse-textured (sand fraction > 90\%), while LOS was a sandy loam. PMM, TS and LOS were hydrophobic when air-dried, but at field moisture, only LOS showed signs of hydrophobicity (Table 1).

The saturated hydraulic conductivity was highest for SUB and lowest for LOS (Table 1). Data obtained from the pressure plates, the HYPROP system, the falling head method and the dewpoint potentiometer were used to model the water retention and hydraulic conductivity curves as a function of soil water tension for each material (Table S3 and Fig. S2, S3 and S4). The water retention curves showed that the volumetric water content of PMM was the highest among the five materials for all water tensions, and that the water content of LOS became much higher than the water content of FFM, SUB or TS for water tensions higher than $10 \mathrm{kPa}$ (field capacity) (Fig. S3). While the hydraulic conductivity of PMM and FFM were very similar for low water tensions, PMM better conducted water for water tensions higher than $2.5 \mathrm{kPa}$ compared to FFM (Fig. S4). SUB and TS materials showed almost identical water retention and hydraulic conductivity curves. LOS led to the lowest hydraulic conductivity between 0 and $10 \mathrm{kPa}$, but became intermediary between the conductivity of FFM and SUB/TS at higher water tensions. Interestingly, an increase in the bulk density of LOS from $1.4 \mathrm{~g} \mathrm{~cm}^{-3}$ (i.e. the bulk density that was practically reachable in the column experiment) to $1.6 \mathrm{~g} \mathrm{~cm}^{-3}$ (i.e. the field bulk density) did not result in any difference in the hydraulic conductivity measured by the HYPROP device between 10 and $100 \mathrm{kPa}$ (Fig. S2).

Peer-reviewed, unedited version of the manuscript of Rees et al. (2020) published by Applied Geochemistry: 
Table 1: Properties of the five materials used in the reclaimed soil profiles. PMM: Peat-mineral mix; FFM: Forest floor mineral mix; SUB: Blended B/C subsoil; TS: Tailing sand; LOS: Lean Oil Sand. Plant available water content is calculated from the difference between the water contents measured at $-10 \mathrm{kPa}$ and $-1500 \mathrm{kPa}$, respectively. ND: Not determined.

\begin{tabular}{|c|c|c|c|c|c|c|c|}
\hline Measurement & Parameter & Unit & PMM & FFM & SUB & TS & LOS \\
\hline \multirow[t]{2}{*}{$\mathbf{p H ^ { 1 }}$} & $\mathrm{pH}$ in water & - & 7.9 & 6.9 & 7.6 & 7.9 & 7.8 \\
\hline & $\mathrm{pH}$ in $0.01 \mathrm{M} \mathrm{CaCl}_{2}$ & - & 7.5 & 6.1 & 6.8 & 7.4 & 7.6 \\
\hline \multirow[t]{10}{*}{ Chemical content ${ }^{1}$} & Organic matter & $\%(\mathrm{w} / \mathrm{w})$ & 28.8 & 2.6 & 0.6 & 0.8 & 6.8 \\
\hline & Total organic $\mathrm{C}$ & $\%(\mathrm{w} / \mathrm{w})$ & 17.9 & 1.7 & 0.2 & 0.3 & 3.7 \\
\hline & Total inorganic $\mathrm{C}$ & $\%(\mathrm{w} / \mathrm{w})$ & 2.5 & 0.0 & 0.0 & 0.1 & 0.5 \\
\hline & Total N & $\%(\mathrm{w} / \mathrm{w})$ & 0.9 & 0.1 & 0.0 & 0.1 & 0.1 \\
\hline & $\mathrm{C} / \mathrm{N}$ & - & 20 & 29 & 31 & 3.5 & 52 \\
\hline & Total organic $\mathrm{P}$ & $\mathrm{mg} \mathrm{kg}^{-1}$ & 183 & 56 & 32 & 17 & 57 \\
\hline & Total inorganic $\mathrm{P}$ & $\mathrm{mg} \mathrm{kg}^{-1}$ & 116 & 115 & 74 & 47 & 236 \\
\hline & Total P & $\mathrm{mg} \mathrm{kg}^{-1}$ & 299 & 172 & 105 & 64 & 294 \\
\hline & Extractable P (Olsen) & $\mathrm{mg} \mathrm{kg}^{-1}$ & 3.7 & 21.3 & 11.2 & 1.5 & 1.8 \\
\hline & CEC & $\mathrm{cmol}^{+} \mathrm{kg}^{-1}$ & 81.1 & 1.9 & 7.2 & 1.9 & 16.0 \\
\hline \multirow[t]{4}{*}{ Particle size distribution } & $>2 \mathrm{~mm}$ & $\%(\mathrm{w} / \mathrm{w})^{3}$ & 4.5 & 2.3 & 0.2 & 0.9 & 7.3 \\
\hline & Sand $^{1}$ & $\%(w / w)^{4}$ & $95^{5}$ & 91 & 95 & 95 & 57 \\
\hline & Silt $^{1}$ & $\%(\mathrm{w} / \mathrm{w})^{4}$ & ND & 6 & 3 & 3 & 27 \\
\hline & Clay $^{1}$ & $\%(w / w)^{4}$ & ND & 3 & 2 & 2 & 16 \\
\hline \multirow[t]{3}{*}{ Gravimetric water content ${ }^{1}$} & At $-10 \mathrm{kPa}$ & $\%(\mathrm{w} / \mathrm{w})$ & 97.6 & 10.9 & 13.2 & 14.4 & 28.7 \\
\hline & At $-1500 \mathrm{kPa}$ & $\%(\mathrm{w} / \mathrm{w})$ & 29.8 & 2.0 & 0.8 & 0.6 & 6.7 \\
\hline & Plant-available & $\%(\mathrm{w} / \mathrm{w})$ & 67.9 & 8.8 & 12.4 & 13.8 & 22.0 \\
\hline \multirow[t]{3}{*}{ Volumetric water content ${ }^{2}$} & At $-10 \mathrm{kPa}$ & $\%(\mathrm{v} / \mathrm{v})$ & 50.9 & 15.8 & 7.5 & 7.7 & 30.6 \\
\hline & At $-1500 \mathrm{kPa}$ & $\%(\mathrm{v} / \mathrm{v})$ & 13.1 & 2.6 & 1.2 & 0.9 & 9.6 \\
\hline & Plant-available & $\%(\mathrm{v} / \mathrm{v})$ & 37.8 & 13.1 & 6.3 & 6.8 & 21.1 \\
\hline \multirow[t]{2}{*}{ Water Drop Penetration Time } & Air-dried ${ }^{1}$ & $\mathrm{~s}$ & 173 & 0.6 & 0.0 & 4320 & 383 \\
\hline & Field-moist ${ }^{2}$ & $\mathrm{~s}$ & 0.0 & 0.5 & 0.0 & 0.0 & 4.8 \\
\hline Hydraulic conductivity ${ }^{2}$ & $\mathrm{~K}_{\mathrm{sat}}$ & $\mathrm{cm} \mathrm{day}^{-1}$ & 319 & 565 & 1477 & 593 & 34 \\
\hline
\end{tabular}

\footnotetext{
1 The results refer to data obtained from air-dried materials sieved to $2 \mathrm{~mm}$.

${ }^{2}$ The results refer to data obtained from field-moist, non-sieved materials.

${ }^{3}$ The results are expressed in dry weight $\%$ relative to the total dry weight of the sample

${ }^{4}$ The results are expressed in dry weight $\%$ relative to the total dry weight of the sample sieved to $2 \mathrm{~mm}$

${ }^{5}$ The sand fraction of PMM was estimated by dry sieving between $53 \mu \mathrm{m}$ and $2000 \mu \mathrm{m}$, without any pretreatment.
} 


\subsection{Comparison of water and nutrient availability between reclaimed soil profiles and natural analog soils}

Based on the characteristic volumetric water contents and the nutrient content of each material, we calculated the amounts of plant-available water and nutrients, and compared them between the six reclaimed soil profiles and the two natural analog coarse soil profiles sampled in the same region. Our results show that the reclaimed soil profiles constructed with PMM in the first $20 \mathrm{~cm}$ contained a higher amount of plant available water (Fig. S5), total organic $\mathrm{C}$ (Fig. S6) and total $\mathrm{N}$ (Fig. S7), but a lower amount of total and 0.5 $\mathrm{M} \mathrm{K}_{2} \mathrm{SO}_{4}$ extractable P (Fig. S10), compared to the reclaimed profiles using FFM. However, the first $20 \mathrm{~cm}$ contained a similar amount of $0.5 \mathrm{M} \mathrm{K} \mathrm{K}_{2} \mathrm{SO}_{4}$ extractable inorganic N (Fig. S9), whether PMM or FFM was used. Among the three materials used below $50 \mathrm{~cm}$, LOS was the one leading to the highest amount of plant-available water, total organic C and total P (Fig. S8). Compared to the natural soils, all reclaimed soil profiles contained a higher amount of total $\mathrm{N}$ and organic $\mathrm{C}$ in the 0-20 cm coversoil layer. The amount of $0.5 \mathrm{M} \mathrm{K}_{2} \mathrm{SO}_{4}$ extractable inorganic $\mathrm{N}$ was also higher in the reclaimed coversoils. The amount of total $\mathrm{P}$ was comparable between reclaimed and natural soils, but the $0.5 \mathrm{M} \mathrm{K} \mathrm{K}_{2} \mathrm{SO}_{4}$ extractable $\mathrm{P}$ was higher in the natural soils.

\subsection{Nutrient retention capacity of the reclamation materials}

Results from the sorption-desorption experiment are presented in Fig. S11-S15. No large immobilization of inorganic $\mathrm{N}$ (ammonium-N + nitrate-N) was observed for any of the materials. In the specific case of PMM (Fig. S11), a significant fraction of ammonium-N (15-20\% of the initial amount of ammonium-N) appeared to be immobilized, but a similar amount of nitrate-N appeared to be concomitantly released, leading to only a low net immobilization of mineral N.

PMM, SUB and LOS were able to immobilize a significant amount of phosphate (Fig. S11, S13 and S14). The comparison of sorption and desorption curves suggested that the sorption of phosphate on PMM was more reversible than on SUB or LOS. According to the Langmuir model, PMM had a higher maximal sorption capacity (14-15 $\left.\mu \mathrm{mol} \mathrm{g}{ }^{-1}\right)$ compared to SUB (4.6-6.8 $\mu \mathrm{mol} \mathrm{g} \mathrm{g}^{-1}$ ) or LOS (4.6-4.8 $\left.\mu \mathrm{mol} \mathrm{g}{ }^{-1}\right)$. PMM was able to immobilize the majority of the introduced phosphate ( $83 \%$ of phosphate immobilized for the highest concentration). Comparatively, LOS could only immobilize 50\% and SUB 35\% of the phosphate introduced at the same high concentration. With FFM, a slight immobilization of phosphate was observed with low nutrient concentration, but a net release of phosphate occurred when more nutrients were added to the tube (Fig. S12). TS material showed the same trends as FFM, but with lower amplitude (Fig. S15).

Peer-reviewed, unedited version of the manuscript of Rees et al. (2020) published by Applied Geochemistry: https://doi.org/10.1016/j.apgeochem.2020.104526 


\subsection{Nutrient leaching in reclaimed soils}

Results of the column leaching experiment are presented in Fig. 2, 3 and 4. The difference between the initial soil water content and the water content 5 days after the intense rainfall showed how each reclamation material retained water and limited its transport down the profile. The water content present in the $0-20 \mathrm{~cm}$ of FMM treatments increased after the rainfall, while it remained the same in the PMM topsoil (Fig. 2). At the end of the experiment, an increase in soil water volume was observed in all segments from $20 \mathrm{~cm}$ to the bottom of the column (Fig. 2), while no water loss was observed through the drainage pipe at the bottom of the columns.

Fig. 2: Plant-available water in each 10-cm segment of reclaimed soil profiles $\left(1 \mathrm{~m}^{-2}\right.$, i.e. $\left.\mathrm{mm}\right)$, prior to leaching $(t=-1$ day) and after a 4-h intense rainfall and a resting period of 5 days $(t=5$ days). PMM: peatmineral mix; PMM + F: peat-mineral mix with fertilizer; FFM: forest floor mineral material; FFM + F: forest floor mineral material with fertilizer; SUB: blended B/C horizons of sandy subsoil; TS: tailing sand; LOS: lean oil sand. Results are presented as mean \pm standard error (3 replicates). A blue color code is used to display the values: the higher the mean value, the darker the background of the cell.

\begin{tabular}{|c|c|c|}
\hline Treatment $\mathbf{1}$ & $\mathbf{t}=-\mathbf{1}$ day & $\mathbf{t}=\mathbf{5}$ days \\
\hline $\boldsymbol{P M M}$ & $36 \pm 1$ & $35 \pm 1$ \\
\hline $\boldsymbol{P M M}$ & $36 \pm 1$ & $34 \pm 1$ \\
\hline SUB & $6 \pm 1$ & $9 \pm 1$ \\
\hline SUB & $6 \pm 1$ & $9 \pm 0$ \\
\hline SUB & $6 \pm 1$ & $9 \pm 0$ \\
\hline SUB & $6 \pm 1$ & $9 \pm 0$ \\
\hline SUB & $6 \pm 1$ & $12 \pm 0$ \\
\hline SUB & $6 \pm 1$ & $11 \pm 0$ \\
\hline SUB & $6 \pm 1$ & $12 \pm 0$ \\
\hline SUB & $6 \pm 1$ & $10 \pm 0$ \\
\hline SUB & $6 \pm 1$ & $12 \pm 1$ \\
\hline SUB & $6 \pm 1$ & $15 \pm 0$ \\
\hline TOTAL & $\mathbf{1 3 0} \pm \mathbf{1 1}$ & $\mathbf{1 7 7} \pm \mathbf{0}$ \\
\hline
\end{tabular}

\begin{tabular}{|c|c|c|}
\hline Treatment $\mathbf{2}$ & $\mathbf{t}=-\mathbf{1}$ day & $\mathbf{t}=\mathbf{5}$ days \\
\hline FFM & $10 \pm 0$ & $13 \pm 0$ \\
\hline FFM & $10 \pm 0$ & $14 \pm 0$ \\
\hline SUB & $6 \pm 1$ & $9 \pm 0$ \\
\hline SUB & $6 \pm 1$ & $8 \pm 0$ \\
\hline SUB & $6 \pm 1$ & $8 \pm 0$ \\
\hline SUB & $6 \pm 1$ & $10 \pm 1$ \\
\hline SUB & $6 \pm 1$ & $12 \pm 0$ \\
\hline SUB & $6 \pm 1$ & $11 \pm 1$ \\
\hline SUB & $6 \pm 1$ & $11 \pm 0$ \\
\hline SUB & $6 \pm 1$ & $11 \pm 0$ \\
\hline SUB & $6 \pm 1$ & $11 \pm 0$ \\
\hline SUB & $6 \pm 1$ & $15 \pm 2$ \\
\hline TOTAL & $77 \pm \mathbf{6}$ & $\mathbf{1 3 4} \pm \mathbf{1}$ \\
\hline
\end{tabular}

\begin{tabular}{|c|c|c|}
\hline Treatment $\mathbf{3}$ & $\mathbf{t}=-\mathbf{1}$ day & $\mathbf{t}=\mathbf{5}$ days \\
\hline PMM & $36 \pm 1$ & $41 \pm 2$ \\
\hline$P M M$ & $36 \pm 1$ & $37 \pm 3$ \\
\hline SUB & $6 \pm 1$ & $9 \pm 0$ \\
\hline SUB & $6 \pm 1$ & $8 \pm 0$ \\
\hline SUB & $6 \pm 1$ & $9 \pm 0$ \\
\hline TS & $6 \pm 0$ & $11 \pm 1$ \\
\hline TS & $6 \pm 0$ & $10 \pm 0$ \\
\hline TS & $6 \pm 0$ & $11 \pm 1$ \\
\hline TS & $6 \pm 0$ & $11 \pm 0$ \\
\hline TS & $6 \pm 0$ & $11 \pm 0$ \\
\hline TS & $6 \pm 0$ & $10 \pm 0$ \\
\hline TS & $6 \pm 0$ & $8 \pm 2$ \\
\hline TOTAL & $\mathbf{1 3 3} \pm \mathbf{1 0}$ & $\mathbf{1 7 7} \pm \mathbf{3}$ \\
\hline
\end{tabular}

\begin{tabular}{|c|c|c|}
\hline Treatment $\mathbf{4}$ & $\mathbf{t}=\mathbf{- 1}$ day & $\mathbf{t}=\mathbf{5}$ days \\
\hline FFM & $10 \pm 0$ & $13 \pm 0$ \\
\hline FFM & $10 \pm 0$ & $13 \pm 0$ \\
\hline SUB & $6 \pm 1$ & $9 \pm 1$ \\
\hline SUB & $6 \pm 1$ & $10 \pm 1$ \\
\hline SUB & $6 \pm 1$ & $12 \pm 3$ \\
\hline TS & $6 \pm 0$ & $11 \pm 1$ \\
\hline TS & $6 \pm 0$ & $10 \pm 0$ \\
\hline TS & $6 \pm 0$ & $10 \pm 0$ \\
\hline TS & $6 \pm 0$ & $11 \pm 0$ \\
\hline TS & $6 \pm 0$ & $9 \pm 1$ \\
\hline TS & $6 \pm 0$ & $9 \pm 2$ \\
\hline TS & $6 \pm 0$ & $9 \pm 2$ \\
\hline TOTAL & $\mathbf{8 0} \pm \mathbf{5}$ & $\mathbf{1 2 6} \pm \mathbf{1}$ \\
\hline
\end{tabular}

\begin{tabular}{|c|c|c|}
\hline Treatment $\mathbf{5}$ & $\mathbf{t}=-\mathbf{1}$ day & $\mathbf{t}=\mathbf{5}$ days \\
\hline PMM & $34 \pm 1$ & $39 \pm 2$ \\
\hline PMM & $34 \pm 1$ & $35 \pm 1$ \\
\hline SUB & $6 \pm 0$ & $9 \pm 0$ \\
\hline SUB & $6 \pm 0$ & $10 \pm 0$ \\
\hline SUB & $6 \pm 0$ & $14 \pm 1$ \\
\hline LOS & $17 \pm 1$ & $23 \pm 1$ \\
\hline LOS & $17 \pm 1$ & $23 \pm 0$ \\
\hline LOS & $17 \pm 1$ & $24 \pm 1$ \\
\hline LOS & $17 \pm 1$ & $24 \pm 1$ \\
\hline LOS & $17 \pm 1$ & $21 \pm 2$ \\
\hline LOS & $17 \pm 1$ & $19 \pm 2$ \\
\hline LOS & $17 \pm 1$ & $17 \pm 1$ \\
\hline TOTAL & $\mathbf{2 0 1} \pm \mathbf{1 0}$ & $\mathbf{2 5 7} \pm \mathbf{5}$ \\
\hline
\end{tabular}

\begin{tabular}{|c|c|c|}
\hline Treatment $\mathbf{6}$ & $\mathbf{t}=\mathbf{- 1}$ day & $\mathbf{t}=\mathbf{5}$ days \\
\hline $\boldsymbol{F F M}$ & $9 \pm 0$ & $15 \pm 1$ \\
\hline $\boldsymbol{F F M}$ & $9 \pm 0$ & $14 \pm 1$ \\
\hline SUB & $6 \pm 0$ & $9 \pm 0$ \\
\hline SUB & $6 \pm 0$ & $9 \pm 0$ \\
\hline SUB & $6 \pm 0$ & $13 \pm 0$ \\
\hline LOS & $17 \pm 1$ & $23 \pm 0$ \\
\hline LOS & $17 \pm 1$ & $23 \pm 1$ \\
\hline LOS & $17 \pm 1$ & $23 \pm 0$ \\
\hline LOS & $17 \pm 1$ & $22 \pm 2$ \\
\hline LOS & $17 \pm 1$ & $21 \pm 2$ \\
\hline LOS & $17 \pm 1$ & $17 \pm 0$ \\
\hline LOS & $17 \pm 1$ & $17 \pm 0$ \\
\hline TOTAL & $\mathbf{1 5 1} \pm \mathbf{8}$ & $\mathbf{2 0 6} \pm \mathbf{3}$ \\
\hline
\end{tabular}

\begin{tabular}{|c|c|c|}
\hline Treatment 7 & $\mathbf{t}=-\mathbf{1}$ day & $\mathbf{t}=\mathbf{5}$ days \\
\hline PMM $+\boldsymbol{F}$ & $36 \pm 1$ & $38 \pm 1$ \\
\hline PMM & $34 \pm 1$ & $36 \pm 1$ \\
\hline SUB & $6 \pm 0$ & $9 \pm 0$ \\
\hline SUB & $6 \pm 0$ & $9 \pm 0$ \\
\hline SUB & $6 \pm 0$ & $14 \pm 0$ \\
\hline LOS & $17 \pm 1$ & $24 \pm 3$ \\
\hline LOS & $17 \pm 1$ & $23 \pm 1$ \\
\hline LOS & $17 \pm 1$ & $20 \pm 1$ \\
\hline LOS & $17 \pm 1$ & $23 \pm 1$ \\
\hline LOS & $17 \pm 1$ & $20 \pm 1$ \\
\hline LOS & $17 \pm 1$ & $20 \pm 3$ \\
\hline LOS & $17 \pm 1$ & $17 \pm 2$ \\
\hline TOTAL & $\mathbf{2 0 3} \pm \mathbf{8}$ & $\mathbf{2 5 2} \pm \mathbf{5}$ \\
\hline
\end{tabular}

\begin{tabular}{|c|c|c|}
\hline Treatment $\boldsymbol{B}$ & $\mathbf{t}=-\mathbf{1}$ day & $\mathbf{t}=\mathbf{5}$ days \\
\hline $\boldsymbol{F F M}+\boldsymbol{F}$ & $10 \pm 0$ & $15 \pm 1$ \\
\hline $\boldsymbol{F F M}$ & $9 \pm 0$ & $14 \pm 0$ \\
\hline SUB & $6 \pm 0$ & $9 \pm 0$ \\
\hline SUB & $6 \pm 0$ & $9 \pm 0$ \\
\hline SUB & $6 \pm 0$ & $13 \pm 0$ \\
\hline LOS & $17 \pm 1$ & $23 \pm 1$ \\
\hline LOS & $17 \pm 1$ & $23 \pm 1$ \\
\hline LOS & $17 \pm 1$ & $23 \pm 1$ \\
\hline LOS & $17 \pm 1$ & $21 \pm 1$ \\
\hline LOS & $17 \pm 1$ & $21 \pm 2$ \\
\hline LOS & $17 \pm 1$ & $17 \pm 0$ \\
\hline LOS & $17 \pm 1$ & $16 \pm 0$ \\
\hline TOTAL & $\mathbf{1 5 2} \pm \mathbf{7}$ & $\mathbf{2 0 5} \pm \mathbf{5}$ \\
\hline
\end{tabular}

Peer-reviewed, unedited version of the manuscript of Rees et al. (2020) published by Applied Geochemistry: 
In the absence of fertilizer, the amount of $0.5 \mathrm{M}-\mathrm{K}_{2} \mathrm{SO}_{4}$ extractable inorganic $\mathrm{N}$ was decreased by $85 \%$ in the $0-20$ $\mathrm{cm}$ horizon of FFM treatments at the end of the 5 days compared to the initial state (Fig. 3). The amount of extractable inorganic $\mathrm{N}$ also decreased by $85 \%$ in the $0-10 \mathrm{~cm}$ of PMM treatments, but only by $20-25 \%$ in the 10 $20 \mathrm{~cm}$ layer. On the contrary, the amount of extractable inorganic $\mathrm{N}$ increased in the underlying horizons, up to 70 cm depth when SUB or TS were used or up to $60 \mathrm{~cm}$ when LOS was used (Fig. 3). In the case where SUB was present from 20 to $120 \mathrm{~cm}$, the maximal increase in inorganic $\mathrm{N}$ occurred at $60-70 \mathrm{~cm}$ when FFM was the overlying material, but only at 20-30 cm when PMM was used as the topsoil. When LOS was present between $50 \mathrm{~cm}$ and $120 \mathrm{~cm}$, extractable inorganic N accumulated above the SUB/LOS interface, with a low accumulation between 20 and $30 \mathrm{~cm}$ and a high accumulation between $40 \mathrm{~cm}$ and $50 \mathrm{~cm}$. Nitrate-N was generally the dominant form of extractable inorganic $\mathrm{N}$ in the soil profiles compared to ammonium-N (Fig. S16- S17). Ammonium-N represented less than $5 \%$ of the extractable inorganic $\mathrm{N}$ in the topsoil materials (PMM and FFM), but accounted for $15 \%$ to $40 \%$ of total inorganic N in the SUB material and up to $80 \%$ of it in the LOS material. The amount of extractable ammonium-N slightly increased in the $0-50 \mathrm{~cm}$ zone between the beginning and the end of the column experiment (Fig. S17).

The introduction of the fertilizer solution containing ammonium- $\mathrm{N}$ in treatments 7 and 8 resulted in an initial increase of the amount of extractable inorganic $\mathrm{N}$ in the first $10 \mathrm{~cm}$ by a factor 2 with PMM (treatment 7 vs 5) and 2.5 with FFM (treatment 8 vs 6) (Fig. 3). At the end of the experiment, the amounts of extractable inorganic $\mathrm{N}$ in the first $0-10 \mathrm{~cm}$ and $10-20 \mathrm{~cm}$ were similar and comparable to the initial amount of extractable inorganic $\mathrm{N}$ in the 10-20 cm layer. The remaining amount of extractable inorganic $\mathrm{N}$ in the $0-20 \mathrm{~cm}$ topsoil horizon after 5 days was therefore increased by a factor of 2.3 (PMM) or 5 (FFM) in the treatments with fertilizer compared to the treatments without fertilizer. Interestingly, no difference in the inorganic $\mathrm{N}$ profile below $20 \mathrm{~cm}$ was seen at the end of the experiment between the fertilizer treatments (treatments 7 and 8) and the control treatments (treatments 5 and 6). While the fertilizer-N was introduced as ammonium, no significantly higher extractable ammonium could be seen at the end of the experiment anywhere in the soil profiles (Fig. S17). As in the treatments without fertilizer, the extractable inorganic $\mathrm{N}$ mostly corresponded to nitrate-N at the end of the experiment (Fig. S16). The measurement of the isotopic composition of nitrate- $\mathrm{N}$ enabled the calculation of the fraction of nitrate- $\mathrm{N}$ derived from the ${ }^{15} \mathrm{~N}$ labelled ammonium at each investigated soil depth. These calculations showed that the fertilizer-derived $\mathrm{N}$ was only present in the topsoil at the end of the experiment, and could not be detected below $20 \mathrm{~cm}$ (Fig. S18). The calculations also suggest that a significant fraction of fertilizer-N, i.e. $9 \%$ with PMM and $25 \%$ with FFM, could not be recovered in the inorganic $\mathrm{N}$ extracted from the soil profiles.

Peer-reviewed, unedited version of the manuscript of Rees et al. (2020) published by Applied Geochemistry: https://doi.org/10.1016/j.apgeochem.2020.104526 
Fig. 3: $0.5 \mathrm{M} \mathrm{K}_{2} \mathrm{SO}_{4}$ extractable inorganic $\mathrm{N}$ (ammonium-N + nitrate- $\mathrm{N}$ ) in each 10-cm segment of reclaimed soil profiles $\left(\mathrm{g} \mathrm{m}^{-2}\right)$, prior to leaching $(\mathrm{t}=-\mathbf{1}$ day) and after a 4-h intense rainfall and a resting period of 5 days $(\mathbf{t}=5$ days). PMM: peat-mineral mix; PMM + F: peat-mineral mix with fertilizer; FFM: forest floor mineral material; FFM + F: forest floor mineral material with fertilizer; SUB: blended B/C horizons of sandy subsoil; TS: tailing sand; LOS: lean oil sand. N.D: Not determined. Results are presented as mean \pm standard error (3 replicates). A green color code is used to display the values: the higher the mean value, the darker the background of the cell.

\begin{tabular}{|c|c|c|}
\hline Treatment 1 & $t=-1$ day & $t=5$ days \\
\hline$P M M$ & $4.35 \pm 0.11$ & $0.59 \pm 0.06$ \\
\hline$P M M$ & $4.35 \pm 0.11$ & $3.20 \pm 0.21$ \\
\hline$S U B$ & $0.32 \pm 0.03$ & $1.16 \pm 0.15$ \\
\hline$S U B$ & $0.32 \pm 0.03$ & $1.14 \pm 0.15$ \\
\hline$S U B$ & $0.32 \pm 0.03$ & $1.00 \pm 0.05$ \\
\hline$S U B$ & $0.32 \pm 0.03$ & $0.86 \pm 0.03$ \\
\hline$S U B$ & $0.32 \pm 0.03$ & $0.69 \pm 0.01$ \\
\hline$S U B$ & $0.32 \pm 0.03$ & $0.42 \pm 0.06$ \\
\hline$S U B$ & $0.32 \pm 0.03$ & \multirow{3}{*}{ N.D. } \\
\hline$S U B$ & $0.32 \pm 0.03$ & \\
\hline$S U B$ & $0.32 \pm 0.03$ & \\
\hline$S U B$ & $0.32 \pm 0.03$ & $0.43 \pm 0.01$ \\
\hline TOTAL & $11.9 \pm 0.5$ & $9.5 \pm 0.5$ \\
\hline
\end{tabular}

\begin{tabular}{|c|c|c|}
\hline Treatment $\mathbf{2}$ & $\mathbf{t}=\mathbf{- 1}$ day & $\mathbf{t}=\mathbf{5}$ days \\
\cline { 1 - 2 } FFM & $2.74 \pm 0.07$ & $0.36 \pm 0.02$ \\
\cline { 1 - 2 } FFM & $2.74 \pm 0.07$ & $0.53 \pm 0.09$ \\
\cline { 1 - 2 } SUB & $0.32 \pm 0.03$ & $0.45 \pm 0.03$ \\
\cline { 1 - 2 } SUB & $0.32 \pm 0.03$ & $0.96 \pm 0.14$ \\
\cline { 1 - 2 } SUB & $0.32 \pm 0.03$ & $1.80 \pm 0.28$ \\
\cline { 1 - 2 } SUB & $0.32 \pm 0.03$ & $2.02 \pm 0.20$ \\
\cline { 1 - 2 } SUB & $0.32 \pm 0.03$ & $2.26 \pm 0.74$ \\
\cline { 1 - 2 } SUB & $0.32 \pm 0.03$ & $0.41 \pm 0.03$ \\
\cline { 1 - 2 } SUB & $0.32 \pm 0.03$ & \multirow{2}{*}{ N.D. } \\
\cline { 1 - 2 } SUB & $0.32 \pm 0.03$ & \multirow{2}{*}{$0.44 \pm 0.05$} \\
\cline { 1 - 2 } SUB & $0.32 \pm 0.03$ & $\mathbf{9 . 2} \pm \mathbf{0 . 9}$ \\
\cline { 1 - 2 } SUB & $0.32 \pm 0.03$ &
\end{tabular}

\begin{tabular}{|c|c|c|}
\hline Treatment 3 & $t=-1$ day & $\mathrm{t}=5$ days \\
\hline$P M M$ & $4.35 \pm 0.11$ & $0.52 \pm 0.03$ \\
\hline$P M M$ & $4.35 \pm 0.11$ & $3.13 \pm 0.30$ \\
\hline$S U B$ & $0.32 \pm 0.03$ & $1.01 \pm 0.06$ \\
\hline$S U B$ & $0.32 \pm 0.03$ & $1.13 \pm 0.13$ \\
\hline$S U B$ & $0.32 \pm 0.03$ & $1.24 \pm 0.31$ \\
\hline$T S$ & $0.10 \pm 0.01$ & $1.06 \pm 0.12$ \\
\hline$T S$ & $0.10 \pm 0.01$ & $1.36 \pm 0.75$ \\
\hline$T S$ & $0.10 \pm 0.01$ & $0.18 \pm 0.02$ \\
\hline$T S$ & $0.10 \pm 0.01$ & \multirow{3}{*}{$N . D}$. \\
\hline$T S$ & $0.10 \pm 0.01$ & \\
\hline$T S$ & $0.10 \pm 0.01$ & \\
\hline$T S$ & $0.10 \pm 0.01$ & $0.13 \pm 0.02$ \\
\hline TOTAL & $10.4 \pm 0.4$ & $9.8 \pm 1.0$ \\
\hline
\end{tabular}

\begin{tabular}{|c|c|c|}
\hline Treatment 4 & $t=-1$ day & $\mathrm{t}=\mathbf{5}$ days \\
\hline$F F M$ & $2.74 \pm 0.07$ & $0.40 \pm 0.02$ \\
\hline$F F M$ & $2.74 \pm 0.07$ & $0.47 \pm 0.03$ \\
\hline$S U B$ & $0.32 \pm 0.03$ & $0.47 \pm 0.04$ \\
\hline$S U B$ & $0.32 \pm 0.03$ & $1.10 \pm 0.24$ \\
\hline$S U B$ & $0.32 \pm 0.03$ & $2.90 \pm 1.23$ \\
\hline$T S$ & $0.10 \pm 0.01$ & $2.11 \pm 0.52$ \\
\hline$T S$ & $0.10 \pm 0.01$ & $1.38 \pm 0.55$ \\
\hline$T S$ & $0.10 \pm 0.01$ & $0.19 \pm 0.02$ \\
\hline$T S$ & $0.10 \pm 0.01$ & \multirow{3}{*}{ N.D. } \\
\hline$T S$ & $0.10 \pm 0.01$ & \\
\hline$T S$ & $0.10 \pm 0.01$ & \\
\hline$T S$ & $0.10 \pm 0.01$ & $0.13 \pm 0.02$ \\
\hline TOTAL & $7.2 \pm 0.3$ & $9.2 \pm 0.9$ \\
\hline
\end{tabular}

\begin{tabular}{|c|c|c|}
\hline Treatment 5 & $t=-1$ day & $t=5$ days \\
\hline$P M M$ & $4.06 \pm 0.05$ & $0.52 \pm 0.04$ \\
\hline$P M M$ & $4.06 \pm 0.05$ & $3.26 \pm 0.15$ \\
\hline$S U B$ & $0.31 \pm 0.01$ & $0.91 \pm 0.06$ \\
\hline$S U B$ & $0.31 \pm 0.01$ & $1.05 \pm 0.12$ \\
\hline$S U B$ & $0.31 \pm 0.01$ & $1.57 \pm 0.37$ \\
\hline LOS & $0.09 \pm 0.00$ & $0.51 \pm 0.05$ \\
\hline LOS & $0.09 \pm 0.00$ & $0.10 \pm 0.02$ \\
\hline LOS & $0.09 \pm 0.00$ & $0.11 \pm 0.02$ \\
\hline $\operatorname{LOS}$ & $0.09 \pm 0.00$ & \multirow{3}{*}{ N.D. } \\
\hline LOS & $0.09 \pm 0.00$ & \\
\hline LOS & $0.09 \pm 0.00$ & \\
\hline LOS & $0.09 \pm 0.00$ & $0.12 \pm 0.03$ \\
\hline TOTAL & $9.7 \pm 0.2$ & $8.1 \pm 0.4$ \\
\hline
\end{tabular}

\begin{tabular}{|c|c|c|}
\hline Treatment 6 & $t=-1$ day & $t=5$ days \\
\hline$F F M$ & $3.33 \pm 0.10$ & $0.56 \pm 0.29$ \\
\hline$F F M$ & $3.33 \pm 0.10$ & $0.42 \pm 0.13$ \\
\hline$S U B$ & $0.31 \pm 0.01$ & $0.29 \pm 0.02$ \\
\hline$S U B$ & $0.31 \pm 0.01$ & $1.10 \pm 0.16$ \\
\hline$S U B$ & $0.31 \pm 0.01$ & $2.96 \pm 0.27$ \\
\hline $\operatorname{LOS}$ & $0.09 \pm 0.00$ & $2.25 \pm 0.04$ \\
\hline LOS & $0.09 \pm 0.00$ & $0.11 \pm 0.02$ \\
\hline LOS & $0.09 \pm 0.00$ & $0.13 \pm 0.02$ \\
\hline $\operatorname{LOS}$ & $0.09 \pm 0.00$ & \multirow{3}{*}{ N.D. } \\
\hline LOS & $0.09 \pm 0.00$ & \\
\hline LOS & $0.09 \pm 0.00$ & \\
\hline LOS & $0.09 \pm 0.00$ & $0.11 \pm 0.01$ \\
\hline TOTAL & $8.3 \pm 0.3$ & $7.9 \pm 0.4$ \\
\hline
\end{tabular}

\begin{tabular}{|c|c|c|}
\hline Treatment 7 & $t=-1$ day & $t=5$ days \\
\hline$P M M+F$ & $8.45 \pm 0.15$ & $4.06 \pm 0.06$ \\
\hline$P M M$ & $4.06 \pm 0.14$ & $4.59 \pm 0.21$ \\
\hline$S U B$ & $0.31 \pm 0.01$ & $0.88 \pm 0.01$ \\
\hline$S U B$ & $0.31 \pm 0.01$ & $1.01 \pm 0.08$ \\
\hline$S U B$ & $0.31 \pm 0.01$ & $1.42 \pm 0.20$ \\
\hline LOS & $0.09 \pm 0.00$ & $0.48 \pm 0.03$ \\
\hline LOS & $0.09 \pm 0.00$ & $0.11 \pm 0.03$ \\
\hline LOS & $0.09 \pm 0.00$ & $0.12 \pm 0.02$ \\
\hline LOS & $0.09 \pm 0.00$ & \multirow{3}{*}{ N.D. } \\
\hline LOS & $0.09 \pm 0.00$ & \\
\hline LOS & $0.09 \pm 0.00$ & \\
\hline LOS & $0.09 \pm 0.00$ & $0.10 \pm 0.01$ \\
\hline TOTAL & $14.1 \pm 0.4$ & $12.8 \pm 0.4$ \\
\hline
\end{tabular}

\begin{tabular}{|c|c|c|}
\hline Treatment 8 & $t=-1$ day & $\mathrm{t}=5$ days \\
\hline$F F M+F$ & $8.38=0.27$ & $3.04 \pm 0.10$ \\
\hline$F F M$ & $3.33 \pm 0.15$ & $1.79 \pm 0.10$ \\
\hline$S U B$ & $0.31 \pm 0.01$ & $0.38 \pm 0.07$ \\
\hline$S U B$ & $0.31 \pm 0.01$ & $1.01 \pm 0.10$ \\
\hline$S U B$ & $0.31 \pm 0.01$ & $2.94 \pm 0.31$ \\
\hline $\operatorname{LOS}$ & $0.09 \pm 0.00$ & $2.19 \pm 0.14$ \\
\hline LOS & $0.09 \pm 0.00$ & $0.13 \pm 0.03$ \\
\hline LOS & $0.09 \pm 0.00$ & $0.13 \pm 0.03$ \\
\hline LOS & $0.09 \pm 0.00$ & \multirow{3}{*}{ N.D. } \\
\hline $\operatorname{LOS}$ & $0.09 \pm 0.00$ & \\
\hline LOS & $0.09 \pm 0.00$ & \\
\hline LOS & $0.09 \pm 0.00$ & $0.10 \pm 0.01$ \\
\hline TOTAL & $13.3 \pm 0.6$ & $11.7 \pm 0.5$ \\
\hline
\end{tabular}

Results related to $0.5 \mathrm{M} \mathrm{K}_{2} \mathrm{SO}_{4}$ extractable $\mathrm{P}$ showed high variations between replicates among the soil samples collected at the end of the leaching experiment (Fig. 4), which may be due to the low efficiency of $0.5 \mathrm{M} \mathrm{K}_{2} \mathrm{SO}_{4}$ in extracting strongly bound P. Nevertheless, some differences could be seen depending on the soil profile and the material considered. It appears that the amount of extractable P increased in the FFM material over the 5-day experiment, while no significant increase was observed in PMM. Extractable P also increased in some SUB horizons, while no increase was observed in the underlying horizon of LOS, whether fertilizer-P was added on the surface (treatments 7 and 8 ) or not (treatment 5 and 6). The input of fertilizer in the $0-10 \mathrm{~cm}$ resulted in an increase in extractable $\mathrm{P}$ at the end of the experiment in the $0-10 \mathrm{~cm}$ compared to the treatments without fertilizer. The 
residual extractable P measured after 5 days in this $0-10 \mathrm{~cm}$ layer represented $34 \%$ and $64 \%$ of the initial fertilizer-

P for PMM and FFM, respectively.

Fig. 4: 0.5 $\mathrm{M} \mathrm{K}_{2} \mathrm{SO}_{4}$ extractable $P$ in each 10-cm segment of reclaimed soil profiles $\left(\mathrm{mg} \mathrm{m}^{-2}\right)$, prior to leaching $(t=-1$ day) and after a 4-h intense rainfall and a resting period of 5 days $(t=5$ days). PMM: peat-mineral mix; PMM + F: peat-mineral mix with fertilizer; FFM: forest floor mineral material; FFM + F: forest floor mineral material with fertilizer; SUB: blended B/C horizons of sandy subsoil; TS: tailing sand; LOS: lean oil sand. N.D: Not determined. Results are presented as mean \pm standard error (3 replicates). A red color code is used to display the values: the higher the mean value, the darker the background of the cell.

\begin{tabular}{|c|c|c|}
\hline Treatment 1 & $t=-1$ day & $t=5$ days \\
\hline$P M M$ & $2.0 \pm 0.1$ & $1.8 \pm 0.1$ \\
\hline$P M M$ & $2.0 \pm 0.1$ & $1.9 \pm 0.3$ \\
\hline$S U B$ & $2.9 \pm 0.9$ & $12 \pm 8$ \\
\hline$S U B$ & $2.9 \pm 0.9$ & $6.4 \pm 0.1$ \\
\hline$S U B$ & $2.9 \pm 0.9$ & $62 \pm 45$ \\
\hline$S U B$ & $2.9 \pm 0.9$ & $2.8 \pm 0.4$ \\
\hline$S U B$ & $2.9 \pm 0.9$ & $27 \pm 15$ \\
\hline$S U B$ & $2.9 \pm 0.9$ & $8.9 \pm 0.3$ \\
\hline$S U B$ & $2.9 \pm 0.9$ & \multirow{3}{*}{ N.D. } \\
\hline$S U B$ & $2.9 \pm 0.9$ & \\
\hline$S U B$ & $2.9 \pm 0.9$ & \\
\hline$S U B$ & $2.9 \pm 0.9$ & $28 \pm 15$ \\
\hline TOTAL & $33 \pm 9$ & $151 \pm 68$ \\
\hline
\end{tabular}

\begin{tabular}{|c|c|c|}
\hline Treatment 2 & $t=-1$ day & $t=5$ days \\
\hline$F F M$ & $15.8 \pm 0.5$ & $69 \pm 29$ \\
\hline$F F M$ & $15.8 \pm 0.5$ & $4 \pm 24$ \\
\hline$S U B$ & $2.9 \pm 0.9$ & $3.4 \pm 1$ \\
\hline$S U B$ & $2.9 \pm 0.9$ & $27 \pm 20$ \\
\hline$S U B$ & $2.9 \pm 0.9$ & $4.2 \pm 0.7$ \\
\hline$S U B$ & $2.9 \pm 0.9$ & $4.3 \pm 0.5$ \\
\hline$S U B$ & $2.9 \pm 0.9$ & $32 \pm 22$ \\
\hline$S U B$ & $2.9 \pm 0.9$ & $8.1 \pm 0.5$ \\
\hline$S U B$ & $2.9 \pm 0.9$ & \multirow{3}{*}{$N . D$. } \\
\hline$S U B$ & $2.9 \pm 0.9$ & \\
\hline$S U B$ & $2.9 \pm 0.9$ & \\
\hline$S U B$ & $2.9 \pm 0.9$ & $61 \pm 37$ \\
\hline TOTAL & $60 \pm 10$ & $250 \pm 82$ \\
\hline
\end{tabular}

\begin{tabular}{|c|c|c|}
\hline Treatment 3 & $t=-1$ day & $\mathrm{t}=5$ days \\
\hline$P M M$ & $2.0 \pm 0.1$ & $11 \pm 9$ \\
\hline$P M M$ & $2.0 \pm 0.1$ & $1.7 \pm 0.3$ \\
\hline$S U B$ & $2.9 \pm 0.9$ & $4.5 \pm 1.7$ \\
\hline$S U B$ & $2.9 \pm 0.9$ & $3.9 \pm 1.4$ \\
\hline$S U B$ & $2.9 \pm 0.9$ & $18 \pm 15$ \\
\hline$T S$ & $6.9 \pm 1.0$ & $3.2 \pm 0.8$ \\
\hline$T S$ & $6.9 \pm 1.0$ & $6.2 \pm 0.8$ \\
\hline$T S$ & $6.9 \pm 1.0$ & $35 \pm 27$ \\
\hline$T S$ & $6.9 \pm 1.0$ & \multirow{3}{*}{ N.D. } \\
\hline$T S$ & $6.9 \pm 1.0$ & \\
\hline$T S$ & $6.9 \pm 1.0$ & \\
\hline$T S$ & $6.9 \pm 1.0$ & $55 \pm 47$ \\
\hline TOTAL & $61 \pm 10$ & $138 \pm 63$ \\
\hline
\end{tabular}

\begin{tabular}{|c|c|c|}
\hline Treatment 4 & $t=-1$ day & $\mathrm{t}=\mathbf{5}$ days \\
\hline$F F M$ & $15.8 \pm 0.5$ & $96 \pm 1$ \\
\hline$F F M$ & $15.8 \pm 0.5$ & $58 \pm 20$ \\
\hline$S U B$ & $2.9 \pm 0.9$ & $91 \pm 6$ \\
\hline$S U B$ & $2.9 \pm 0.9$ & $86 \pm 42$ \\
\hline$S U B$ & $2.9 \pm 0.9$ & $56 \pm 35$ \\
\hline$T S$ & $6.9 \pm 1.0$ & $4.4 \pm 0.8$ \\
\hline$T S$ & $6.9 \pm 1.0$ & $38 \pm 33$ \\
\hline$T S$ & $6.9 \pm 1.0$ & $5.2 \pm 1.7$ \\
\hline$T S$ & $6.9 \pm 1.0$ & \multirow{3}{*}{$N . D$. } \\
\hline$T S$ & $6.9 \pm 1.0$ & \\
\hline$T S$ & $6.9 \pm 1.0$ & \\
\hline$T S$ & $6.9 \pm 1.0$ & $15 \pm 8$ \\
\hline TOTAL & $89 \pm 11$ & $449 \pm 115$ \\
\hline
\end{tabular}

\begin{tabular}{|c|c|c|}
\hline Treatment 5 & $t=-1$ day & $\mathrm{t}=5$ days \\
\hline$P M M$ & $2.2 \pm 0.2$ & $0.8 \pm 0.2$ \\
\hline$P M M$ & $2.2 \pm 0.2$ & $1.0 \pm 0.7$ \\
\hline$S U B$ & $2.9 \pm 0.9$ & $62 \pm 46.3$ \\
\hline$S U B$ & $2.9 \pm 0.9$ & $19 \pm 17$ \\
\hline$S U B$ & $2.9 \pm 0.9$ & $17 \pm 7$ \\
\hline LOS & $2.0 \pm 0.8$ & $1.6 \pm 0.4$ \\
\hline $\operatorname{LOS}$ & $2.0 \pm 0.8$ & $1.5 \pm 0.9$ \\
\hline $\operatorname{LOS}$ & $2.0 \pm 0.8$ & $3.9 \pm 0.5$ \\
\hline LOS & $2.0 \pm 0.8$ & \multirow{3}{*}{ N.D. } \\
\hline LOS & $2.0 \pm 0.8$ & \\
\hline $\operatorname{LOS}$ & $2.0 \pm 0.8$ & \\
\hline LOS & $2.0 \pm 0.8$ & $2.2 \pm 1.0$ \\
\hline TOTAL & $27 \pm 9$ & $109 \pm 51$ \\
\hline
\end{tabular}

\begin{tabular}{|c|c|c|}
\hline Treatment 6 & $t=-1$ day & $t=5$ days \\
\hline$F F M$ & $12.5 \pm 0.8$ & $35 \pm 14$ \\
\hline$F F M$ & $12.5 \pm 0.8$ & $82 \pm 21$ \\
\hline$S U B$ & $2.9 \pm 0.9$ & $41 \pm 5$ \\
\hline$S U B$ & $2.9 \pm 0.9$ & $36 \pm 5$ \\
\hline$S U B$ & $2.9 \pm 0.9$ & $27 \pm 1$ \\
\hline LOS & $2.0 \pm 0.8$ & $2.0 \pm 0.5$ \\
\hline $\operatorname{LOS}$ & $2.0 \pm 0.8$ & $2.2 \pm 0.9$ \\
\hline LOS & $2.0 \pm 0.8$ & $4.7 \pm 2.0$ \\
\hline LOS & $2.0 \pm 0.8$ & \multirow{3}{*}{$N . D$. } \\
\hline $\operatorname{LOS}$ & $2.0 \pm 0.8$ & \\
\hline LOS & $2.0 \pm 0.8$ & \\
\hline LOS & $2.0 \pm 0.8$ & $1.9 \pm 0.6$ \\
\hline TOTAL & $48 \pm 10$ & $220 \pm 25$ \\
\hline
\end{tabular}

\begin{tabular}{|c|c|c|}
\hline Treatment 7 & $t=-1$ day & $\mathrm{t}=5$ days \\
\hline$P M M+F$ & $132 \pm 15$ & $44 \pm 2$ \\
\hline$P M M$ & $2.2 \pm 0.2$ & $0.7 \pm 0.1$ \\
\hline$S U B$ & $2.9 \pm 0.9$ & $2.5 \pm 1.1$ \\
\hline$S U B$ & $2.9 \pm 0.9$ & $38 \pm 17$ \\
\hline$S U B$ & $2.9 \pm 0.9$ & $7.4 \pm 4.8$ \\
\hline LOS & $2.0 \pm 0.8$ & $2.4 \pm 0.7$ \\
\hline LOS & $2.0 \pm 0.8$ & $1.8 \pm 0.5$ \\
\hline LOS & $2.0 \pm 0.8$ & $3.8 \pm 0.9$ \\
\hline LOS & $2.0 \pm 0.8$ & \multirow{3}{*}{$N . D$. } \\
\hline LOS & $2.0 \pm 0.8$ & \\
\hline $\operatorname{LOS}$ & $2.0 \pm 0.8$ & \\
\hline LOS & $2.0 \pm 0.8$ & $1.2 \pm 0.6$ \\
\hline TOTAL & $157 \pm 38$ & $102 \pm 19$ \\
\hline
\end{tabular}

\begin{tabular}{|c|c|c|}
\hline Treatment 8 & $t=-1$ day & $\mathrm{t}=5$ days \\
\hline$F F M+F$ & $152 \pm 6$ & $97 \pm 1.8$ \\
\hline$F F M$ & $12 \pm 1$ & $104 \pm 72$ \\
\hline$S U B$ & $2.9 \pm 0.9$ & $24 \pm 14$ \\
\hline$S U B$ & $2.9 \pm 0.9$ & $2.3 \pm 0.4$ \\
\hline$S U B$ & $2.9 \pm 0.9$ & $19 \pm 9$ \\
\hline LOS & $2.0 \pm 0.8$ & $3.4 \pm 1.2$ \\
\hline $\operatorname{LOS}$ & $2.0 \pm 0.8$ & $1.6 \pm 0.5$ \\
\hline $\operatorname{LOS}$ & $2.0 \pm 0.8$ & $3.9 \pm 0.6$ \\
\hline $\operatorname{LOS}$ & $2.0 \pm 0.8$ & \multirow{3}{*}{ N.D. } \\
\hline $\operatorname{LOS}$ & $2.0 \pm 0.8$ & \\
\hline $\operatorname{LOS}$ & $2.0 \pm 0.8$ & \\
\hline $\operatorname{LOS}$ & $2.0 \pm 0.8$ & $2.0 \pm 0.7$ \\
\hline TOTAL & $187 \pm 19$ & $257 \pm 52$ \\
\hline
\end{tabular}

\subsection{Short-term changes in nutrient availability}

Data showing the evolution of inorganic $\mathrm{N}$ and $\mathrm{P}$ extracted by $0.5 \mathrm{M} \mathrm{K} \mathrm{K}_{2} \mathrm{SO}_{4}$ from the two capping materials (PMM and FFM) over the 25 days of the incubation experiment are presented in Table 2. As ammonium-N represented less than $2 \%$ of the extractable inorganic $\mathrm{N}$ fraction for each investigated time in the absence of fertilizer, the evolution of extractable inorganic $\mathrm{N}$ mostly corresponded to the variations in soil nitrate-N. Results showed that the amount of inorganic $\mathrm{N}$ significantly decreased within the first $24 \mathrm{~h}$, reaching $63 \%$ and $67 \%$ of its initial value for PMM and FFM, respectively (Table 2). The total extractable inorganic $\mathrm{N}$ then slightly increased between 1

Peer-reviewed, unedited version of the manuscript of Rees et al. (2020) published by Applied Geochemistry: https://doi.org/10.1016/j.apgeochem.2020.104526 
and 5 days, back to $77 \%$ of its initial value for both materials, which corresponded to a net increase of 12 and 2.6 $\mathrm{mg}_{\mathrm{N}} \mathrm{kg}^{-1}$ for PMM and FFM, respectively. From 5 to 25 days, the extractable inorganic $\mathrm{N}$ decreased again in PMM, but remained constant in FFM.

When ammonium sulfate was added at the beginning of the experiment as fertilizer, ammonium- $\mathrm{N}$ represented $67 \%$ and $88 \%$ of the initial extractable inorganic $\mathrm{N}$ fraction for PMM and FFM, respectively, but after 25 days, ammonium made up only $0.3 \%$ and $14 \%$ of the inorganic $\mathrm{N}$ (Table 2 ). In the first $24 \mathrm{~h}$ following the addition of fertilizer, the amount of extractable ammonium-N decreased by $77 \%$ and $61 \%$ in PMM and FFM, which represents a net decrease of $143 \mathrm{mg}_{\mathrm{N}} \mathrm{kg}^{-1}$ and $120 \mathrm{mg}_{\mathrm{N}} \mathrm{kg}^{-1}$, respectively. At the same time, nitrate- $\mathrm{N}$ decreased by $33 \%$ and $35 \%$, similarly to what happened in the non-fertilized treatments. However, while the amount of extractable ammonium- $\mathrm{N}$ continued to decrease until the end of the incubation, the amount of extractable nitrate- $\mathrm{N}$ increased between 1 and 5 days. Nitrate-N concentrations in PPM increased by $96 \mathrm{mg}_{\mathrm{N}} \mathrm{kg}^{-1}$, while it increased by $7 \mathrm{mg}_{\mathrm{N}} \mathrm{kg}^{-}$ ${ }^{1}$ in FFM. The amount of nitrate-N then decreased between 5 days and 25 days in the PMM, but continued to rise in FFM. At the end of the experiment nitrate-N in both PMM and FFM remained higher than in the non-fertilized treatments; PMM was more than double the non-fertilized PMM treatment, while FFM was more than four times the non-fertilized FFM treatment.

When no fertilizer was added, the amount of $0.5 \mathrm{M} \mathrm{K}_{2} \mathrm{SO}_{4}$ extractable phosphate-P was low, ranging from 0.019 to $0.036 \mathrm{mg} \mathrm{kg}^{-1}$ in the case of PMM and from 0.129 to $0.192 \mathrm{mg} \mathrm{kg}^{-1}$ in the case of FFM (Table 2). When fertilizer was added, the initial amount of extractable phosphate-P rose up to $81 \mathrm{mg}_{\mathrm{P}} \mathrm{kg}^{-1}$ and $117 \mathrm{mg}_{\mathrm{P}} \mathrm{kg}^{-1}$ with PMM and FFM, respectively (Table 2). It sharply decreased within the first 24 h (by $91 \%$ for PMM and by $87 \%$ for FFM), and then more slowly decreased for the duration of the experiment to $1.7 \mathrm{mg}_{\mathrm{P}} \mathrm{kg}^{-1}$ for $\mathrm{PMM}$ and $8 \mathrm{mg}_{\mathrm{P}}$ $\mathrm{kg}^{-1}$ for FFM.

The accumulation of $\mathrm{CO}_{2}$ inside the jars was measured over the duration of the incubation experiment, and the mineralization rate $\left(\mu \mathrm{g}_{\mathrm{CO} 2-\mathrm{C}} \mathrm{g}_{\mathrm{SOC}^{-1}}\right.$ day $\left.^{-1}\right)$ was calculated from these data. Results showed that the organic matter in PMM was degraded more slowly than the organic matter in FFM (Fig. S18). The rate of respiration in PMM decreased from day 1 to day 10, and increased back to its initial rate between day 10 and day 15 . However, there was no clear evolution of FFM mineralization rate over time. The addition of fertilizer at the beginning of the incubation led to an increase in the respiration rate of PMM, particularly between day 2 and day 10, while no significant effect of fertilizer on FFM's respiration was observed. 
Nitrous oxide $\left(\mathrm{N}_{2} \mathrm{O}\right)$ emissions were measured at 1,5 and 25 days. $\mathrm{N}_{2} \mathrm{O}$ emissions were generally below detection limits (data not shown), except after 5 days in the case of PMM, where the net emission rate of $\mathrm{N}_{2} \mathrm{O}$ corresponded to $12 \pm 2 \mu \mathrm{g}_{\mathrm{N}} \mathrm{kg}^{-1} \mathrm{day}^{-1}$ in the absence of fertilizer and $198 \pm 43 \mu \mathrm{g}_{\mathrm{N}} \mathrm{kg}^{-1}$ day $^{-1}$ in the presence of fertilizer. Calculations based on the isotopic composition of the $\mathrm{N}_{2} \mathrm{O}$ emitted by PMM after fertilizer addition showed that $61 \%$ of the $\mathrm{N}_{2} \mathrm{O}$ emissions originated from the $\mathrm{N}$ introduced by the fertilizer. Assuming that this rate of $\mathrm{N}_{2} \mathrm{O}$ emission had been maintained between day 1 and day 5 , we concluded that less than $0.49 \mathrm{mg}_{\mathrm{N}} \mathrm{kg}^{-1}$ may have been lost from the fertilizer as $\mathrm{N}_{2} \mathrm{O}$ emissions over the first five days, i.e. less than $0.5 \%$ of the total amount of fertilizer$\mathrm{N}$ that was initially added. The calculations also suggested that a net flux of $65 \mu \mathrm{g}_{\mathrm{N}} \mathrm{kg}^{-1} \mathrm{day}^{-1}$ may have corresponded to a "priming effect", i.e. an increase in the amount of unlabeled $\mathrm{N}_{2} \mathrm{O}$ emitted by PMM induced by the addition of the fertilizer.

Table 2: $0.5 \mathrm{M} \mathrm{K}_{2} \mathrm{SO}_{4}$ extractable inorganic nutrients from peat-mineral mix (PMM) and forest floor mineral material (FFM) with or without fertilizer (F) addition, measured throughout the incubation experiment. Results are presented as mean \pm standard error (4 replicates).

\begin{tabular}{|c|c|c|c|c|c|}
\hline Nutrient & Treatment & 0 day & 1 day & 5 days & 25 days \\
\hline \multirow{4}{*}{$\begin{array}{l}\text { Ammonium-N } \\
\left(\mathrm{mg} \mathrm{kg}^{-1}\right)\end{array}$} & $P M M$ & $0.38 \pm 0.02$ & $0.25 \pm 0.04$ & $0.27 \pm 0.02$ & $0.44 \pm 0.06$ \\
\hline & $P M M+F$ & $185 \pm 2$ & $42 \pm 3$ & $0.27 \pm 0.02$ & $0.32 \pm 0.02$ \\
\hline & $F F M$ & $0.38 \pm 0.02$ & $0.24 \pm 0.01$ & $0.28 \pm 0.01$ & $0.35 \pm 0.01$ \\
\hline & $F F M+F$ & $196 \pm 1$ & $76 \pm 4$ & $79 \pm 2$ & $14 \pm 2$ \\
\hline \multirow{4}{*}{$\begin{array}{l}\text { Nitrate-N } \\
\left(\mathrm{mg} \mathrm{kg}^{-1}\right)\end{array}$} & $P M M$ & $89 \pm 1$ & $56 \pm 3$ & $68 \pm 3$ & $53 \pm 2$ \\
\hline & $P M M+F$ & $88 \pm 2$ & $59 \pm 10$ & $155 \pm 4$ & $113 \pm 3$ \\
\hline & $F F M$ & $26 \pm 1$ & $18 \pm 1$ & $20 \pm 0$ & $19 \pm 1$ \\
\hline & $F F M+F$ & $27 \pm 1$ & $17 \pm 1$ & $24 \pm 0$ & $85 \pm 2$ \\
\hline \multirow{4}{*}{$\begin{array}{l}\text { Inorganic } N \\
\left(\mathrm{mg} \mathrm{kg}^{-1}\right)\end{array}$} & $P M M$ & $89 \pm 1$ & $57 \pm 3$ & $69 \pm 3$ & $54 \pm 2$ \\
\hline & $P M M+F$ & $274 \pm 4$ & $101 \pm 10$ & $155 \pm 4$ & $113 \pm 3$ \\
\hline & $F F M$ & $27 \pm 1$ & $18 \pm 1$ & $20 \pm 0$ & $19 \pm 1$ \\
\hline & $F F M+F$ & $223 \pm 2$ & $93 \pm 5$ & $103 \pm 2$ & $98 \pm 3$ \\
\hline \multirow{4}{*}{$\begin{array}{l}\text { Phosphate-P } \\
\left(\mathrm{mg} \mathrm{kg}^{-1}\right)\end{array}$} & $P M M$ & $0.03 \pm 0.02$ & $0.03 \pm 0.00$ & $0.04 \pm 0.01$ & $0.02 \pm 0.00$ \\
\hline & $P M M+F$ & $81 \pm 1$ & $7.5 \pm 0.3$ & $2.1 \pm 0.1$ & $1.7 \pm 0.2$ \\
\hline & $F F M$ & $0.18 \pm 0.01$ & $0.19 \pm 0.01$ & $0.13 \pm 0.00$ & $0.18 \pm 0.01$ \\
\hline & $F F M+F$ & $117 \pm 0$ & $15.6 \pm 0.4$ & $9.9 \pm 0.4$ & $8.0 \pm 0.5$ \\
\hline
\end{tabular}

Peer-reviewed, unedited version of the manuscript of Rees et al. (2020) published by Applied Geochemistry: 


\subsection{Modelling the movement of water and nutrients in reclaimed soils}

Different simulations were done with HYDRUS-1D in order to assess the risk of nutrient leaching, either solely from hydraulic properties or in combination with nutrient immobilization/mineralization mechanisms determined by the sorption experiment or the incubation experiment. All simulations led to water content profiles in reclaimed soils very similar to those experimentally determined at the end of the leaching experiment, with only slight differences observed for certain layers of materials, such as the 10-20 cm layer of PMM (Fig. S20a).

By contrast, profiles of extractable $\mathrm{N}$ or $\mathrm{P}$ measured at the end of the leaching experiment could not be accurately reproduced by any of the three simulations (Fig. S120b and S20c). This was particularly true for P (Fig. S20c). Some comparable general trends between experimental and simulated data were observed for inorganic $\mathrm{N}$ with all simulations, e.g. i) a decrease in the amount of inorganic $\mathrm{N}$ in the capping materials and an increase in the underlying material between the initial and final time, ii) a lower amount of inorganic $\mathrm{N}$ in the $0-10 \mathrm{~cm}$ PMM layer compared to the 10-20 cm PMM layer when no fertilizer was introduced. However, significant differences were also observed between simulated and experimental data, such as an overestimation of the remaining amount of inorganic $\mathrm{N}$ in the $0-20 \mathrm{~cm}$ horizon and an underestimation of inorganic $\mathrm{N}$ in the $20-50 \mathrm{~cm}$ by the three simulations (Fig. S20b). 


\section{DISCUSSION}

Our work aimed to assess how nutrient leaching may occur in coarse-textured reclaimed soils from the Athabasca Oil Sands Region (AOSR). Our results showed that the amount of plant-available water and nutrients was similar between the reclaimed soils and two natural analog soils of the region. Intense rainfalls had a different impact on nutrient leaching in the reclaimed soils, depending on the soil cover design and the underlying substrate. These results have implications for the design of soils with a water and nutrient regime similar to natural coarse-textured soils of the region, as well as water and nutrient retention of substrates that are reclaimed.

\subsection{Nutrient and water availability in reclaimed soil profiles compared to natural soils}

Boreal forest species and community assemblages of the AOSR have been shown to be dependent on the soil moisture and nutrient regimes, in some cases requiring a low soil moisture status to promote the development of specific vegetation species. This is consistent with the study of Barnes et al. (2018), who investigated natural coarse-textured soils which were dominated by either jack pine forest canopy, or aspen and white spruce forest canopy. Jack pine forest stands were present on coarser-textured soils (indicative of lower soil water and nutrient retention), while a shift to aspen and white spruce forest stands corresponded to a slight increase in clay and silt content from $6 \%$ to $12 \%$ (indicative of increased soil water and nutrient retention). In our work, the design of coarse-textured soils aimed to recreate the water and nutrient regimes associated with these forest ecosystems. The forest floor mineral material (FFM) used in the study led to similar or better soil characteristics than the surface soil horizons $(20 \mathrm{~cm})$ of the two natural soils, i.e. the mixture of LFH and Ae horizons (Fig. 1), in terms of total organic C, N and P and plant-available water and inorganic N. These differences may actually result from the lower proportion of mineral soil (Ae or B horizons) incorporated in the FFM or from the variation in the surface soil characteristics of natural soils in the region, rather than from a hypothetical improvement of the soil characteristics caused by soil salvage or placement practice. The use of peat (PMM) instead of FFM led to an increase in the stock of $\mathrm{N}$ and the reservoir of plant-available water compared to the natural soils. In a reclaimed landscape with relatively low forest productivity like that of coarse-textured upland soils of the region, it is likely that a PMM coversoil will progressively be depleted of its organic matter as it reaches equilibrium with its environment, which may eventually transition to a coversoil similar to FFM (i.e., surface LFH horizon). However, it was suggested from a 325-day incubation experiment that the time for PMM and FFM to be completely depleted of organic matter (assuming no plant C inputs) would be greater than 600 years and 40 years, respectively (Quideau 
et al., 2017). This suggests that both soil reclamation coversoils will provide in the near term at least as much water and nutrients to plants than natural soils of the region. Compared to the two coversoil materials, the underlying materials (SUB, LOS, TS) did not contribute much to the total amount of extractable inorganic $\mathrm{N}$ available in the reclaimed soil profiles, and only moderately to the reservoir of soil water, with the exception of LOS. However, their main expected contribution was their ability to modulate nutrient leaching: if nutrients are leached from the soil profile, the characteristics of the underlying substrate will determine if nutrients will persist near the interface or leach relatively quickly out of the soil root zone.

An important objective of the study was therefore to assess how much of the initial nutrient stocks in the soil could be lost by leaching, especially after an intense rainfall. We hypothesized that the movement of nutrients down the soil profiles would be mainly controlled by water retention and by the hydraulic conductivity of the materials used in these soils. According to this hypothesis, nutrient immobilization processes such as chemical sorption on soil organic or mineral phases, and microbial processing of $\mathrm{N}$ and $\mathrm{P}$, would be negligible or too slow to prevent the leaching of inorganic nutrients caused by the fast movement of water through the coarse-textured soil, leading to a loss of nutrients from the coversoil. This phenomenon could indeed occur in the context of intense rainfalls, which happens in this region between the end of May and the mid of August (i.e. at the peak of plant growth when the nutrient demand is the highest). Based on this hypothesis, we first focused our efforts on characterizing the movement of water in the reclaimed soils.

\subsection{Water dynamics in reclaimed soil profiles}

The water retention and hydraulic conductivity curves modelled for each material from the data obtained by a range of experimental methods showed sharp differences between some of the materials. Our results showed that $38 \%$ of the volume of the PMM could be used to hold water that remains directly available to the plants, likely because of its high organic matter content and low density. By contrast, the amount of plant-available water potentially retained by FFM material only represented $13 \%$ of its volume, because of the high sand fraction and the lower content of organic matter of this material. Interestingly, the lean oil sands also had a high water retention capacity, which was probably due to the higher silt and clay content of this material.

In terms of nutrient leaching limitations, hydraulic conductivity is considered the determinant factor. In this regard, LOS had the most interesting behavior as it acted as semi-permeable barrier, with a lower water conductivity than the other materials in moist conditions (water tension lower than $10 \mathrm{kPa}$ ), and then a conductivity equivalent to 
the forest floor mineral material for higher water tensions (Fig. S4). Interestingly, the blended B/C subsoil and the tailings sand had very similar water retention and hydraulic conductivity curves. This suggests that the higher hydrophobicity classes measured for the tailings sand in dry conditions, which was likely caused by the physicochemical treatment that the material experienced during bitumen extraction and/or by the presence of residual hydrocarbons (Bowman et al., 2014), did not significantly affect its overall hydric properties.

The results of the column leaching experiment show that following an intense rainfall, the water redistribution in the soil profiles followed the patterns expected from the individual hydric properties of their soil constituents (Fig. S20a). This matching between experimental and simulated water distribution in the column experiment allowed us to use HYDRUS-1D as a prospective tool. In particular, a practical limitation of the column experiment was that the bottom of the columns was open to atmospheric pressure through a small drainage pipe. An artificial boundary condition like this does not exist in the environment; this likely resulted in higher water retentions at the bottom of the column. By reproducing realistic conditions in the simulations (see details in Supporting Material 11), we found that a water volume corresponding to $4-8 \%$ of the incoming water (50 mm rain) could have actually percolated below $120 \mathrm{~cm}$ at the end of the 5 days in the profiles that did not contain lean oil sand, had the reclaimed soil profiles been in field conditions (Fig. S21, Test 2 and 3). These simulations also suggest that the amount of water lost at the bottom could have increased up to $70-75 \%$ of the initial rainfall if the experiment had continued for 100 days (Fig. S21, Test 2 and 3). While additional processes may limit this movement of water (e.g. root water uptake and evapotranspiration), this data shows that water may be quickly drained from these reclaimed soils. It also suggests that a significant fraction of nutrients could be lost not only from the coversoil, but also from the entire soil profile (Fig. S21, Test 2), if nutrients followed water movement.

\subsection{Abiotic or biotic control of nutrient leaching}

The movement of nutrients down the reclaimed soil profiles was slower than the movement of water, and HYDRUS-1D failed to simulate such a delay (Fig. S19b,c - Simulation 1). This suggested that either adsorptiondesorption processes or biological processes affected the movement of nutrients over the duration of the experiment. The net immobilizing capacity of each material for inorganic $\mathrm{N}$ was rather low, as shown by the sorption experiment, implying that sorption processes did not play a large role in slowing down the movement of inorganic $\mathrm{N}$ down the soil profiles. Consequently, including the sorption parameters measured for $\mathrm{NH}_{4}-\mathrm{N}$ and $\mathrm{NO}_{3}-\mathrm{N}$ into the HYDRUS-1D model did not improve its capacity to reproduce the observed redistribution of inorganic N (Fig. S19b - Simulation 2). However, the sorption capacity of phosphate-P was high in the case of https://doi.org/10.1016/j.apgeochem.2020.104526 
PMM, LOS and SUB according to the sorption isotherms. We may speculate that the presence of calcium carbonate in the first two materials may explain the high $\mathrm{P}$ retention capacity through sorption/precipitation processes. The ability of SUB to immobilize $\mathrm{P}$ was however more surprising considering its low content in carbonate, clay or organic matter. The fact that no $\mathrm{P}$ immobilization was observed in the tailings sand despite the similar characteristics of both materials suggests that the $\mathrm{P}$ retention capacity was altered by the bitumen extraction process, as shown previously (Lanoue, 2003). Including P sorption equilibrium in the HYDRUS-1D model also did not improve its ability to simulate the unexpected release of P by some of the materials such as FFM and SUB over the 6 days of the column leaching experiment (Fig. S19c - Simulation 2). Including explicit processes such as calcium phosphate dissolution or $\mathrm{pH}$-dependent $\mathrm{P}$ retention could perhaps help to reproduce such a behavior, but additional experimental data would be needed to describe such processes.

Assuming that biological processes were limiting the mobility of nutrients in the coversoils, we conducted an additional incubation experiment with PMM and FFM by reproducing the same environmental conditions as in the columns, but without variations in water content. The decrease in the size of the pool of inorganic $\mathrm{N}$ within the first $24 \mathrm{~h}$ suggested a significant contribution of $\mathrm{N}$ immobilization by microbial biomass, although small losses of $\mathrm{N}$ into gaseous $\mathrm{N}_{2} \mathrm{O}$ or $\mathrm{N}_{2}$ by denitrification process cannot be excluded. This means that the amount of mineral$\mathrm{N}$ present in the coversoil materials at the start of the simulated rainfall was actually lower than the one measured on the previous day when columns were filled. Furthermore, the incubation of the unfertilized capping materials showed that a small amount of nitrate was also generated between 1 day and 5 days through the (re)mineralization of the immobilized $\mathrm{N}$. When ammonium sulfate was added to the coversoil materials, the ammonium-N was quickly immobilized within the first day, and then progressively nitrified between day 1 and day 5 in the PMM and between day 5 and day 25 in the FFM, i.e. after the rainfall event had stopped. This could explain why the fertilizer-derived inorganic $\mathrm{N}$ was still present in the first $20 \mathrm{~cm}$ of the columns at the end of the leaching experiment, and had not been leached out similarly to most of the initial nitrate- $\mathrm{N}$ in the coversoil materials. To take these immobilization and nitrification processes into account, we used the data from the incubation experiment to reproduce the relative increase/decrease in the $\mathrm{NH}_{4}-\mathrm{N}, \mathrm{NO}_{3}-\mathrm{N}$ and $\mathrm{P}$ concentrations in the liquid phase with HYDRUS-1D (Fig. S19b,c - Simulation 3). However, this did not improve the correspondence with the experimental data from the column experiment for either $\mathrm{N}$ or P. Refinements of HYDRUS-1D simulations using non-equilibrium reactions, optimized diffusion parameters and various chain reactions would certainly improve the predictive power of the model, but such approaches are beyond the scope of this manuscript. The inability of the HYDRUS-1D model to reproduce the observed evolution of soil nutrient profiles by any of the three Peer-reviewed, unedited version of the manuscript of Rees et al. (2020) published by Applied Geochemistry: https://doi.org/10.1016/j.apgeochem.2020.104526 
simulations suggests that the risk of nutrient leaching in the investigated coarse-textured reclaimed soils is only partially controlled by the fast movement of water, and depends on a complex set of inter-dependent physical, chemical and biological processes that cannot be easily reproduced in silico. Important conclusions can however be drawn from these results regarding the probability of nutrient losses by leaching in coarse-textured soils of oil sand mine reclamation in the AOSR.

\subsection{Practical implications for coarse-textured soils in oil sands mine reclamation}

Our work shows that plant-available $\mathrm{N}$ in the reclaimed soils profiles is mostly concentrated in the $20 \mathrm{~cm}$ of the coversoil (PMM or FFM materials) compared to the subsoil (SUB) or the underlying reclaimed substrates (LOS and TS). Although the organic matter content in FFM is 10 times lower than in PMM, both types of coversoil resulted in a similar initial amount of mineral $\mathrm{N}$ extractable from the first $20 \mathrm{~cm}$ of the soil profile. However, this similarity between the two materials may not last over time. A 325-day laboratory incubation showed that the rate of $\mathrm{N}$ mineralization was identical between both materials when expressed as $\mathrm{mg}$ of $\mathrm{N}$ per kilogram of soil (Quideau et al., 2017). Considering the 2.7 times higher bulk density of FFM compared to PMM, this suggests that a coversoil of FFM could provide at least two times more $\mathrm{N}$ to plants over time, providing that the mineral $\mathrm{N}$ generated through soil organic matter mineralization is not leached below the rooting zone.

In this regard, the use of subsoil and reclaimed substrates may play a significant role, as we showed here that the presence of lean oil sand, and, to a lower extent, tailing sand below $50 \mathrm{~cm}$ helped to slow down the movement of mineral $\mathrm{N}$ following an intense rainfall. Specifically, the fastest leaching of inorganic $\mathrm{N}$ was observed in the reclaimed profile R2 with $20 \mathrm{~cm}$ FFM material overlying $100 \mathrm{~cm}$ of blended B/C subsoil, and the lowest leaching was in profile R5 containing a PMM coversoil and LOS below $50 \mathrm{~cm}$. Furthermore, considering that LOS has a higher bulk density in the environment than what was established in the column experiment and that an increase in bulk density may result in a 5-times lower saturated hydraulic conductivity (Pernitsky et al., 2016), the potential for water and nutrient leaching from the R5 profile is likely lower than what was measured in the study. Thus, even though LOS may have some characteristics that could limit root development and ultimately vegetation growth (i.e., elevated hydrocarbon concentration, high bulk density), it also has the advantage of restricting water and nutrients leaching from the soil root zone, relative to a native upland soil with a coarse-textured soil profile that extends beyond $1 \mathrm{~m}$ from the surface. The thickness of the coversoil and subsoil applied on the top of this substrate should therefore be carefully chosen for optimizing plant growth. Furthermore, the conclusions drawn so far do not take into account the availability of $\mathrm{P}$. When comparing the stocks of total or extractable $\mathrm{P}$ among 
the materials, it is clear that a coversoil of PMM can lead to a very low availability of P for the plants, in contrast to the use of FFM. Whether this would be a limiting factor for the growth of specific species is still uncertain. However, the subsoil reclamation material or the lean oil sand below $50 \mathrm{~cm}$ may represent in this case an interesting alternative source of $\mathrm{P}$ for the plants.

When considering the potential impacts of the different designs of reclaimed soils on plant growth, it should be kept in mind that different forest ecosystems have different requirements in terms of water and nutrient availability. In this region, jack pine stands are naturally found on soils with a higher sand content (94\%) than soils under aspen forests, which had an average $88 \%$ sand (Barnes et al., 2018). This illustrates the preferential growth of jack pines with relatively lower moisture and nutrient regimes (Beckingham and Archibald, 1996). Our results therefore suggest that reclaimed profiles using FFM as coversoil overlying SUB or TS (profiles R2 and R4) may be more suitable to jack pine's growth, while aspen and/or white spruce would be more competitive than jack pine in areas reclaimed with LOS substrate (e.g. profiles R5 with PMM).

The addition of fertilizer was tested in this study as a way to further investigate the functioning of the reclaimed soil profiles and the leaching risk of applied nutrients. Virtually no leaching of fertilizer-derived $\mathrm{N}$ or $\mathrm{P}$ was observed below $20 \mathrm{~cm}$ at the end of the experiment. However, as explained in the previous subsection, it should not be extrapolated from the results of the column experiment that no loss of fertilizer-N can occur in a reclamation setting. The quantification of ${ }^{15} \mathrm{~N}$ at the end of the leaching experiment showed that a significant part of the fertilizer-N (i.e. $9 \%$ for PMM and 25\% for the FFM) could not be recovered in the extractable inorganic N fraction. While this could be due to the temporary immobilization of fertilizer-N within microbial biomass or to the strong binding of $\mathrm{NH}_{4}{ }^{+}$to specific phases, this may also reflect possible losses of fertilizer-N as gaseous $\mathrm{NH}_{3}$. Such losses could have been significant with PMM considering its relatively high $\mathrm{pH}$ and the presence of calcium carbonate known to promote ammonia volatilization, especially in the case of ammonium sulfate (Sommer et al., 2004). Besides the risk of ammonia volatilization, and to a lower extent $\mathrm{N}_{2} \mathrm{O}$ or $\mathrm{N}_{2}$, our results suggest that the risk of losing fertilizer-N by leaching would be high if an intense rainfall occurred after all ammonium was nitrified and before the vegetation can take it up from the soil. In those cases, fertilizer addition would have little effect on vegetation response. In the case of $\mathrm{P}$, our results showed that the risk of losing fertilizer-P from the coversoil by leaching processes was very small. We may however speculate that adding fertilizer-P to the PMM coversoil may have little impact on potential plant growth, at least on the short term, considering the high initial stock of $\mathrm{P}$ in PMM, its very low extractability and the fast immobilization of the added P. 


\section{CONCLUSIONS}

Our work aimed to evaluate how nutrient availability in reclamation soils from the Athabasca Oil Sands Region may be impacted by sudden, intense summer rainfalls, and how different combinations of predominantly coarsetextured soil reclamation materials and substrate materials could alter nutrient leaching. By artificially recreating the effects of an intense rainfall at the surface of the reclaimed soil profiles, we demonstrated that the potential for soil water and inorganic $\mathrm{N}$ leaching was significant when specific materials were combined, e.g. forest floor mineral mix and coarse-textured $\mathrm{B} / \mathrm{C}$ subsoil. In particular, $84 \%$ of the inorganic $\mathrm{N}$ initially retained in the forest floor mineral mix within the top $20 \mathrm{~cm}$ of the reclaimed soil profiles had been leached down five days after the rainfall, while only $66 \%$ of the inorganic $\mathrm{N}$ from the peat mineral mix moved below $20 \mathrm{~cm}$. The leaching of $\mathrm{N}$ down the soil profiles was however partly restricted by the presence of lean oil sand below $50 \mathrm{~cm}$, and to a lesser degree tailing sand. When ammonium- $\mathrm{N}$ was added in the first $10 \mathrm{~cm}$ of the soil profiles, most of this additional inorganic $\mathrm{N}$ remained in the top $20 \mathrm{~cm}$ following the rainfall, although our incubation experiment later suggested that the biological conversion of ammonium to nitrate, the more mobile form of inorganic $\mathrm{N}$, only occurred after the simulated rainfall. In all cases, the leaching of nitrate down the soil profiles was slower than the movement of water. In the case of $\mathrm{P}$, no leaching could be clearly demonstrated, as conflicting results between $\mathrm{P}$ immobilization and $\mathrm{P}$ release were obtained depending on the tested material and experimental setup. Contrary to our hypothesis, we found that the movement of nutrients in these coarse-textured soils could not be solely predicted from the fast movement of water, even in the case of nitrate-N, nor by simple sorption processes. Based on our experimental data and on additional simulations, we conclude that the loss of inorganic $\mathrm{N}$ by leaching can be significant in reclaimed soils if coarse-textured materials are used and if an intense rainfall occurs at a period coinciding with a high concentration of nitrate- $\mathrm{N}$ in the topsoil. Further investigations should be done to identify the factors controlling the mobility of $\mathrm{P}$ in these soils, and to understand how root development and plant water and nutrient uptake may eventually affect the extent of nutrient leaching.

Peer-reviewed, unedited version of the manuscript of Rees et al. (2020) published by Applied Geochemistry: 


\section{ACKNOWLEDGEMENTS}

This work was co-funded by Syncrude Canada Ltd. and Alberta Innovates. The authors are grateful to Dallas Johnson for his constructive comments. The authors also warmly thank Jela Burkus, Kyle Kipps, Jiahui Gu, Sylyanne Foo, Tam Kang, Kris Guenette, Pierre-Emmanuel Roger, Lewis Fausak, and Sarah Thacker for their precious help in running the different experiments. 


\section{REFERENCES}

Alberta Environment, 2010. Guidelines for reclamation to forest vegetation in the Athabasca Oil Sands Region (2nd edition). Prepared by the Terrestrial Subgroup of the Reclamation Working Group of the Cumulative Environmental Management Association, Fort McMurray, AB.

Alberta Innovates, 2013. Bulk Density Characterization of Surface Reclamation Cover Soil for the Aurora Capping Study. Prepared by B. Drozdowski, A. Underwood, D. Degenhardt and R. Faught from Land and Water Management, Alberta Innovates - Technology Futures.

Barnes, W.A., Quideau, S.A., Swallow, M.J.B., 2018. Nutrient distribution in sandy soils along a forest productivity gradient in the Athabasca Oil Sands Region of Alberta, Canada. Can. J. Soil. Sci. 98, $277-291$. https://doi.org/10.1139/cjss-2017-0074

Beckingham, J.D., Archibald, J.H., 1996. Field guide to ecosites of Northern Alberta. Natural Resources Canada, Canadian Forest Service, Northern Forestry Centre, Edmonton, Alberta.

Bouyoucos, G.J., 1962. Hydrometer Method Improved for Making Particle Size Analyses of Soils 1. Agronomy Journal 54, 464-465. https://doi.org/10.2134/agronj1962.00021962005400050028x

Bowman, D.T., Slater, G.F., Warren, L.A., McCarry, B.E., 2014. Identification of individual thiophene-, indane-, tetralin-, cyclohexane-, and adamantane-type carboxylic acids in composite tailings pore water from Alberta oil sands. Rapid Communications in Mass Spectrometry 28, 2075-2083. https://doi.org/10.1002/rcm.6996

Brookes, P.C., Kragt, J.F., Powlson, D.S., Jenkinson, D.S., 1985. Chloroform fumigation and the release of soil nitrogen: The effects of fumigation time and temperature. Soil Biology and Biochemistry 17, 831-835. https://doi.org/10.1016/0038-0717(85)90143-9

Doerr, S.H., 1998. On standardizing the 'Water Drop Penetration Time' and the 'Molarity of an Ethanol Droplet' techniques to classify soil hydrophobicity: A case study using medium textured soils. Earth Surface Processes and Landforms 23, 663-668. https://doi.org/10.1002/(SICI)1096-9837(199807)23:7<663::AID-ESP909>3.0.CO;2-6

Durner, W., 1994. Hydraulic conductivity estimation for soils with heterogeneous pore structure. Water Resources Research 30, 211-223. https://doi.org/10.1029/93WR02676

Flores-Mangual, M.L., Lowery, B., Bockheim, J.G., Pagliari, P.H., 2011. Revised water drop method for assessing soil water repellency in sandy soils. SOIL SCI. 176, 124-128. https://doi.org/10.1097/SS.0b013e31820afb1c

Jung, K., Chang, S.X., 2012. Four years of simulated $\mathrm{N}$ and $\mathrm{S}$ depositions did not cause $\mathrm{N}$ saturation in a mixedwood boreal forest ecosystem in the oil sands region in northern Alberta, Canada. Forest Ecology and Management 280, 62-70. https://doi.org/10.1016/j.foreco.2012.06.002

Klute, A., Dirksen, C., 1986. Hydraulic conductivity and diffusivity. Laboratory methods., in: Methods of Soil Analysis - Part 1. Physical and Mineralogical Methods. pp. 687-734.

Kwak, J.-H., Chang, S.X., Naeth, M.A., Schaaf, W., 2015. Coarse woody debris extract decreases nitrogen availability in two reclaimed oil sands soils in Canada. Ecological Engineering 84, 13-21. https://doi.org/10.1016/j.ecoleng.2015.07.012

Lanoue, A.V.L., 2003. Phosphorus content and accumulation of carbon and nitrogen in boreal forest soils. University of Alberta.

MacKenzie, M.D., Quideau, S.A., 2012. Laboratory-based nitrogen mineralization and biogeochemistry of two soils used in oil sands reclamation. Can. J. Soil. Sci. 92, 131-142. https://doi.org/10.4141/cjss2010-070 
Maynard, D.G., Paré, D., Thiffault, E., Lafleur, B., Hogg, K.E., Kishchuk, B., 2014. How do natural disturbances and human activities affect soils and tree nutrition and growth in the Canadian boreal forest? Environ. Rev. 22, 161-178. https://doi.org/10.1139/er-2013-0057

McMillan, R., Quideau, S.A., MacKenzie, M.D., Biryukova, O., 2007. Nitrogen mineralization and microbial activity in oil sands reclaimed boreal forest soils. J. Environ. Qual. 36, 1470-1478. https://doi.org/10.2134/jeq2006.0530

Metson, A.J., 1956. Methods of chemical analysis for soil survey samples. New Zealand Department of Scientific and Industrial Research.

O’Halloran, I., Cade-Menun, B., 2008. Total and Organic Phosphorus, in: M.R. Carter and E.G. Gregorich, Eds. Soil Sampling and Methods of Analysis. 2nd Ed. CRC Press, Boca Raton, FL, USA, pp. $265-291$. https://doi.org/10.1201/9781420005271.ch24

Olsen, S.R. (Sterling R., 1954. Estimation of available phosphorus in soils by extraction with sodium bicarbonate. United States Department Of Agriculture; Washington.

Pernitsky, T., Hu, W., Si, B.C., Barbour, L., 2016. Effects of petroleum hydrocarbon concentration and bulk density on the hydraulic properties of lean oil sand overburden. Can. J. Soil. Sci. 96, 435-446. https://doi.org/10.1139/cjss-2015-0126

Pinno, B.D., Landhäusser, S.M., MacKenzie, M.D., Quideau, S.A., Chow, P.S., 2012. Trembling aspen seedling establishment, growth and response to fertilization on contrasting soils used in oil sands reclamation. Can. J. Soil. Sci. 92, 143-151. https://doi.org/10.4141/cjss2011-004

Quideau, S.A., Norris, C.E., Rees, F., Dyck, M., Samadi, N., Oh, S.-W., 2017. Carbon, nitrogen, and phosphorus release from peat and forest floor-based cover soils used during oil sands reclamation. Can. J. Soil. Sci. 97, 757768. https://doi.org/10.1139/cjss-2017-0037

Rees, F., Simonnot, M.O., Morel, J.L., 2014. Short-term effects of biochar on soil heavy metal mobility are controlled by intra-particle diffusion and soil $\mathrm{pH}$ increase. Eur J Soil Sci 65, 149-161. https://doi.org/10.1111/ejss.12107

Rock, L., Ellert, B.H., 2007. Nitrogen-15 and Oxygen-18 Natural Abundance of Potassium Chloride Extractable Soil Nitrate Using the Denitrifier Method. Soil Science Society of America Journal 71 (2), 355-361. https://doi.org/10.2136/sssaj2006.0266

Schindler, U., Durner, W., Unold, G. von, Mueller, L., Wieland, R., 2010. The evaporation method: Extending the measurement range of soil hydraulic properties using the air-entry pressure of the ceramic cup. Journal of Plant Nutrition and Soil Science 173, 563-572. https://doi.org/10.1002/jpln.200900201

Šimůnek, J., van Genuchten, M.T., Šejna, M., 2008. Development and Applications of the HYDRUS and STANMOD Software Packages and Related Codes. Vadose Zone Journal 7, 587-600. https://doi.org/10.2136/vzj2007.0077

Sitthaphanit, S., Limpinuntana, V., Toomsan, B., Panchaban, S., Bell, R.W., 2009. Fertiliser strategies for improved nutrient use efficiency on sandy soils in high rainfall regimes. Nutr Cycl Agroecosyst 85, 123-139. https://doi.org/10.1007/s10705-009-9253-z

Sommer, S.G., Schjoerring, J.K., Denmead, O.T., 2004. Ammonia emission from mineral fertilizers and fertilized crops. Advances in agronomy 82, 557-622. https://doi.org/10.1016/S0065-2113(03)82008-4

Yarmuch, M., 2003. Measurement of soil physical parameters to evaluate soil structure quality in reclaimed oil sands soils, Alberta, Canada (M.Sc. Thesis). University of Alberta.

Zettl, J., Lee Barbour, S., Huang, M., Si, B., Leskiw, L.A., 2011. Influence of textural layering on field capacity of coarse soils. Can. J. Soil. Sci. 91, 133-147. https://doi.org/10.4141/cjss09117 


\section{- SUPPORTING MATERIAL -}

\section{Water and nutrient retention in coarse-textured soil profiles}

\section{from the Athabasca Oil Sand Region}

Frédéric Rees ${ }^{1,2}$, Sylvie Quideau ${ }^{1, *}$, Miles Dyck ${ }^{1}$, Guillermo Hernandez ${ }^{1}$, Marty Yarmuch ${ }^{3}$

${ }^{1}$ University of Alberta, Department of Renewable Resources, Edmonton, AB, Canada

${ }^{2}$ Current address: UMR ECOSYS, INRA, AgroParisTech, Université Paris-Saclay, Thiverval-Grignon, France

${ }^{3}$ Mine Closure Research, Syncrude Canada Ltd., Edmonton, AB, Canada

*Corresponding author: Frédéric Rees, frederic.rees@inra.fr

1. MODELLING WATER RETENTION AND CONDUCTIVITY CURVES __ 34

2. DESIGN OF THE COLUMN EXPERIMENT____ 35

3. WEATHER DATA___ 36

4. DETAILS ABOUT THE SIMULATIONS WITH HYDRUS-1D___ 37

5. HYDRIC PROPERTIES OF THE MATERIALS ___ 39

6. COMPARISON WITH NATURAL SOIL PROFILES____ 43

7. NUTRIENT SORPTION CAPACITY___ 46

8. NITRATE-N, AMMONIUM-N AND FERTILIZER-N RESULTS FROM THE COLUMN LEACHING EXPERIMENT _ 51

9. RATE OF ORGANIC MATTER MINERALIZATION ___ 54

10. EXPERIMENTAL AND MODELLED DISTRIBUTION OF WATER AND NUTRIENTS IN SOIL PROFILES __ 55

11. ESTIMATIONS OF POSSIBLE WATER AND NUTRIENT LOSSES BY LEACHING ___ 61

REFERENCES __ 65 


\section{Modelling water retention and conductivity curves}

The water retention curve and the hydraulic conductivity curve were modelled from the experimental data obtained at various water tensions by different methods and for different replicates, using the bimodal constrained van Genuchten model (Durner, 1994). The HYPROP Data Evaluation Software was used to fit specific functions by minimizing the sum of squares deviations between data points and fitted functions.

In the bimodal constrained van Genuchten model, the volumetric water content $\Theta\left[\mathrm{cm}^{3} \mathrm{~cm}^{-3}\right]$ and the hydraulic conductivity $K\left[\mathrm{~cm} \mathrm{day}^{-1}\right]$ are expressed as a function of the water tension $h[\mathrm{~cm}]$ by the equation:

$$
\begin{gathered}
\theta(h)=\theta_{r}+\left(\theta_{s}-\theta_{r}\right) \times \sum_{i=1}^{2} w_{i}\left[\frac{1}{1+\left(\alpha_{i}|h|\right)^{n_{i}}}\right]^{1-\frac{1}{n_{i}}} \\
K(h)=K_{s}\left[\sum_{i=1}^{2} w_{i}\left[1+\left(\alpha_{i}|h|\right)^{n_{i}}\right]^{\frac{1}{n_{i}}-1}\right]\left[\sum_{i=1}^{\tau} w_{i} \alpha_{i} \frac{\left.\left\{1-\left(\alpha_{i}|h|\right)^{n_{i}-1}\left[1+\left(\alpha_{i}|h|\right)^{n_{i}}\right]^{\frac{1}{n_{i}}-1}\right\}\right]^{2}}{\sum_{i=1}^{2} w_{i} \alpha_{i}}\right]
\end{gathered}
$$

where $\Theta_{r}$ is the residual water content, $\Theta_{s}$ is the saturated water content, $w_{i}$ is the weight given to the van Genuchten function $i\left(w_{1}+w_{2}=1\right), \alpha_{i}\left[\mathrm{~cm}^{-1}\right]$ is a shape parameter of the function $i$ that is related to the inverse of the air-entry pressure, $n_{i}[-]$ is another shape parameter that controls both the bending of the retention curve at the air-entry region and the asymptotic curvature towards the residual water content, $K_{s}$ is the hydraulic conductivity at saturation, and $\tau$ is a tortuosity parameter [-]. 


\section{Design of the column experiment}

Fig. S1: Design of the column leaching experiment. Each column consisted in an ABS pipe (A) overlaid by a watering system (C). The column was divided in 13 different $10-\mathrm{cm}$ segments sealed with silicone glue (B, D). An additional column with a larger diameter $(10.2 \mathrm{~cm})$ was used to protect the inner soil column (B) and to maintain the Mariotte's bottle at the top of the column (C). A small plastic pipe was placed at the bottom of the column so that water could be drained (E). At the end of the experiment, the soil column was sampled by separating each 10$\mathrm{cm}$ segment using a flat spatula $(\mathrm{F})$.
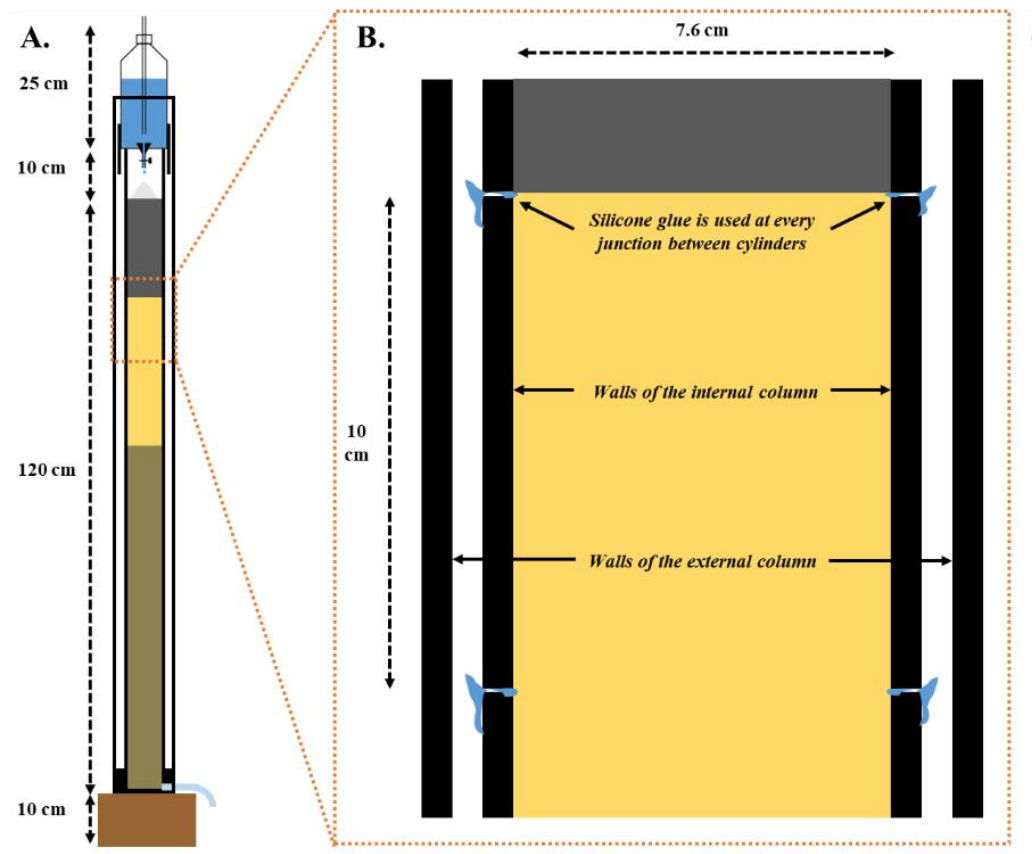

C.
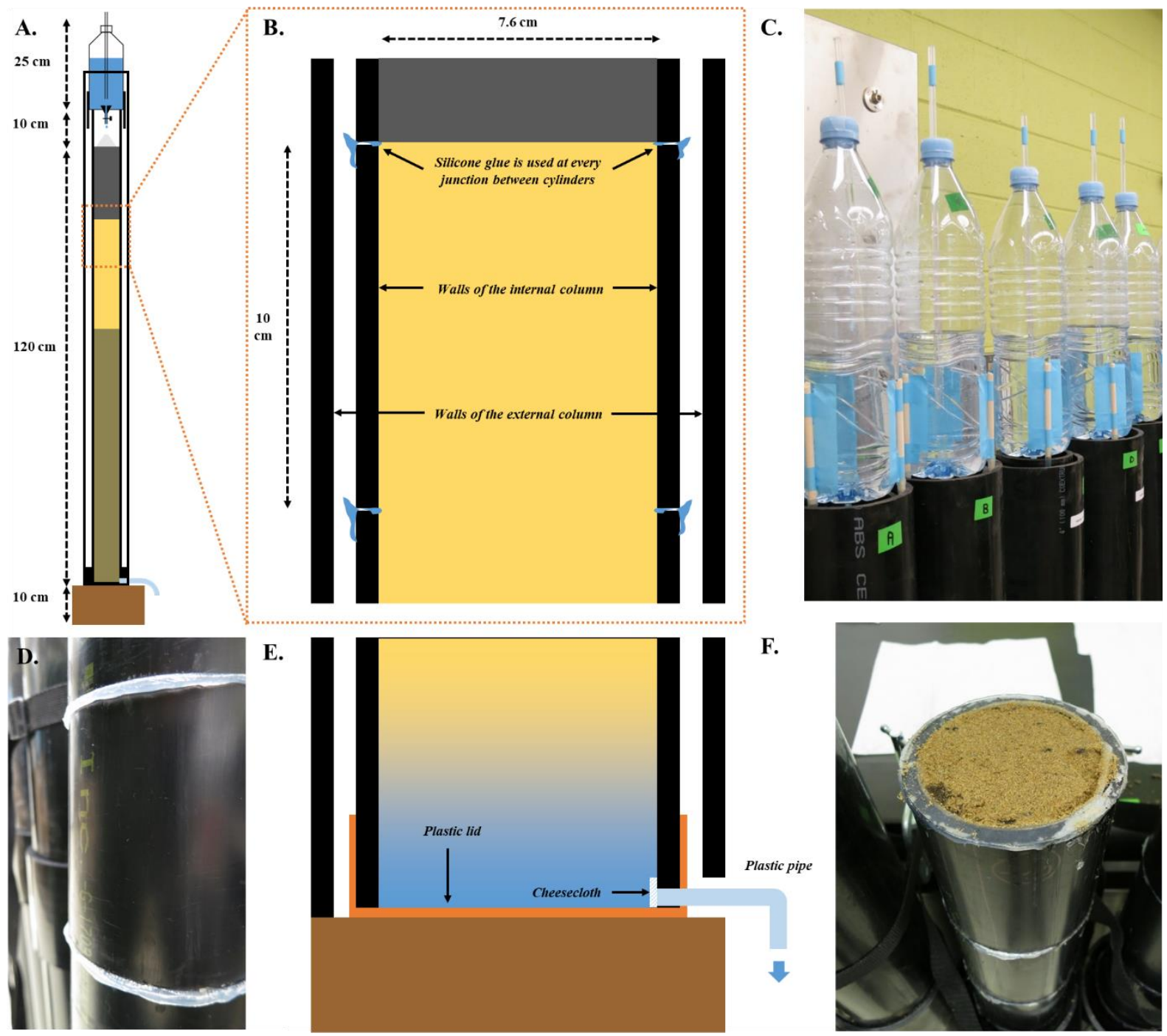

E.

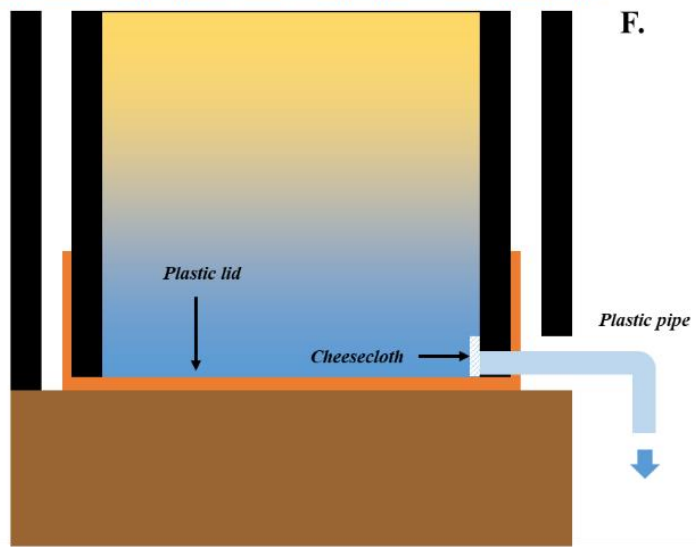

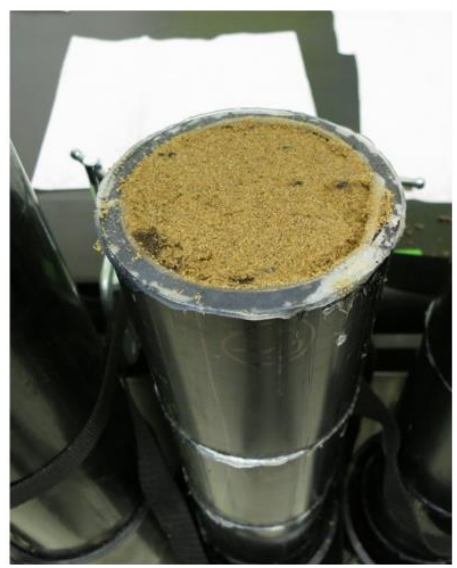




\section{Weather data}

Table S1: Summary of the weather data from Fort McMurray, AB, Canada between 2001 and 2010. Daily weather data from Fort McMurray station were collected and compiled in order to calculate for each year: the total annual precipitation, the maximal amount of melting snow in the spring (in $\mathrm{mm}$ of equivalent water), the average duration of the melting period, the maximal amount of rain per intense rainfall event in the summer, and the average duration of the intense rainfall. Results are shown as mean \pm standard error (12-15 replicates).

\begin{tabular}{cccc}
\hline Period & Parameter & Value & Unit \\
\hline \multirow{2}{*}{ All year } & Total annual precipitation $(\mathrm{mm})$ & $359 \pm 27$ & $\mathrm{~mm}$ \\
\hline \multirow{2}{*}{ Spring } & Maximal amount of melting snow & $83 \pm 9$ & $\mathrm{~mm}$ \\
\cline { 2 - 5 } & Duration of the snow melting period & $24 \pm 3$ & day \\
\hline \multirow{2}{*}{ Summer } & Maximal precipitation per rainfall event & $49 \pm 6$ & $\mathrm{~mm}$ \\
\cline { 2 - 5 } & Duration of the intense rainfall event & $1.5 \pm 0.3$ & day \\
\hline
\end{tabular}




\section{Details about the simulations with HYDRUS-1D}

The vertical movement of water, $\mathrm{NH}_{4}-\mathrm{N}, \mathrm{NO}_{3}-\mathrm{N}$ and $\mathrm{P}$ within the different reclaimed soil profiles were modelled using the HYDRUS-1D (v.4.16.0110) software package (Šimůnek et al., 2008). The dynamics of water was simulated according to the water retention curves and the hydraulic curves determined for each material and to their initial water content prior to the rainfall event. The initial nutrient concentration in the liquid phase in contact with the solid phase was calculated by assuming that the amount of $0.5 \mathrm{M} \mathrm{K}_{2} \mathrm{SO}_{4}$ extractable nutrients measured at the beginning of the column experiment was only present in the liquid phase. Three types of simulations were used (Table S2).

- In Simulation 1, no possibility of nutrient exchange between the liquid phase and the solid phase was considered; the initial nutrient concentration in the liquid phase was calculated by considering that the amount of $0.5 \mathrm{M} \mathrm{K}_{2} \mathrm{SO}_{4}$ extractable nutrients measured at the beginning of the column experiment was only present in the liquid phase.

- In Simulation 2, sorption parameters from the Freundlich desorption curves determined in the nutrient sorption experiment were used to simulate an equilibrium between nutrients immobilized on the solid phase and nutrients in the liquid phase; the initial equilibrium between both phases was calculated by considering that the amount of $0.5 \mathrm{M} \mathrm{K}_{2} \mathrm{SO}_{4}$ extractable nutrients measured at the beginning of the column experiment was only present in the liquid phase. This simulation therefore implied that a net release of additional nutrients initially sorbed on the materials may occur when the solution in contact with the material gets replaced by rain water.

- In Simulation 3, the results from the incubation experiment were used to mimic the mobilization/immobilization dynamics of nutrients in the capping materials PMM and FFM, without considering sorption parameters. This simulation was assumed to best represent the actual initial nutrient availability in the columns at the beginning of the rainfall event, as the rainfall started more than $16 \mathrm{~h}$ after having filled the columns. We separated the simulation in two phases. Over the first phase lasting for $24 \mathrm{~h}$, the initial nutrient concentration in the liquid phase was calculated from the nutrient extractability measured after 1 day in the incubation experiment, in order to reproduce the short-term immobilization of nutrients that was observed in the incubation experiment and which probably also occurred over the first $16 \mathrm{~h}$ before the rainfall event. As the incubation experiment also revealed a possible immobilization or release of nutrients from the materials between Day 1 and Day 5, we artificially modified the nutrient 
concentrations in the liquid phase $24 \mathrm{~h}$ after the start of the rainfall event, i.e. at the beginning of the second phase (from $24 \mathrm{~h}$ to 5 days). The initial nutrient concentrations in the liquid phase at the beginning of the second phase was calculated from the nutrient concentrations simulated at the end of phase 1 by applying a corresponding relative increase or decrease of nutrient extractability observed in the incubation experiment between Day 1 and Day 5. The outputs of Simulation 3 therefore corresponded to the outputs of the second phase.

Table S2: Summary of the differences between the three types of simulations with HYDRUS-1D used to reproduce the experimental conditions of the column leaching experiment

\begin{tabular}{|c|c|c|c|c|c|}
\hline & $\begin{array}{l}\text { Simulation } \\
\text { period }\end{array}$ & $\begin{array}{l}\text { Sorption } \\
\text { processes } \\
\text { included }\end{array}$ & $\begin{array}{l}\text { Use of observations } \\
\text { from the } \\
\text { incubation } \\
\text { experiment }\end{array}$ & $\begin{array}{l}\text { Starting } \\
\text { water } \\
\text { content }\end{array}$ & $\begin{array}{l}\text { Starting nutrient } \\
\text { concentrations in the } \\
\text { liquid phase }\end{array}$ \\
\hline Simulation 1 & 0-5 day & No & No & $\begin{array}{l}\text { Initial water } \\
\text { content } \\
\text { before } \\
\text { leaching }\end{array}$ & $\begin{array}{l}\text { Initial } 0.5 \mathrm{M} \mathrm{K}_{2} \mathrm{SO}_{4} \\
\text { extractable nutrients } \\
\text { before leaching }\end{array}$ \\
\hline Simulation 2 & 0-5 day & Yes & No & $\begin{array}{l}\text { Initial water } \\
\text { content } \\
\text { before } \\
\text { leaching }\end{array}$ & $\begin{array}{l}\text { Initial } 0.5 \mathrm{M} \mathrm{K}_{2} \mathrm{SO}_{4} \\
\text { extractable nutrients } \\
\text { before leaching }\end{array}$ \\
\hline \multirow[t]{2}{*}{ Simulation 3} & $\begin{array}{l}0-1 \text { day } \\
\text { (phase 1) }\end{array}$ & No & $\begin{array}{l}\text { Yes (difference } \\
\text { between Day } 0 \text { and } \\
\text { Day 1) }\end{array}$ & $\begin{array}{l}\text { Initial water } \\
\text { content } \\
\text { before } \\
\text { leaching }\end{array}$ & $\begin{array}{l}\text { Initial } 0.5 \mathrm{M} \mathrm{K}_{2} \mathrm{SO}_{4} \\
\text { extractable nutrients } \\
\text { before leaching, } \\
\text { modified with } \\
\text { observations from the } \\
\text { incubation experiment }\end{array}$ \\
\hline & $\begin{array}{l}1-5 \text { day } \\
\text { (phase 2) }\end{array}$ & No & $\begin{array}{l}\text { Yes (difference } \\
\text { between Day } 1 \text { and } \\
\text { Day 5) }\end{array}$ & $\begin{array}{l}\text { Outputs from } \\
\text { phase } 1\end{array}$ & $\begin{array}{l}\text { Outputs from phase } 1 \text {, } \\
\text { modified with } \\
\text { observations from the } \\
\text { incubation experiment }\end{array}$ \\
\hline
\end{tabular}




\section{Hydric properties of the materials}

Table S3: Parameters used in the bimodal constrained van Genuchten model (see Supplementary material 1), fitted from experimental data. PMM: peat-mineral mix; FFM: forest floor mineral material; SUB: blended B/C horizons of sandy subsoil; TS: tailing sand; LOS 1.42: lean oil sand at the bulk density of $1.42 \mathrm{~g} \mathrm{~cm}^{-3}$; LOS 1.59: lean oil sand at the bulk density of $1.59 \mathrm{~g} \mathrm{~cm}^{-3}$.

\begin{tabular}{|c|c|c|c|c|c|c|c|c|}
\hline Parameter & Symbol & Unit & PMM & FFM & SUB1 & TS & LOS & LOS* \\
\hline $\begin{array}{l}\text { Parameter alpha } \\
\text { in the first function }\end{array}$ & $\alpha 1$ & $\mathrm{~cm}^{-1}$ & 0.0105 & 0.0375 & 0.0127 & 0.0278 & 0.0035 & 0.0005 \\
\hline $\begin{array}{l}\text { Parameter } \mathrm{n} \\
\text { in the first function }\end{array}$ & $\mathrm{n} 1$ & $\mathrm{~cm}^{-1}$ & 1.2960 & 11.0420 & 1.4890 & 6.1620 & 1.2880 & 1.3150 \\
\hline $\begin{array}{l}\text { Residual } \\
\text { water content }\end{array}$ & $\Theta_{\text {res }}$ & $\mathrm{cm}^{3} \mathrm{~cm}^{-3}$ & 0.000 & 0.010 & 0.005 & 0.003 & 0.000 & 0.000 \\
\hline $\begin{array}{l}\text { Water content } \\
\text { at saturation }\end{array}$ & $\Theta_{\text {sat }}$ & $\mathrm{cm}^{3} \mathrm{~cm}^{-3}$ & 0.782 & 0.484 & 0.392 & 0.425 & 0.443 & 0.380 \\
\hline $\begin{array}{l}\text { Parameter alpha } \\
\text { in the second function }\end{array}$ & $\alpha 2$ & $\mathrm{~cm}^{-1}$ & 0.0341 & 0.0336 & 0.0283 & 0.0130 & 0.0476 & 0.0193 \\
\hline $\begin{array}{l}\text { Parameter } \mathrm{n} \\
\text { in the second function }\end{array}$ & $\mathrm{n} 2$ & $\mathrm{~cm}^{-1}$ & 4.0490 & 1.4450 & 8.5720 & 1.5390 & 2.3280 & 1.3960 \\
\hline $\begin{array}{l}\text { Relative weighting } \\
\text { factor for the second } \\
\text { function }\end{array}$ & $\mathrm{w}$ & - & 0.2380 & 0.5610 & 0.7580 & 0.2360 & 0.3130 & 0.5190 \\
\hline $\begin{array}{l}\text { Hydraulic conductivity } \\
\text { at saturation }\end{array}$ & $\mathrm{K}_{\text {sat }}$ & $\mathrm{cm}$ day $^{-1}$ & 272.3 & 281.2 & 2104.3 & 1036.1 & 36.8 & 1.3 \\
\hline $\begin{array}{l}\text { Tortuosity } \\
\text { parameter }\end{array}$ & $\tau$ & - & 2.19 & 1.90 & 3.26 & 2.70 & 7.34 & 3.22 \\
\hline
\end{tabular}


Fig. S2: Water retention curve and hydraulic conductivity curve (continuous lines) fitted to the experimental data (blue diamond) for each material. PMM: peat-mineral mix; FFM: forest floor mineral material; SUB: blended B/C horizons of sandy subsoil; TS: tailing sand; LOS: lean oil sand, for which two sets of data are used (the main one at the bulk density of $1.42 \mathrm{~g} \mathrm{~cm}^{-3}$, in blue, and the second one at the bulk density of $1.59 \mathrm{~g} \mathrm{~cm}^{-3}$, in red). The $\mathrm{pF}$ values on the $\mathrm{x}$-axis refer to the soil tension $\mathrm{h}(\mathrm{cm})$, with $\mathrm{pF}=\log (\mathrm{h})$.

PMM - Water retention curve

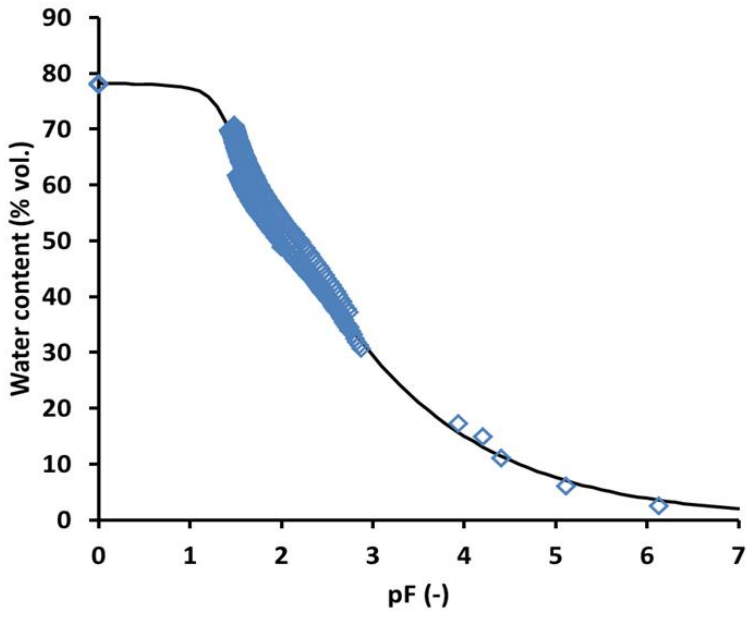

$\diamond$ Experimental data - Model

FFM - Water retention curve

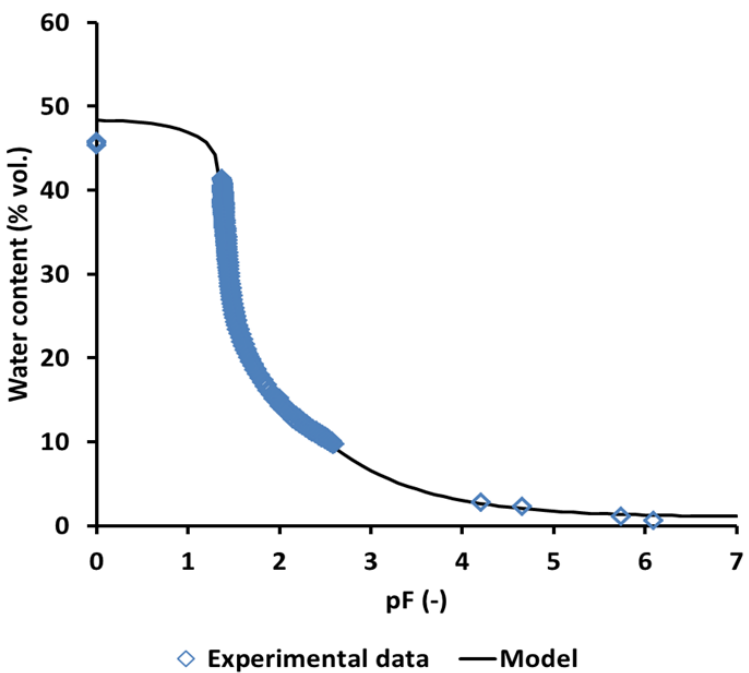

PMM - Hydraulic conductivity curve

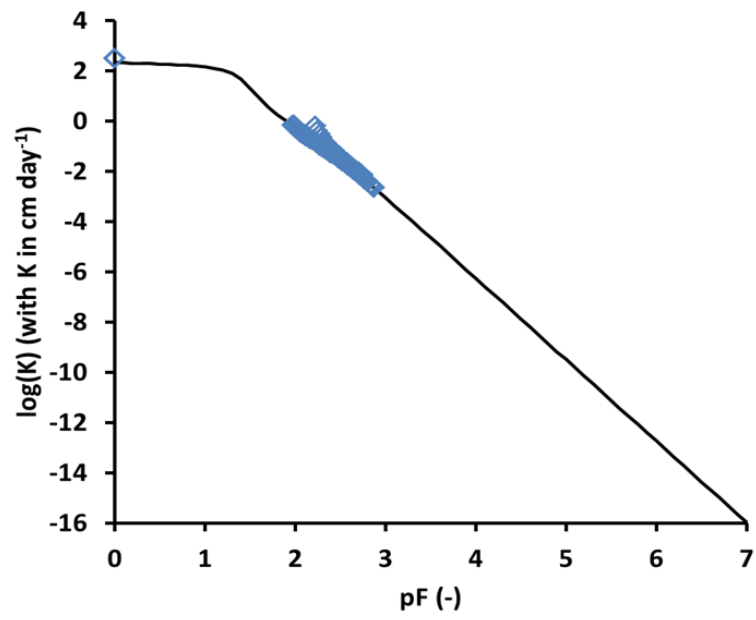

$\diamond$ Experimental data -Model

FFM - Hydraulic conductivity curve

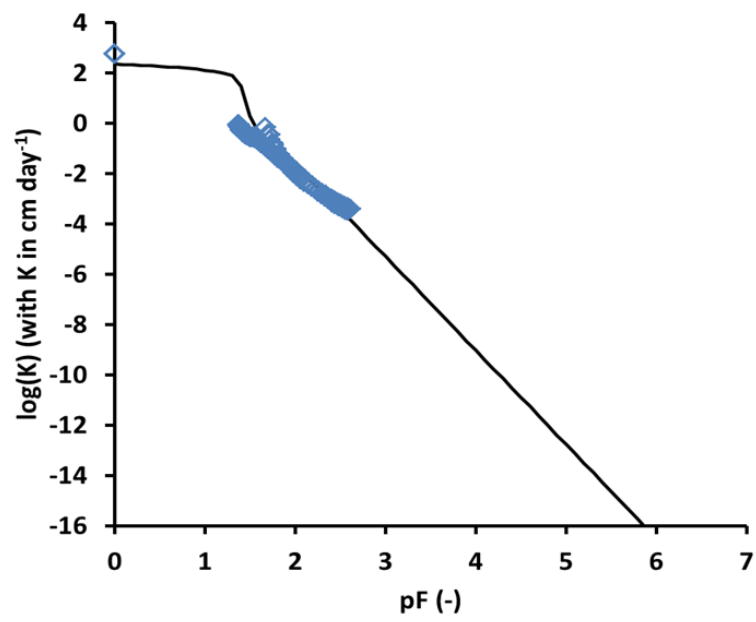

Experimental data - Model 


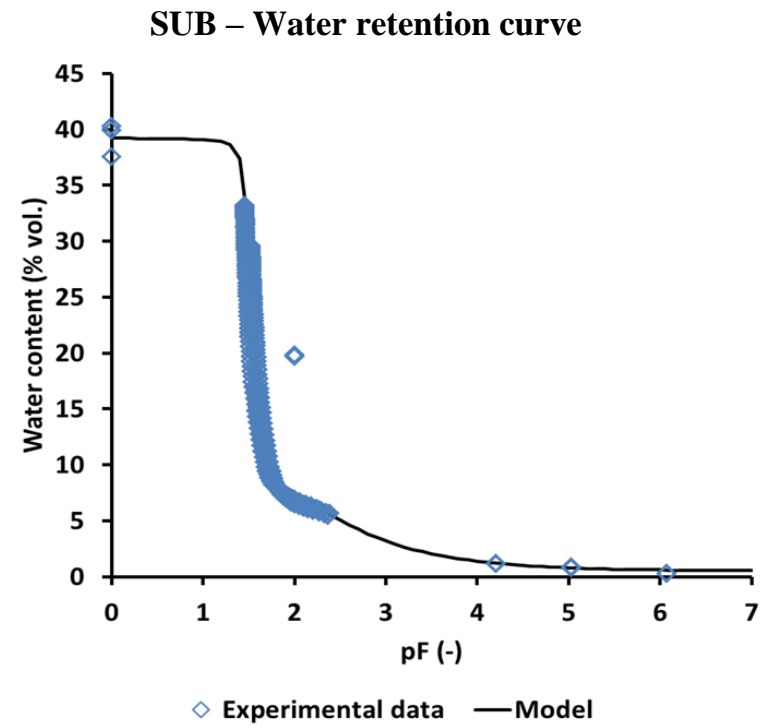

TS - Water retention curve

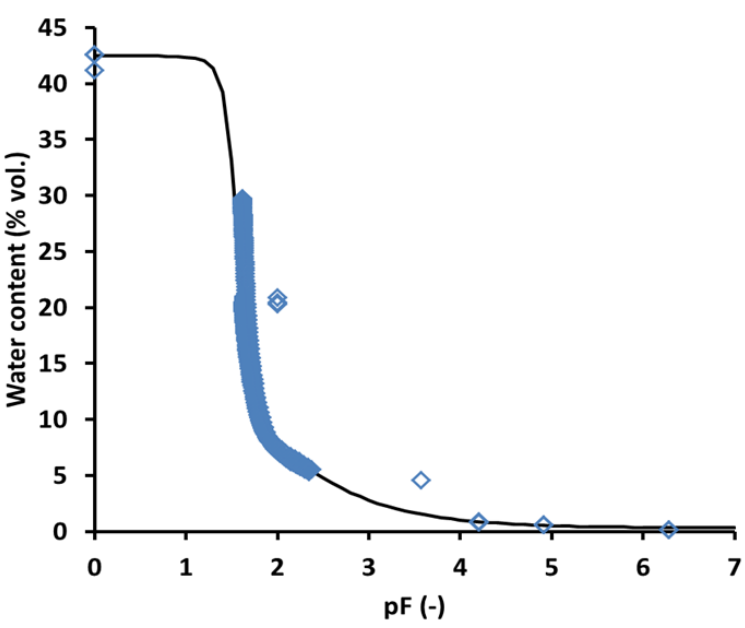

$\diamond$ Experimental data - Model

LOS - Water retention curve

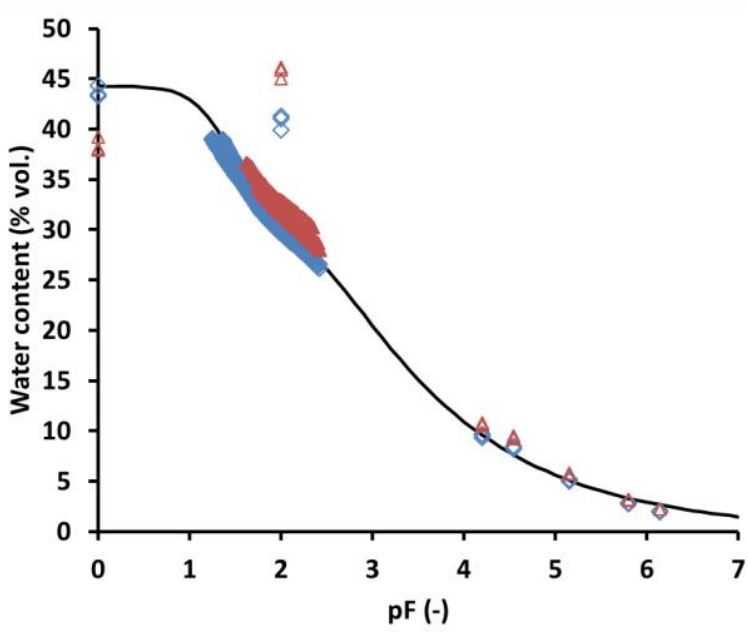

$\diamond \operatorname{LOS} 1.42 \Delta \operatorname{LOS} 1.59-$ Model of LOS 1.42
SUB - Hydraulic conductivity curve

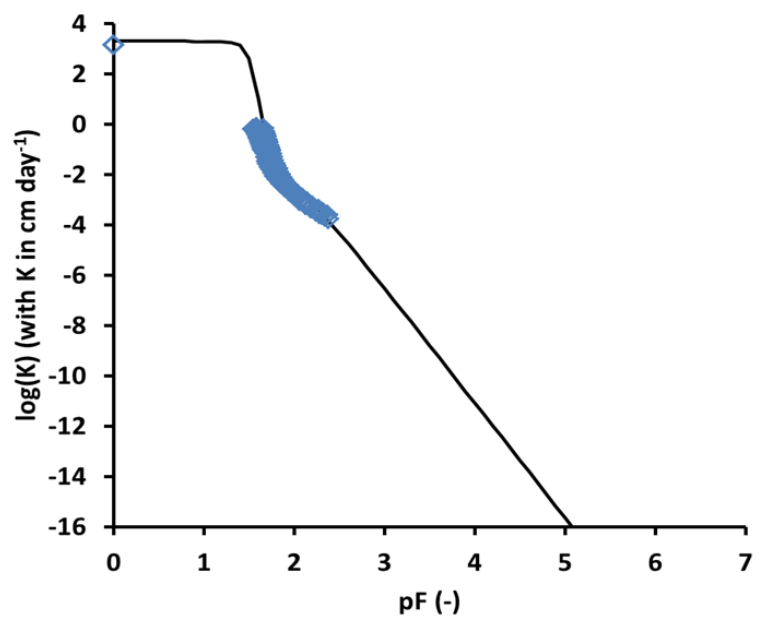

$\diamond$ Experimental data - Model

TS - Hydraulic conductivity curve

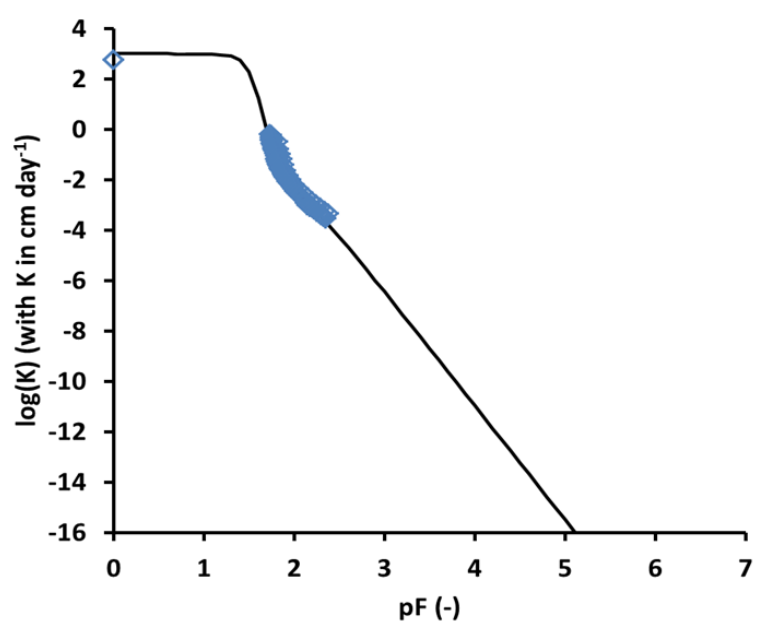

$\diamond$ Experimental data -Model

LOS - Hydraulic conductivity curve

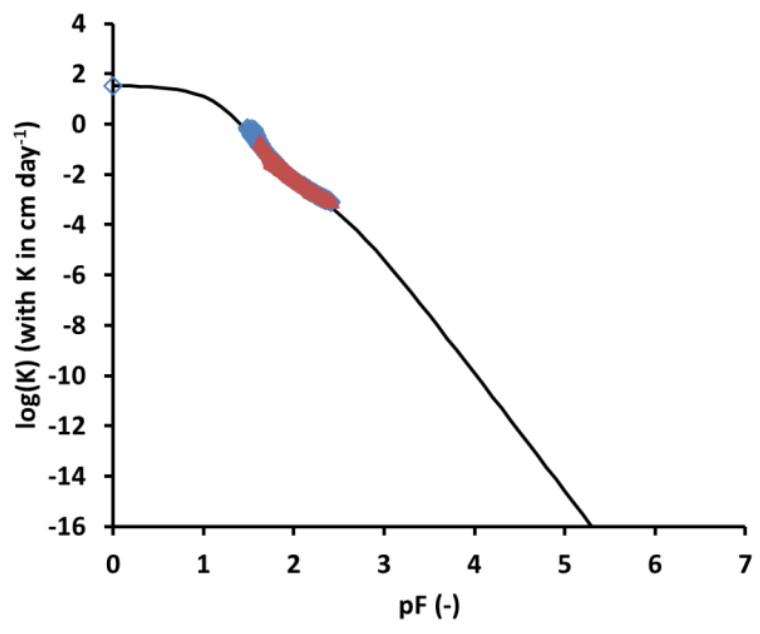

$\diamond \operatorname{LOS} 1.42 \Delta \operatorname{LOS} 1.59-$ Model of LOS 1.42 
Fig. S3: Water retention curves modelled from the experimental data obtained by pressure plates, HYPROP and dewpoint measurements. PMM: peat-mineral mix; FFM: forest floor mineral material; SUB: blended B/C horizons of sandy subsoil; LOS: lean oil sand at the bulk density of $1.42 \mathrm{~g} \mathrm{~cm}^{-3}$; TS: tailing sand. The pF values on the $\mathrm{x}$-axis refer to the soil tension $\mathrm{h}(\mathrm{cm})$, with $\mathrm{pF}=\log (\mathrm{h})$.

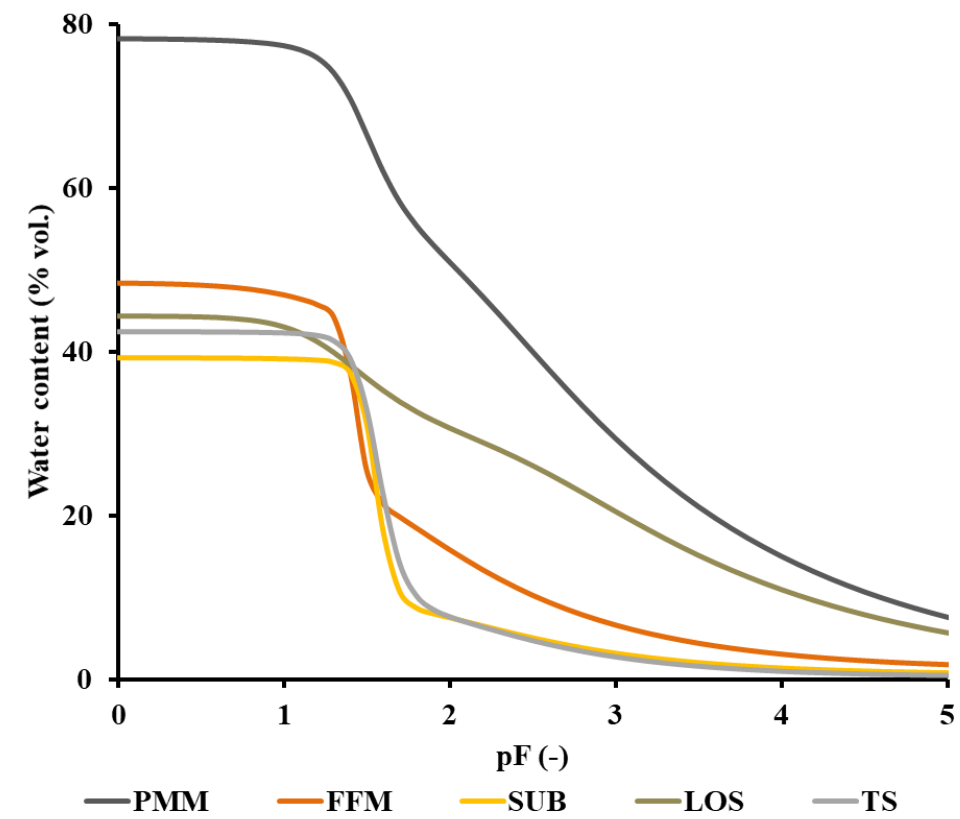

Fig. S4: Hydraulic conductivity curves modelled from experimental data obtained by pressure plates, HYPROP, dewpoint measurements and falling head method. PMM: peat-mineral mix; FFM: forest floor mineral material; SUB: blended B/C horizons of sandy subsoil; LOS: lean oil sand at the bulk density of $1.42 \mathrm{~g}$ $\mathrm{cm}^{-3}$; TS: tailing sand. The $\mathrm{pF}$ values on the $\mathrm{x}$-axis refer to the soil tension $\mathrm{h}(\mathrm{cm})$, with $\mathrm{pF}=\log (\mathrm{h})$.

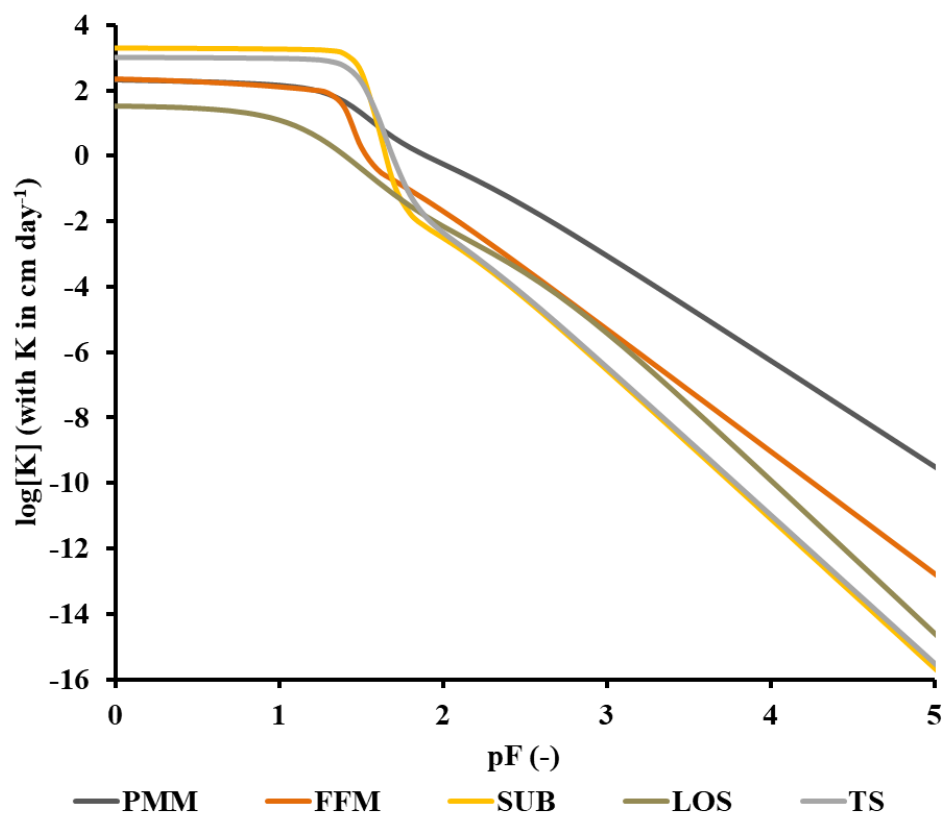




\section{Comparison with natural soil profiles}

Fig. S5: Plant-available water $\left(1 \mathrm{~m}^{-2}\right.$, i.e. $\left.\mathrm{mm}\right)$ initially present in the 6 reclaimed profiles (R1-R6) and the two natural soil profiles (N1, N2). The six reclaimed soil profiles are constructed with: $100 \mathrm{~cm}$ of SUB covered by $20 \mathrm{~cm}$ of PMM (profile R1) or $20 \mathrm{~cm}$ of FFM (profile R2), $70 \mathrm{~cm}$ of TS overlaid by $30 \mathrm{~cm}$ of SUB and covered by $20 \mathrm{~cm}$ of PMM (profile R3) or $20 \mathrm{~cm}$ of FFM (profile R4), and $70 \mathrm{~cm}$ of LOS overlaid by $30 \mathrm{~cm}$ of SUB and covered by $20 \mathrm{~cm}$ of PMM (profile R5) or $20 \mathrm{~cm}$ of FFM (profile R6). The two natural soil profiles correspond to Eluviated Dystric Brunisols with jack pine dominated stands (profile N1) or aspen and white spruce dominated stands (profile N2). See Fig. 1 for more details about each horizon. Two color codes are used to display the values per 10-cm horizon or for the whole profile, respectively: the higher the value, the darker the background of the cell.

\begin{tabular}{|c|c|c|c|c|c|c|}
\cline { 2 - 7 } \multicolumn{1}{c|}{} & $\boldsymbol{R 1}$ & $\boldsymbol{R 2}$ & $\boldsymbol{R 3}$ & $\boldsymbol{R 4}$ & $\boldsymbol{R 5}$ & $\boldsymbol{R 6}$ \\
\hline $0-10 \mathrm{~cm}$ & 27.1 & 12.0 & 27.1 & 12.0 & 27.1 & 12.0 \\
\hline $10-20 \mathrm{~cm}$ & 27.1 & 12.0 & 27.1 & 12.0 & 27.1 & 12.0 \\
\hline $20-30 \mathrm{~cm}$ & 19.8 & 19.8 & 19.8 & 19.8 & 19.8 & 19.8 \\
\hline $30-40 \mathrm{~cm}$ & 19.8 & 19.8 & 19.8 & 19.8 & 19.8 & 19.8 \\
\hline $40-50 \mathrm{~cm}$ & 19.8 & 19.8 & 19.8 & 19.8 & 19.8 & 19.8 \\
\hline $50-60 \mathrm{~cm}$ & 19.8 & 19.8 & 22.1 & 22.1 & 35.1 & 35.1 \\
\hline $60-70 \mathrm{~cm}$ & 19.8 & 19.8 & 22.1 & 22.1 & 35.1 & 35.1 \\
\hline $70-80 \mathrm{~cm}$ & 19.8 & 19.8 & 22.1 & 22.1 & 35.1 & 35.1 \\
\hline $80-90 \mathrm{~cm}$ & 19.8 & 19.8 & 22.1 & 22.1 & 35.1 & 35.1 \\
\hline $90-100 \mathrm{~cm}$ & 19.8 & 19.8 & 22.1 & 22.1 & 35.1 & 35.1 \\
\hline $100-110 \mathrm{~cm}$ & 19.8 & 19.8 & 22.1 & 22.1 & 35.1 & 35.1 \\
\hline $110-120 \mathrm{~cm}$ & 19.8 & 19.8 & 22.1 & 22.1 & 35.1 & 35.1 \\
\hline $\mathbf{0 - 1 2 0} \mathbf{c m}$ & $\mathbf{2 5 3}$ & $\mathbf{2 2 3}$ & $\mathbf{2 6 9}$ & $\mathbf{2 3 8}$ & $\mathbf{3 6 0}$ & $\mathbf{3 3 0}$ \\
\hline
\end{tabular}

\begin{tabular}{|c|c|c|}
\cline { 2 - 3 } \multicolumn{1}{c|}{} & N1 & N2 \\
\hline $0-10 \mathrm{~cm}$ & 14.5 & 12.0 \\
\hline $10-20 \mathrm{~cm}$ & 21.7 & 23.1 \\
\hline $20-30 \mathrm{~cm}$ & 21.7 & 27.9 \\
\hline $30-40 \mathrm{~cm}$ & 21.7 & 27.9 \\
\hline $40-50 \mathrm{~cm}$ & 21.7 & 27.9 \\
\hline $50-60 \mathrm{~cm}$ & 30.4 & 29.6 \\
\hline $60-70 \mathrm{~cm}$ & 30.4 & 29.6 \\
\hline $70-80 \mathrm{~cm}$ & 30.4 & 25.1 \\
\hline $80-90 \mathrm{~cm}$ & 24.8 & 25.1 \\
\hline $90-100 \mathrm{~cm}$ & 24.8 & 29.0 \\
\hline $100-110 \mathrm{~cm}$ & 24.8 & 29.0 \\
\hline $110-120 \mathrm{~cm}$ & 24.8 & 29.0 \\
\hline $\mathbf{0 - 1 2 0} \mathbf{c m}$ & $\mathbf{2 9 2}$ & $\mathbf{3 1 5}$ \\
\hline
\end{tabular}
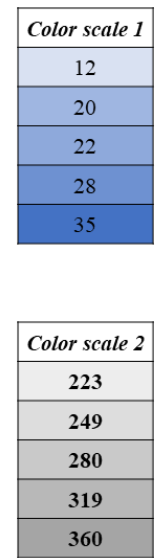

Fig. S6: Total organic $\mathrm{C}\left(\mathrm{kgC} \mathrm{m}^{-2}\right)$ initially present in the 6 reclaimed profiles $(\mathrm{R} 1-\mathrm{R6})$ and the two natural soil profiles (N1, N2). The six reclaimed soil profiles are constructed with: $100 \mathrm{~cm}$ of SUB covered by $20 \mathrm{~cm}$ of PMM (profile R1) or $20 \mathrm{~cm}$ of FFM (profile R2), $70 \mathrm{~cm}$ of TS overlaid by $30 \mathrm{~cm}$ of SUB and covered by $20 \mathrm{~cm}$ of PMM (profile R3) or $20 \mathrm{~cm}$ of FFM (profile R4), and $70 \mathrm{~cm}$ of LOS overlaid by $30 \mathrm{~cm}$ of SUB and covered by $20 \mathrm{~cm}$ of PMM (profile R5) or $20 \mathrm{~cm}$ of FFM (profile R6). The two natural soil profiles correspond to Eluviated Dystric Brunisols with jack pine dominated stands (profile N1) or aspen and white spruce dominated stands (profile N2). See Fig. 1 for more details about each horizon. Two color codes are used to display the values per $10-\mathrm{cm}$ horizon or for the whole profile, respectively: the higher the value, the darker the background of the cell.

\begin{tabular}{|c|c|c|c|c|c|c|}
\cline { 2 - 7 } \multicolumn{1}{c|}{} & $\boldsymbol{R 1}$ & $\boldsymbol{R 2}$ & $\boldsymbol{R 3}$ & $\boldsymbol{R 4}$ & $\boldsymbol{R 5}$ & $\boldsymbol{R 6}$ \\
\hline $0-10 \mathrm{~cm}$ & 7.2 & 2.3 & 7.2 & 2.3 & 7.2 & 2.3 \\
\hline $10-20 \mathrm{~cm}$ & 7.2 & 2.3 & 7.2 & 2.3 & 7.2 & 2.3 \\
\hline $20-30 \mathrm{~cm}$ & 0.4 & 0.4 & 0.4 & 0.4 & 0.4 & 0.4 \\
\hline $30-40 \mathrm{~cm}$ & 0.4 & 0.4 & 0.4 & 0.4 & 0.4 & 0.4 \\
\hline $40-50 \mathrm{~cm}$ & 0.4 & 0.4 & 0.4 & 0.4 & 0.4 & 0.4 \\
\hline $50-60 \mathrm{~cm}$ & 0.4 & 0.4 & 0.6 & 0.6 & 5.8 & 5.8 \\
\hline $60-70 \mathrm{~cm}$ & 0.4 & 0.4 & 0.6 & 0.6 & 5.8 & 5.8 \\
\hline $70-80 \mathrm{~cm}$ & 0.4 & 0.4 & 0.6 & 0.6 & 5.8 & 5.8 \\
\hline $80-90 \mathrm{~cm}$ & 0.4 & 0.4 & 0.6 & 0.6 & 5.8 & 5.8 \\
\hline $90-100 \mathrm{~cm}$ & 0.4 & 0.4 & 0.6 & 0.6 & 5.8 & 5.8 \\
\hline $100-110 \mathrm{~cm}$ & 0.4 & 0.4 & 0.6 & 0.6 & 5.8 & 5.8 \\
\hline $110-120 \mathrm{~cm}$ & 0.4 & 0.4 & 0.6 & 0.6 & 5.8 & 5.8 \\
\hline $\mathbf{0 - 1 2 0} \mathbf{c m}$ & $\mathbf{1 8}$ & $\mathbf{9}$ & $\mathbf{1 9}$ & $\mathbf{1 0}$ & $\mathbf{5 6}$ & $\mathbf{4 7}$ \\
\hline
\end{tabular}

\begin{tabular}{|c|c|c|}
\cline { 2 - 3 } \multicolumn{1}{c|}{} & N1 & N2 \\
\hline $0-10 \mathrm{~cm}$ & 1.2 & 2.8 \\
\hline $10-20 \mathrm{~cm}$ & 0.1 & 0.4 \\
\hline $20-30 \mathrm{~cm}$ & 0.1 & 0.2 \\
\hline $30-40 \mathrm{~cm}$ & 0.1 & 0.2 \\
\hline $40-50 \mathrm{~cm}$ & 0.1 & 0.2 \\
\hline $50-60 \mathrm{~cm}$ & 0.1 & 0.2 \\
\hline $60-70 \mathrm{~cm}$ & 0.1 & 0.2 \\
\hline $70-80 \mathrm{~cm}$ & 0.1 & 0.5 \\
\hline $80-90 \mathrm{~cm}$ & 0.1 & 0.5 \\
\hline $90-100 \mathrm{~cm}$ & 0.1 & 1.1 \\
\hline $100-110 \mathrm{~cm}$ & 0.1 & 1.1 \\
\hline $110-120 \mathrm{~cm}$ & 0.1 & 1.1 \\
\hline $\mathbf{0 - 1 2 0} \mathbf{c m}$ & $\mathbf{2}$ & $\mathbf{8}$ \\
\hline
\end{tabular}

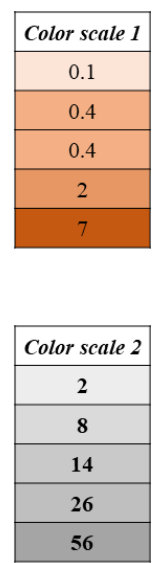

Peer-reviewed, unedited version of the manuscript of Rees et al. (2020) published by Applied Geochemistry: https://doi.org/10.1016/j.apgeochem.2020.104526 
Fig. S7: Total $\mathbf{N}\left(\mathrm{gN} \mathrm{m}^{-2}\right)$ initially present in the 6 reclaimed profiles (R1-R6) and the two natural soil profiles (N1, N2). The six reclaimed soil profiles are constructed with: $100 \mathrm{~cm}$ of SUB covered by $20 \mathrm{~cm}$ of PMM (profile R1) or $20 \mathrm{~cm}$ of FFM (profile R2), $70 \mathrm{~cm}$ of TS overlaid by $30 \mathrm{~cm}$ of SUB and covered by $20 \mathrm{~cm}$ of PMM (profile R3) or $20 \mathrm{~cm}$ of FFM (profile R4), and $70 \mathrm{~cm}$ of LOS overlaid by $30 \mathrm{~cm}$ of SUB and covered by $20 \mathrm{~cm}$ of PMM (profile R5) or $20 \mathrm{~cm}$ of FFM (profile R6). The two natural soil profiles correspond to Eluviated Dystric Brunisols with jack pine dominated stands (profile N1) or aspen and white spruce dominated stands (profile N2). See Fig. 1 for more details about each horizon. Two color codes are used to display the values per 10-cm horizon or for the whole profile, respectively: the higher the value, the darker the background of the cell.

\begin{tabular}{|c|c|c|c|c|c|c|}
\cline { 2 - 7 } \multicolumn{1}{c|}{} & $\boldsymbol{R 1}$ & $\boldsymbol{R 2}$ & $\boldsymbol{R 3}$ & $\boldsymbol{R 4}$ & $\boldsymbol{R 5}$ & $\boldsymbol{R 6}$ \\
\hline $0-10 \mathrm{~cm}$ & 359 & 82 & 359 & 82 & 359 & 82 \\
\hline $10-20 \mathrm{~cm}$ & 359 & 82 & 359 & 82 & 359 & 82 \\
\hline $20-30 \mathrm{~cm}$ & 12 & 12 & 12 & 12 & 12 & 12 \\
\hline $30-40 \mathrm{~cm}$ & 12 & 12 & 12 & 12 & 12 & 12 \\
\hline $40-50 \mathrm{~cm}$ & 12 & 12 & 12 & 12 & 12 & 12 \\
\hline $50-60 \mathrm{~cm}$ & 12 & 12 & 198 & 198 & 113 & 113 \\
\hline $60-70 \mathrm{~cm}$ & 12 & 12 & 198 & 198 & 113 & 113 \\
\hline $70-80 \mathrm{~cm}$ & 12 & 12 & 198 & 198 & 113 & 113 \\
\hline $80-90 \mathrm{~cm}$ & 12 & 12 & 198 & 198 & 113 & 113 \\
\hline $90-100 \mathrm{~cm}$ & 12 & 12 & 198 & 198 & 113 & 113 \\
\hline $100-110 \mathrm{~cm}$ & 12 & 12 & 198 & 198 & 113 & 113 \\
\hline $110-120 \mathrm{~cm}$ & 12 & 12 & 198 & 198 & 113 & 113 \\
\hline $\mathbf{0 - 1 2 0} \mathbf{c m}$ & $\mathbf{8 4 3}$ & $\mathbf{2 8 8}$ & $\mathbf{2 1 4 3}$ & $\mathbf{1 5 8 7}$ & $\mathbf{1 5 4 7}$ & $\mathbf{9 9 2}$ \\
\hline
\end{tabular}

\begin{tabular}{|c|c|c|}
\cline { 2 - 3 } \multicolumn{1}{c|}{} & N1 & N2 \\
\hline $0-10 \mathrm{~cm}$ & 40 & 127 \\
\hline $10-20 \mathrm{~cm}$ & 16 & 22 \\
\hline $20-30 \mathrm{~cm}$ & 16 & 21 \\
\hline $30-40 \mathrm{~cm}$ & 16 & 21 \\
\hline $40-50 \mathrm{~cm}$ & 16 & 21 \\
\hline $50-60 \mathrm{~cm}$ & 16 & 19 \\
\hline $60-70 \mathrm{~cm}$ & 16 & 19 \\
\hline $70-80 \mathrm{~cm}$ & 16 & 37 \\
\hline $80-90 \mathrm{~cm}$ & 0 & 37 \\
\hline $90-100 \mathrm{~cm}$ & 0 & 64 \\
\hline $100-110 \mathrm{~cm}$ & 0 & 64 \\
\hline $110-120 \mathrm{~cm}$ & 0 & 64 \\
\hline $\mathbf{0 - 1 2 0} \mathbf{c m}$ & $\mathbf{1 4 9}$ & $\mathbf{5 1 6}$ \\
\hline
\end{tabular}
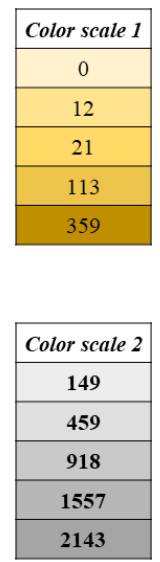

Fig. S8: Total $P\left(\mathrm{gP} \mathrm{m}^{-2}\right)$ initially present in the 6 reclaimed profiles (R1-R6) and the two natural soil profiles (N1, N2). The six reclaimed soil profiles are constructed with: $100 \mathrm{~cm}$ of SUB covered by $20 \mathrm{~cm}$ of PMM (profile R1) or $20 \mathrm{~cm}$ of FFM (profile R2), $70 \mathrm{~cm}$ of TS overlaid by $30 \mathrm{~cm}$ of SUB and covered by $20 \mathrm{~cm}$ of PMM (profile R3) or $20 \mathrm{~cm}$ of FFM (profile R4), and $70 \mathrm{~cm}$ of LOS overlaid by $30 \mathrm{~cm}$ of SUB and covered by $20 \mathrm{~cm}$ of PMM (profile R5) or $20 \mathrm{~cm}$ of FFM (profile R6). The two natural soil profiles correspond to Eluviated Dystric Brunisols with jack pine dominated stands (profile N1) or aspen and white spruce dominated stands (profile N2). See Fig. 1 for more details about each horizon. Two color codes are used to display the values per 10-cm horizon or for the whole profile, respectively: the higher the value, the darker the background of the cell.

\begin{tabular}{|c|c|c|c|c|c|c|}
\cline { 2 - 7 } \multicolumn{1}{c|}{} & $\boldsymbol{R 1}$ & $\boldsymbol{R 2}$ & $\boldsymbol{R 3}$ & $\boldsymbol{R 4}$ & $\boldsymbol{R 5}$ & $\boldsymbol{R 6}$ \\
\hline $0-10 \mathrm{~cm}$ & 10 & 26 & 10 & 26 & 10 & 26 \\
\hline $10-20 \mathrm{~cm}$ & 10 & 26 & 10 & 26 & 10 & 26 \\
\hline $20-30 \mathrm{~cm}$ & 17 & 17 & 17 & 17 & 17 & 17 \\
\hline $30-40 \mathrm{~cm}$ & 17 & 17 & 17 & 17 & 17 & 17 \\
\hline $40-50 \mathrm{~cm}$ & 17 & 17 & 17 & 17 & 17 & 17 \\
\hline $50-60 \mathrm{~cm}$ & 17 & 17 & 10 & 10 & 37 & 37 \\
\hline $60-70 \mathrm{~cm}$ & 17 & 17 & 10 & 10 & 37 & 37 \\
\hline $70-80 \mathrm{~cm}$ & 17 & 17 & 10 & 10 & 37 & 37 \\
\hline $80-90 \mathrm{~cm}$ & 17 & 17 & 10 & 10 & 37 & 37 \\
\hline $90-100 \mathrm{~cm}$ & 17 & 17 & 10 & 10 & 37 & 37 \\
\hline $100-110 \mathrm{~cm}$ & 17 & 17 & 10 & 10 & 37 & 37 \\
\hline $110-120 \mathrm{~cm}$ & 17 & 17 & 10 & 10 & 37 & 37 \\
\hline $\mathbf{0 - 1 2 0} \mathbf{c m}$ & $\mathbf{1 9 2}$ & $\mathbf{2 2 3}$ & $\mathbf{1 4 1}$ & $\mathbf{1 7 1}$ & $\mathbf{3 3 4}$ & $\mathbf{3 6 4}$ \\
\hline
\end{tabular}

\begin{tabular}{|c|c|c|}
\cline { 2 - 3 } \multicolumn{1}{c|}{} & N1 & N2 \\
\hline $0-10 \mathrm{~cm}$ & 14 & 12 \\
\hline $10-20 \mathrm{~cm}$ & 32 & 9 \\
\hline $20-30 \mathrm{~cm}$ & 32 & 30 \\
\hline $30-40 \mathrm{~cm}$ & 32 & 30 \\
\hline $40-50 \mathrm{~cm}$ & 32 & 30 \\
\hline $50-60 \mathrm{~cm}$ & 21 & 29 \\
\hline $60-70 \mathrm{~cm}$ & 21 & 29 \\
\hline $70-80 \mathrm{~cm}$ & 21 & 23 \\
\hline $80-90 \mathrm{~cm}$ & 16 & 23 \\
\hline $90-100 \mathrm{~cm}$ & 16 & 41 \\
\hline $100-110 \mathrm{~cm}$ & 16 & 41 \\
\hline $110-120 \mathrm{~cm}$ & 16 & 41 \\
\hline $\mathbf{0 - 1 2 0} \mathbf{c m}$ & $\mathbf{2 6 8}$ & $\mathbf{3 3 7}$ \\
\hline
\end{tabular}

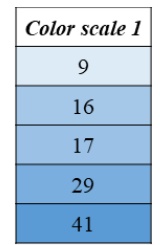

\begin{tabular}{|c|}
\hline Color scale 2 \\
\hline 141 \\
\hline 187 \\
\hline 245 \\
\hline 335 \\
\hline 364 \\
\hline
\end{tabular}

Peer-reviewed, unedited version of the manuscript of Rees et al. (2020) published by Applied Geochemistry: 
Fig. S9: 0.5M K $\mathrm{SO}_{4}$ extractable mineral $\mathrm{N}\left(\mathrm{gN} \mathrm{m}^{-2}\right)$ initially present in the 6 reclaimed profiles (R1-R6) and the two natural soil profiles (N1, N2). The six reclaimed soil profiles are constructed with: $100 \mathrm{~cm}$ of SUB covered by $20 \mathrm{~cm}$ of PMM (profile R1) or $20 \mathrm{~cm}$ of FFM (profile R2), $70 \mathrm{~cm}$ of TS overlaid by $30 \mathrm{~cm}$ of SUB and covered by $20 \mathrm{~cm}$ of PMM (profile R3) or $20 \mathrm{~cm}$ of FFM (profile R4), and $70 \mathrm{~cm}$ of LOS overlaid by $30 \mathrm{~cm}$ of SUB and covered by $20 \mathrm{~cm}$ of PMM (profile R5) or $20 \mathrm{~cm}$ of FFM (profile R6). The two natural soil profiles correspond to Eluviated Dystric Brunisols with jack pine dominated stands (profile N1) or aspen and white spruce dominated stands (profile N2). See Fig. 1 for more details about each horizon. Two color codes are used to display the values per 10-cm horizon or for the whole profile, respectively: the higher the value, the darker the background of the cell.

\begin{tabular}{|c|c|c|c|c|c|c|}
\cline { 2 - 7 } \multicolumn{1}{c|}{} & $\boldsymbol{R 1}$ & $\boldsymbol{R 2}$ & $\boldsymbol{R 3}$ & $\boldsymbol{R 4}$ & $\boldsymbol{R 5}$ & $\boldsymbol{R} \boldsymbol{6}$ \\
\hline $0-10 \mathrm{~cm}$ & 3.4 & 3.0 & 3.4 & 3.0 & 3.4 & 3.0 \\
\hline $10-20 \mathrm{~cm}$ & 3.4 & 3.0 & 3.4 & 3.0 & 3.4 & 3.0 \\
\hline $20-30 \mathrm{~cm}$ & 0.3 & 0.3 & 0.3 & 0.3 & 0.3 & 0.3 \\
\hline $30-40 \mathrm{~cm}$ & 0.3 & 0.3 & 0.3 & 0.3 & 0.3 & 0.3 \\
\hline $40-50 \mathrm{~cm}$ & 0.3 & 0.3 & 0.3 & 0.3 & 0.3 & 0.3 \\
\hline $50-60 \mathrm{~cm}$ & 0.3 & 0.3 & 0.1 & 0.1 & 0.1 & 0.1 \\
\hline $60-70 \mathrm{~cm}$ & 0.3 & 0.3 & 0.1 & 0.1 & 0.1 & 0.1 \\
\hline $70-80 \mathrm{~cm}$ & 0.3 & 0.3 & 0.1 & 0.1 & 0.1 & 0.1 \\
\hline $80-90 \mathrm{~cm}$ & 0.3 & 0.3 & 0.1 & 0.1 & 0.1 & 0.1 \\
\hline $90-100 \mathrm{~cm}$ & 0.3 & 0.3 & 0.1 & 0.1 & 0.1 & 0.1 \\
\hline $100-110 \mathrm{~cm}$ & 0.3 & 0.3 & 0.1 & 0.1 & 0.1 & 0.1 \\
\hline $110-120 \mathrm{~cm}$ & 0.3 & 0.3 & 0.1 & 0.1 & 0.1 & 0.1 \\
\hline $\mathbf{0 - 1 2 0} \mathbf{c m}$ & $\mathbf{1 0}$ & $\mathbf{9}$ & $\mathbf{9}$ & $\mathbf{8}$ & $\mathbf{8}$ & $\mathbf{8}$ \\
\hline
\end{tabular}

\begin{tabular}{|c|c|c|}
\cline { 2 - 3 } \multicolumn{1}{c|}{} & N1 & N2 \\
\hline $0-10 \mathrm{~cm}$ & 0.6 & 3.0 \\
\hline $10-20 \mathrm{~cm}$ & 0.3 & 0.2 \\
\hline $20-30 \mathrm{~cm}$ & 0.3 & 0.3 \\
\hline $30-40 \mathrm{~cm}$ & 0.3 & 0.3 \\
\hline $40-50 \mathrm{~cm}$ & 0.3 & 0.3 \\
\hline $50-60 \mathrm{~cm}$ & 0.2 & 0.3 \\
\hline $60-70 \mathrm{~cm}$ & 0.2 & 0.3 \\
\hline $70-80 \mathrm{~cm}$ & 0.2 & 0.4 \\
\hline $80-90 \mathrm{~cm}$ & 0.2 & 0.4 \\
\hline $90-100 \mathrm{~cm}$ & 0.2 & 0.3 \\
\hline $100-110 \mathrm{~cm}$ & 0.2 & 0.3 \\
\hline $110-120 \mathrm{~cm}$ & 0.2 & 0.3 \\
\hline $\mathbf{0 - 1 2 0} \mathbf{c m}$ & $\mathbf{3}$ & $\mathbf{7}$ \\
\hline
\end{tabular}

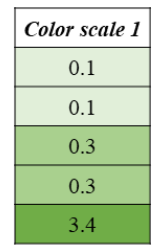

Fig. S10: $0.5 \mathrm{M} \mathrm{K}_{2} \mathrm{SO}_{4}$ extractable $\mathrm{P}\left(\mathrm{gP} \mathrm{m}^{-2}\right)$ initially present in the 6 reclaimed profiles (R1-R6) and the two natural soil profiles (N1, N2). The six reclaimed soil profiles are constructed with: $100 \mathrm{~cm}$ of SUB covered by $20 \mathrm{~cm}$ of PMM (profile R1) or $20 \mathrm{~cm}$ of FFM (profile R2), $70 \mathrm{~cm}$ of TS overlaid by $30 \mathrm{~cm}$ of SUB and covered by $20 \mathrm{~cm}$ of PMM (profile R3) or $20 \mathrm{~cm}$ of FFM (profile R4), and $70 \mathrm{~cm}$ of LOS overlaid by $30 \mathrm{~cm}$ of SUB and covered by $20 \mathrm{~cm}$ of PMM (profile R5) or $20 \mathrm{~cm}$ of FFM (profile R6). The two natural soil profiles correspond to Eluviated Dystric Brunisols with jack pine dominated stands (profile N1) or aspen and white spruce dominated stands (profile N2). See Fig. 1 for more details about each horizon. Two color codes are used to display the values per 10-cm horizon or for the whole profile, respectively: the higher the value, the darker the background of the cell.

\begin{tabular}{|c|c|c|c|c|c|c|}
\cline { 2 - 7 } \multicolumn{1}{c|}{} & $\boldsymbol{R 1}$ & $\boldsymbol{R 2}$ & $\boldsymbol{R 3}$ & $\boldsymbol{R 4}$ & $\boldsymbol{R 5}$ & $\boldsymbol{R} \boldsymbol{0}$ \\
\hline $0-10 \mathrm{~cm}$ & 0.00 & 0.01 & 0.00 & 0.01 & 0.00 & 0.01 \\
\hline $10-20 \mathrm{~cm}$ & 0.00 & 0.01 & 0.00 & 0.01 & 0.00 & 0.01 \\
\hline $20-30 \mathrm{~cm}$ & 0.00 & 0.00 & 0.00 & 0.00 & 0.00 & 0.00 \\
\hline $30-40 \mathrm{~cm}$ & 0.00 & 0.00 & 0.00 & 0.00 & 0.00 & 0.00 \\
\hline $40-50 \mathrm{~cm}$ & 0.00 & 0.00 & 0.00 & 0.00 & 0.00 & 0.00 \\
\hline $50-60 \mathrm{~cm}$ & 0.00 & 0.00 & 0.01 & 0.01 & 0.00 & 0.00 \\
\hline $60-70 \mathrm{~cm}$ & 0.00 & 0.00 & 0.01 & 0.01 & 0.00 & 0.00 \\
\hline $70-80 \mathrm{~cm}$ & 0.00 & 0.00 & 0.01 & 0.01 & 0.00 & 0.00 \\
\hline $80-90 \mathrm{~cm}$ & 0.00 & 0.00 & 0.01 & 0.01 & 0.00 & 0.00 \\
\hline $90-100 \mathrm{~cm}$ & 0.00 & 0.00 & 0.01 & 0.01 & 0.00 & 0.00 \\
\hline $100-110 \mathrm{~cm}$ & 0.00 & 0.00 & 0.01 & 0.01 & 0.00 & 0.00 \\
\hline $110-120 \mathrm{~cm}$ & 0.00 & 0.00 & 0.01 & 0.01 & 0.00 & 0.00 \\
\hline $\mathbf{0 - 1 2 0} \mathbf{c m}$ & $\mathbf{0 . 0 3}$ & $\mathbf{0 . 0 6}$ & $\mathbf{0 . 0 7}$ & $\mathbf{0 . 0 9}$ & $\mathbf{0 . 0 3}$ & $\mathbf{0 . 0 5}$ \\
\hline
\end{tabular}

\begin{tabular}{|c|c|c|}
\cline { 2 - 3 } \multicolumn{1}{c|}{} & N1 & N2 \\
\hline $0-10 \mathrm{~cm}$ & 0.05 & 0.08 \\
\hline $10-20 \mathrm{~cm}$ & 0.05 & 0.04 \\
\hline $20-30 \mathrm{~cm}$ & 0.05 & 0.07 \\
\hline $30-40 \mathrm{~cm}$ & 0.05 & 0.07 \\
\hline $40-50 \mathrm{~cm}$ & 0.05 & 0.07 \\
\hline $50-60 \mathrm{~cm}$ & 0.04 & 0.05 \\
\hline $60-70 \mathrm{~cm}$ & 0.04 & 0.05 \\
\hline $70-80 \mathrm{~cm}$ & 0.04 & 0.00 \\
\hline $80-90 \mathrm{~cm}$ & 0.03 & 0.00 \\
\hline $90-100 \mathrm{~cm}$ & 0.03 & 0.01 \\
\hline $100-110 \mathrm{~cm}$ & 0.03 & 0.01 \\
\hline $110-120 \mathrm{~cm}$ & 0.03 & 0.01 \\
\hline $\mathbf{0 - 1 2 0} \mathbf{c m}$ & $\mathbf{0 . 4 9}$ & $\mathbf{0 . 4 4}$ \\
\hline
\end{tabular}

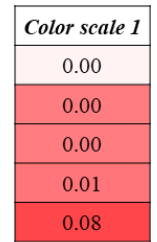

\begin{tabular}{|c|}
\hline Color scale 2 \\
\hline 0.03 \\
\hline 0.05 \\
\hline 0.06 \\
\hline 0.18 \\
\hline 0.49 \\
\hline
\end{tabular}

Peer-reviewed, unedited version of the manuscript of Rees et al. (2020) published by Applied Geochemistry: 


\section{Nutrient sorption capacity}

Fig. S11: Sorption (dark grey) and desorption (light grey) curves obtained with the peat mineral mix (PMM) for $\mathrm{NH}_{4}-\mathrm{N}$, NO3-N, mineral $\mathbf{N}$ and $\mathrm{PO}_{4}-\mathrm{P}$. Experimental data are indicated as diamonds or triangles, while lines show the curves fitted, when possible, with Langmuir (dashed lines) or Freundlich (dotted lines) models. Error bars represent standard error (3 replicates).
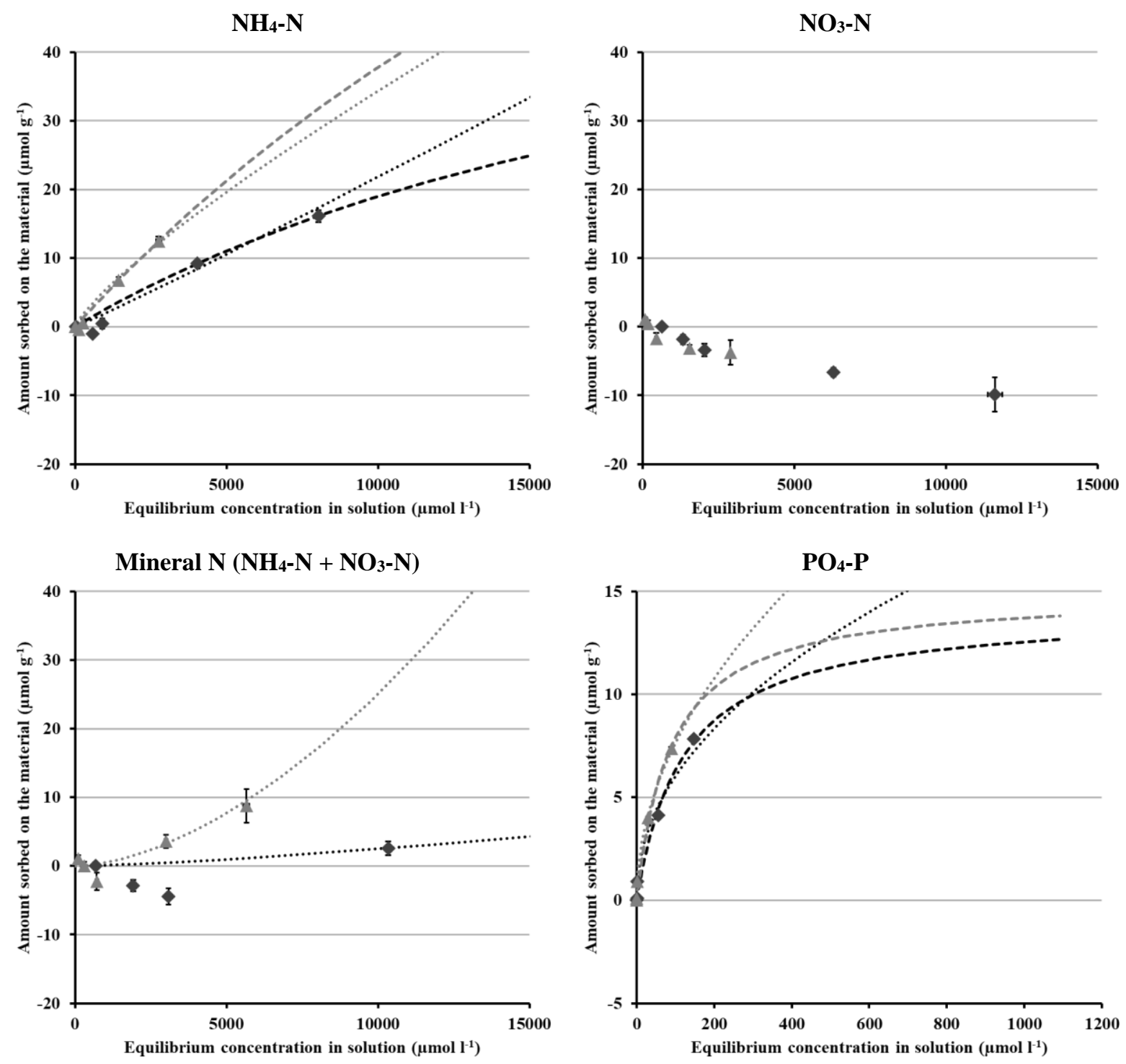
Fig. S12: Sorption (dark grey) and desorption (light grey) curves obtained with the forest floor mineral material (FFM) for $\mathbf{N H}_{4}-\mathbf{N}, \mathbf{N O}_{3}-\mathbf{N}$, mineral $\mathbf{N}$ and $\mathbf{P O}_{4}-\mathbf{P}$. Experimental data are indicated as diamonds or triangles, while lines show the curves fitted, when possible, with Langmuir (dashed lines) or Freundlich (dotted lines) models. Error bars represent standard error (3 replicates).
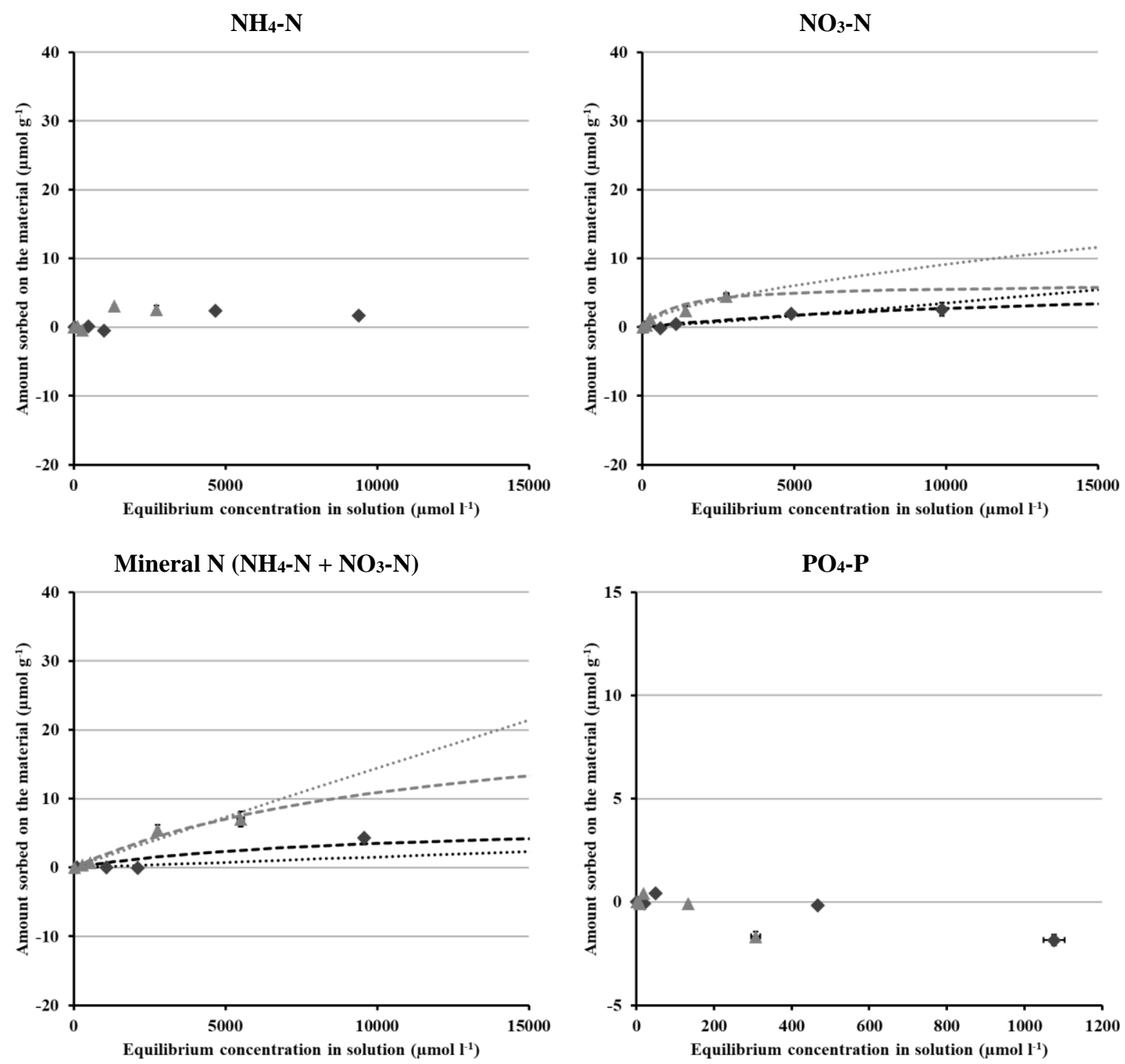
Fig. S13: Sorption (dark grey) and desorption (light grey) curves obtained with the blended B/C subsoil (SUB) for $\mathrm{NH}_{4}-\mathrm{N}, \mathrm{NO}_{3}-\mathrm{N}$, mineral $\mathrm{N}$ and $\mathrm{PO}_{4}-\mathrm{P}$. Experimental data are indicated as diamonds or triangles, while lines show the curves fitted, when possible, with Langmuir (dashed lines) or Freundlich (dotted lines) models. Error bars represent standard error (3 replicates).
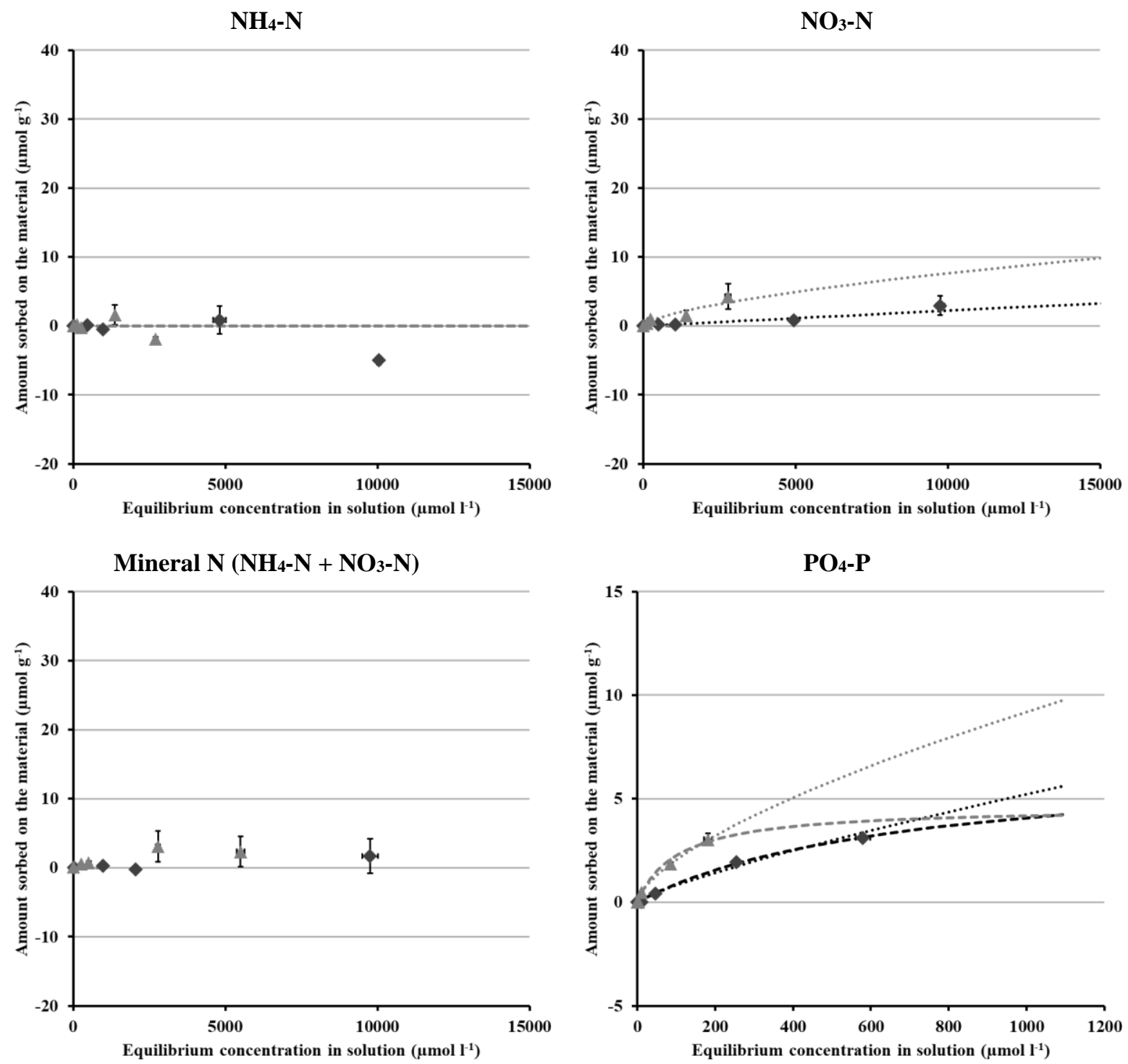
Fig. S14: Sorption (dark grey) and desorption (light grey) curves obtained with tailing sands (TS) for $\mathrm{NH}_{4}-$ $\mathbf{N}, \mathrm{NO}_{3}-\mathbf{N}$, mineral $\mathbf{N}$ and $\mathbf{P O}_{4}-\mathbf{P}$. Experimental data are indicated as diamonds or triangles, while lines show the curves fitted, when possible, with Langmuir (dashed lines) or Freundlich (dotted lines) models. Error bars represent standard error (3 replicates).
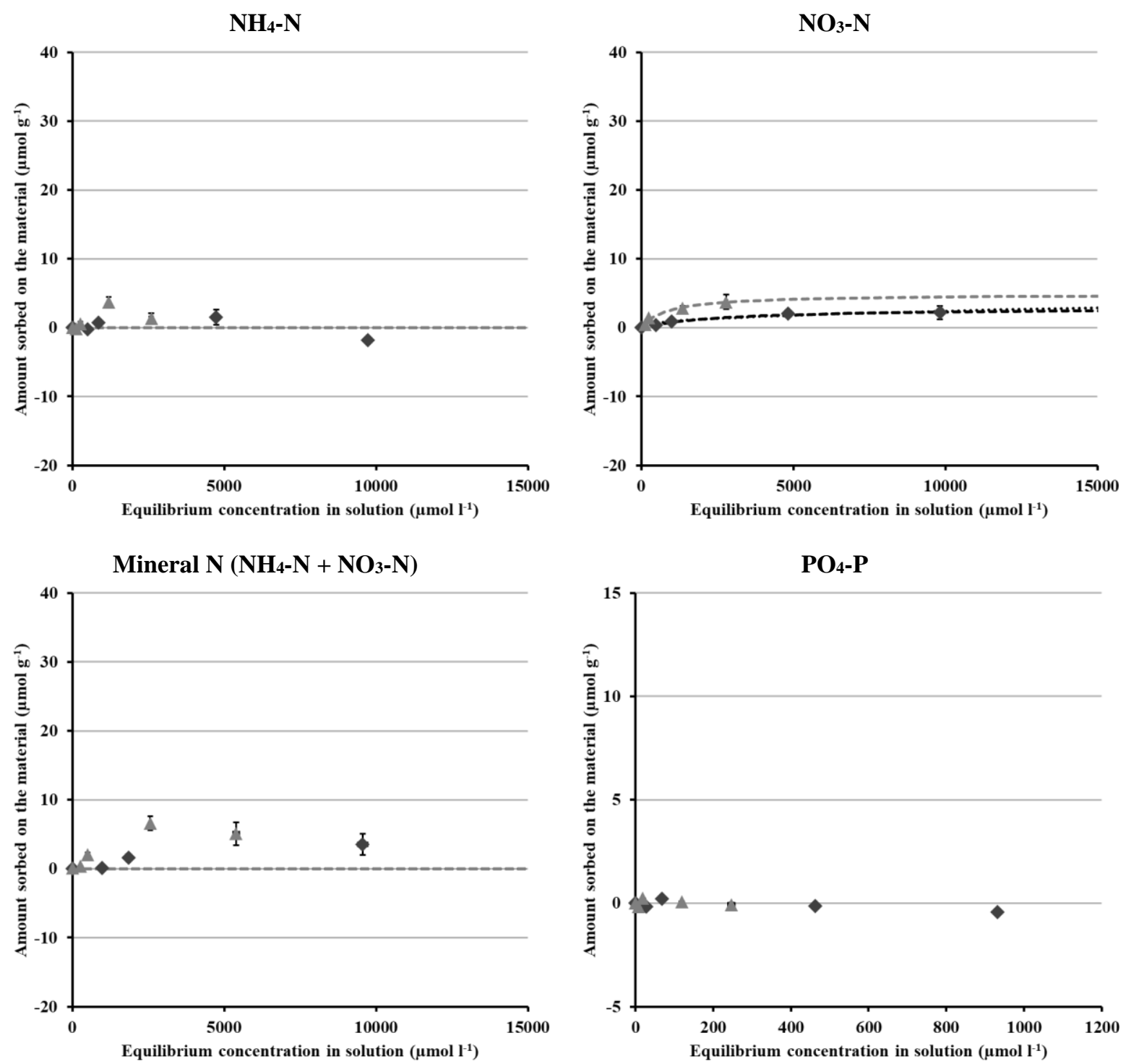

Peer-reviewed, unedited version of the manuscript of Rees et al. (2020) published by Applied Geochemistry: 
Fig. S15: Sorption (dark grey) and desorption (light grey) curves obtained with lean oil sands (LOS) for NH4-N, NO $3-\mathbf{N}$, mineral $\mathbf{N}$ and $\mathbf{P O}_{4}-\mathbf{P}$. Experimental data are indicated as diamonds or triangles, while lines show the curves fitted, when possible, with Langmuir (dashed lines) or Freundlich (dotted lines) models. Error bars represent standard error (3 replicates).
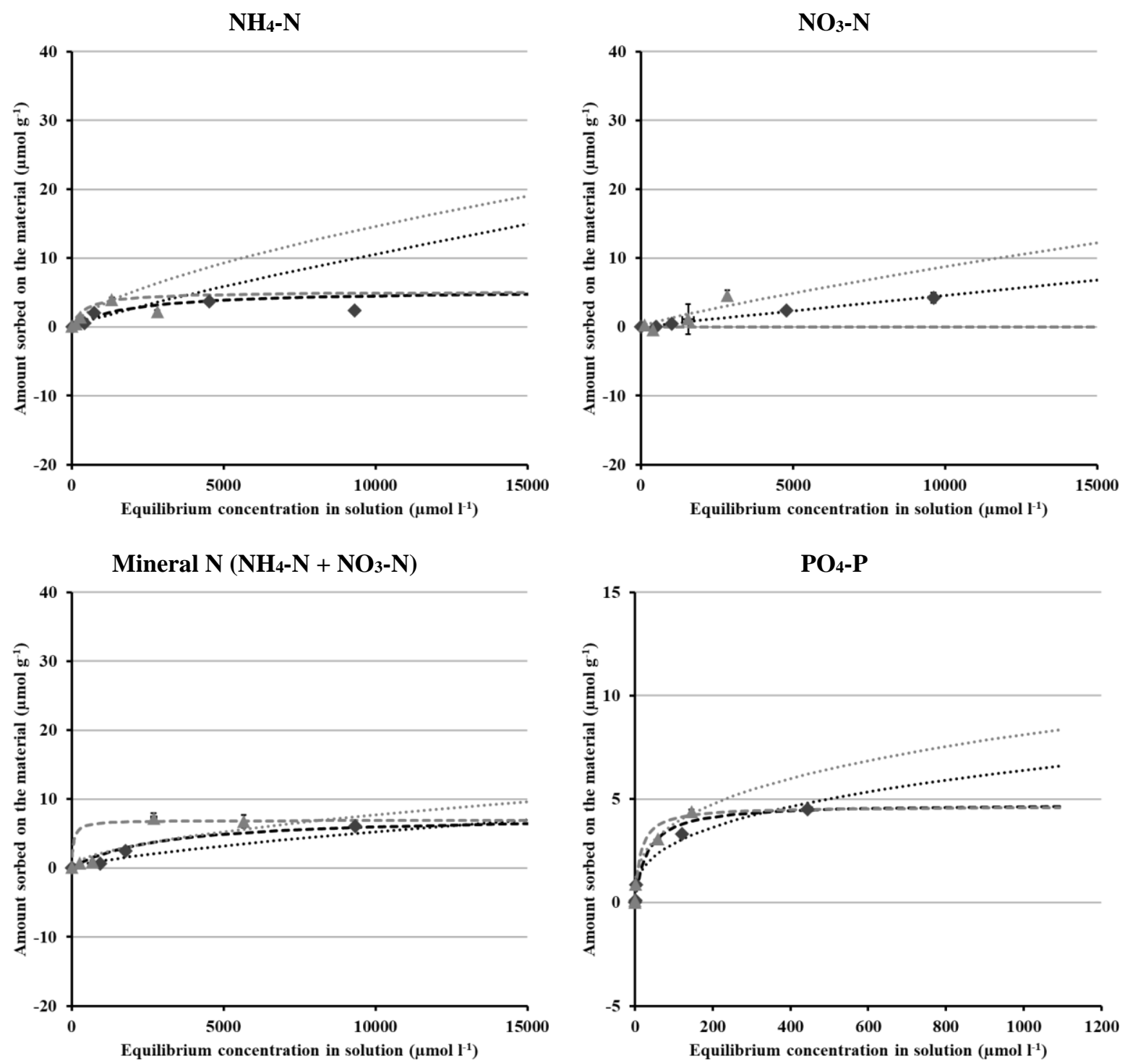


\section{Nitrate- $\mathrm{N}$, ammonium- $\mathrm{N}$ and fertilizer- $\mathrm{N}$ results from the column leaching experiment}

Fig. S16: $0.5 \mathrm{M} \mathrm{K}_{2} \mathrm{SO}_{4}$ extractable nitrate- $\mathrm{N}$ in each 10-cm segment of reclaimed soil profiles $\left(\mathrm{g} \mathrm{m}^{-2}\right)$, prior to leaching $(t=-1$ day $)$ and after a 4-h intense rainfall and a resting period of 5 days $(t=5$ days). PMM: peatmineral mix; PMM + F: peat-mineral mix with fertilizer; FFM: forest floor mineral material; FFM + F: forest floor mineral material with fertilizer; SUB: blended B/C horizons of sandy subsoil; TS: tailing sand; LOS: lean oil sand. N.D: Not determined. Results are presented as mean \pm standard error (3 replicates). A green color code is used to display the values: the higher the mean value, the darker the background of the cell.

\begin{tabular}{|c|c|c|}
\hline Treatment 1 & $t=-1$ day & $t=5$ days \\
\hline$P M M$ & $4.33 \pm 0.11$ & $0.54 \pm 0.06$ \\
\hline$P M M$ & $4.33 \pm 0.11$ & $3.11 \pm 0.18$ \\
\hline$S U B$ & $0.27 \pm 0.02$ & $0.81 \pm 0.04$ \\
\hline$S U B$ & $0.27 \pm 0.02$ & $0.78 \pm 0.05$ \\
\hline$S U B$ & $0.27 \pm 0.02$ & $0.80 \pm 0.01$ \\
\hline$S U B$ & $0.27 \pm 0.02$ & $0.67 \pm 0.01$ \\
\hline$S U B$ & $0.27 \pm 0.02$ & $0.58 \pm 0.00$ \\
\hline$S U B$ & $0.27 \pm 0.02$ & $0.3 \pm 0.00$ \\
\hline$S U B$ & $0.27 \pm 0.02$ & \multirow{3}{*}{ N.D. } \\
\hline$S U B$ & $0.27 \pm 0.02$ & \\
\hline$S U B$ & $0.27 \pm 0.02$ & \\
\hline$S U B$ & $0.27 \pm 0.02$ & $0.36 \pm 0.00$ \\
\hline TOTAL & $11.3 \pm 0.4$ & $7.9 \pm 0.2$ \\
\hline
\end{tabular}

\begin{tabular}{|c|c|c|}
\hline Treatment 2 & $t=-1$ day & $t=5$ days \\
\hline$F F M$ & $2.67 \pm 0.07$ & $0.18 \pm 0.02$ \\
\hline$F F M$ & $2.67 \pm 0.07$ & $0.24 \pm 0.01$ \\
\hline$S U B$ & $0.27 \pm 0.02$ & $0.19 \pm 0.01$ \\
\hline$S U B$ & $0.27 \pm 0.02$ & $0.64 \pm 0.06$ \\
\hline$S U B$ & $0.27 \pm 0.02$ & $1.49 \pm 0.14$ \\
\hline$S U B$ & $0.27 \pm 0.02$ & $1.83 \pm 0.17$ \\
\hline$S U B$ & $0.27 \pm 0.02$ & $1.49 \pm 0.06$ \\
\hline$S U B$ & $0.27 \pm 0.02$ & $0.33 \pm 0.01$ \\
\hline$S U B$ & $0.27 \pm 0.02$ & \multirow{3}{*}{$N . D}$. \\
\hline$S U B$ & $0.27 \pm 0.02$ & \\
\hline$S U B$ & $0.27 \pm 0.02$ & \\
\hline$S U B$ & $0.27 \pm 0.02$ & $0.35 \pm 0.03$ \\
\hline TOTAL & $8.0 \pm 0.4$ & $6.7 \pm 0.2$ \\
\hline
\end{tabular}

\begin{tabular}{|c|c|c|}
\hline Treatment 3 & $t=-1$ day & $\mathrm{t}=\mathbf{5}$ days \\
\hline$P M M$ & $4.33 \pm 0.11$ & $0.47 \pm 0.03$ \\
\hline$P M M$ & $4.33 \pm 0.11$ & $3.07 \pm 0.30$ \\
\hline$S U B$ & $0.27 \pm 0.02$ & $0.77 \pm 0.06$ \\
\hline$S U B$ & $0.27 \pm 0.02$ & $0.77 \pm 0.01$ \\
\hline$S U B$ & $0.27 \pm 0.02$ & $0.77 \pm 0.02$ \\
\hline$T S$ & $0.05 \pm 0.01$ & $0.80 \pm 0.03$ \\
\hline$T S$ & $0.05 \pm 0.01$ & $0.55 \pm 0.02$ \\
\hline$T S$ & $0.05 \pm 0.01$ & $0.11 \pm 0.02$ \\
\hline$T S$ & $0.05 \pm 0.01$ & \multirow{3}{*}{ N.D. } \\
\hline$T S$ & $0.05 \pm 0.01$ & \\
\hline$T S$ & $0.05 \pm 0.01$ & \\
\hline$T S$ & $0.05 \pm 0.01$ & $0.05 \pm 0.01$ \\
\hline TOTAL & $9.8 \pm 0.4$ & $7.4 \pm 0.3$ \\
\hline
\end{tabular}

\begin{tabular}{|c|c|c|}
\hline Treatment 4 & $t=-1$ day & $\mathrm{t}=5$ days \\
\hline$F F M$ & $2.67 \pm 0.07$ & $0.21 \pm 0.01$ \\
\hline$F F M$ & $2.67 \pm 0.07$ & $0.26 \pm 0.03$ \\
\hline$S U B$ & $0.27 \pm 0.02$ & $0.21 \pm 0.01$ \\
\hline$S U B$ & $0.27 \pm 0.02$ & $0.82 \pm 0.23$ \\
\hline$S U B$ & $0.27 \pm 0.02$ & $2.11 \pm 0.66$ \\
\hline$T S$ & $0.05 \pm 0.01$ & $1.73 \pm 0.29$ \\
\hline$T S$ & $0.05 \pm 0.01$ & $1.19 \pm 0.44$ \\
\hline$T S$ & $0.05 \pm 0.01$ & $0.12 \pm 0.02$ \\
\hline$T S$ & $0.05 \pm 0.01$ & \multirow{3}{*}{ N.D. } \\
\hline$T S$ & $0.05 \pm 0.01$ & \\
\hline$T S$ & $0.05 \pm 0.01$ & \\
\hline$T S$ & $0.05 \pm 0.01$ & $0.05 \pm 0.01$ \\
\hline TOTAL & $6.5 \pm 0.3$ & $6.7 \pm 0.2$ \\
\hline
\end{tabular}

\begin{tabular}{|c|c|c|}
\hline Treatment 5 & $t=-1$ day & $t=5$ days \\
\hline$P M M$ & $4.03=0.05$ & $0.49 \pm 0.04$ \\
\hline$P M M$ & $4.03 \pm 0.05$ & $3.23 \pm 0.14$ \\
\hline$S U B$ & $0.19 \pm 0.01$ & $0.78 \pm 0.02$ \\
\hline$S U B$ & $0.19 \pm 0.01$ & $0.86 \pm 0.03$ \\
\hline$S U B$ & $0.19 \pm 0.01$ & $1.13 \pm 0.03$ \\
\hline LOS & $0.02 \pm 0.00$ & $0.43 \pm 0.04$ \\
\hline LOS & $0.02 \pm 0.00$ & $0.04 \pm 0.01$ \\
\hline LOS & $0.02 \pm 0.00$ & $0.03 \pm 0.01$ \\
\hline LOS & $0.02 \pm 0.00$ & \multirow{3}{*}{ N.D. } \\
\hline LOS & $0.02 \pm 0.00$ & \\
\hline LOS & $0.02 \pm 0.00$ & \\
\hline LOS & $0.02 \pm 0.00$ & $0.02 \pm 0.00$ \\
\hline TOTAL & $8.8 \pm 0.1$ & $7.0 \pm 0.2$ \\
\hline
\end{tabular}

\begin{tabular}{|c|c|c|}
\hline Treatment 6 & $t=-1$ day & $\mathrm{t}=\mathbf{5}$ days \\
\hline$F F M$ & $3.22 \pm 0.09$ & $0.27 \pm 0.11$ \\
\hline$F F M$ & $3.22 \pm 0.09$ & $0.21 \pm 0.02$ \\
\hline$S U B$ & $0.19 \pm 0.01$ & $0.18 \pm 0.01$ \\
\hline$S U B$ & $0.19 \pm 0.01$ & $0.86 \pm 0.02$ \\
\hline$S U B$ & $0.19 \pm 0.01$ & $2.77 \pm 0.22$ \\
\hline LOS & $0.02 \pm 0.00$ & $2.17 \pm 0.03$ \\
\hline LOS & $0.02 \pm 0.00$ & $0.04 \pm 0.02$ \\
\hline LOS & $0.02 \pm 0.00$ & $0.03 \pm 0.01$ \\
\hline $\operatorname{LOS}$ & $0.02 \pm 0.00$ & \multirow{3}{*}{ N.D. } \\
\hline LOS & $0.02 \pm 0.00$ & \\
\hline LOS & $0.02 \pm 0.00$ & \\
\hline $\operatorname{LOS}$ & $0.02 \pm 0.00$ & $0.02 \pm 0.00$ \\
\hline TOTAL & $7.2 \pm 0.2$ & $6.5 \pm 0.3$ \\
\hline
\end{tabular}

\begin{tabular}{|c|c|c|}
\hline Treatment 7 & $t=-1$ day & $t=5$ days \\
\hline$P M M+F$ & $4.18 \pm 0.06$ & $4.03 \pm 0.05$ \\
\hline$P M M$ & $4.03 \pm 0.05$ & $4.56 \pm 0.21$ \\
\hline$S U B$ & $0.19 \pm 0.01$ & $0.77 \pm 0.00$ \\
\hline$S U B$ & $0.19 \pm 0.01$ & $0.84 \pm 0.01$ \\
\hline$S U B$ & $0.19 \pm 0.01$ & $1.13 \pm 0.03$ \\
\hline LOS & $0.02 \pm 0.00$ & $0.41 \pm 0.02$ \\
\hline LOS & $0.02 \pm 0.00$ & $0.04 \pm 0.01$ \\
\hline LOS & $0.02 \pm 0.00$ & $0.03 \pm 0.01$ \\
\hline LOS & $0.02 \pm 0.00$ & \multirow{3}{*}{ N.D. } \\
\hline LOS & $0.02 \pm 0.00$ & \\
\hline LOS & $0.02 \pm 0.00$ & \\
\hline LOS & $0.02 \pm 0.00$ & $0.02 \pm 0.00$ \\
\hline TOTAL & $8.9 \pm 0.2$ & $11.8 \pm 0.2$ \\
\hline
\end{tabular}

\begin{tabular}{|c|c|c|}
\hline Treatment 8 & $t=-1$ day & $\mathrm{t}=\mathbf{5}$ days \\
\hline$F F M+F$ & $3.36 \pm 0.21$ & $2.75 \pm 0.06$ \\
\hline$F F M$ & $3.22 \pm 0.09$ & $1.69 \pm 0.10$ \\
\hline$S U B$ & $0.19 \pm 0.01$ & $0.22 \pm 0.03$ \\
\hline$S U B$ & $0.19 \pm 0.01$ & $0.87 \pm 0.06$ \\
\hline$S U B$ & $0.19 \pm 0.01$ & $2.60 \pm 0.06$ \\
\hline LOS & $0.02 \pm 0.00$ & $2.13 \pm 0.14$ \\
\hline LOS & $0.02 \pm 0.00$ & $0.07 \pm 0.02$ \\
\hline LOS & $0.02 \pm 0.00$ & $0.03 \pm 0.01$ \\
\hline LOS & $0.02 \pm 0.00$ & \multirow{3}{*}{ N.D. } \\
\hline LOS & $0.02 \pm 0.00$ & \\
\hline LOS & $0.02 \pm 0.00$ & \\
\hline LOS & $0.02 \pm 0.00$ & $0.02 \pm 0.00$ \\
\hline TOTAL & $7.3 \pm 0.5$ & $10.4 \pm 0.2$ \\
\hline
\end{tabular}

Peer-reviewed, unedited version of the manuscript of Rees et al. (2020) published by Applied Geochemistry: 
Fig. S17: $0.5 \mathrm{M} \mathrm{K}_{2} \mathrm{SO}_{4}$ extractable ammonium-N in each 10-cm segment of reclaimed soil profiles $\left(\mathrm{g} \mathrm{m}^{-2}\right)$, prior to leaching $(t=-1$ day $)$ and after a 4-h intense rainfall and a resting period of 5 days $(t=5$ days $)$. PMM: peat-mineral mix; PMM + F: peat-mineral mix with fertilizer; FFM: forest floor mineral material; FFM + F: forest floor mineral material with fertilizer; SUB: blended B/C horizons of sandy subsoil; TS: tailing sand; LOS: lean oil sand. N.D: Not determined. Results are presented as mean \pm standard error (3 replicates). A green color code is used to display the values: the higher the mean value, the darker the background of the cell.

\begin{tabular}{|c|c|c|}
\hline Treatment 1 & $t=-1$ day & $\mathrm{t}=5$ days \\
\hline$P M M$ & $0.02 \pm 0.00$ & $0.05 \pm 0.00$ \\
\hline$P M M$ & $0.02 \pm 0.00$ & $0.09 \pm 0.02$ \\
\hline$S U B$ & $0.05 \pm 0.00$ & $0.35 \pm 0.11$ \\
\hline$S U B$ & $0.05 \pm 0.00$ & $0.37 \pm 0.10$ \\
\hline$S U B$ & $0.05 \pm 0.00$ & $0.20 \pm 0.04$ \\
\hline$S U B$ & $0.05 \pm 0.00$ & $0.18 \pm 0.03$ \\
\hline$S U B$ & $0.05 \pm 0.00$ & $0.12 \pm 0.01$ \\
\hline$S U B$ & $0.05 \pm 0.00$ & $0.13 \pm 0.05$ \\
\hline$S U B$ & $0.05 \pm 0.00$ & \multirow{3}{*}{$N . D$. } \\
\hline$S U B$ & $0.05 \pm 0.00$ & \\
\hline$S U B$ & $0.05 \pm 0.00$ & \\
\hline$S U B$ & $0.05 \pm 0.00$ & $0.07 \pm 0.01$ \\
\hline TOTAL & $0.58 \pm 0.03$ & $1.55 \pm 0.27$ \\
\hline
\end{tabular}

\begin{tabular}{|c|c|c|}
\hline Treatment 2 & $t=-1$ day & $t=5$ days \\
\hline$F F M$ & $0.07 \pm 0.00$ & $0.18 \pm 0.00$ \\
\hline$F F M$ & $0.07 \pm 0.00$ & $0.29 \pm 0.08$ \\
\hline$S U B$ & $0.05 \pm 0.00$ & $0.25 \pm 0.02$ \\
\hline$S U B$ & $0.05 \pm 0.00$ & $0.32 \pm 0.08$ \\
\hline$S U B$ & $0.05 \pm 0.00$ & $0.31 \pm 0.15$ \\
\hline$S U B$ & $0.05 \pm 0.00$ & $0.19 \pm 0.02$ \\
\hline$S U B$ & $0.05 \pm 0.00$ & $0.77 \pm 0.67$ \\
\hline$S U B$ & $0.05 \pm 0.00$ & $0.09 \pm 0.01$ \\
\hline$S U B$ & $0.05 \pm 0.00$ & \multirow{3}{*}{$N . D}$. \\
\hline$S U B$ & $0.05 \pm 0.00$ & \\
\hline$S U B$ & $0.05 \pm 0.00$ & \\
\hline$S U B$ & $0.05 \pm 0.00$ & $0.09 \pm 0.02$ \\
\hline TOTAL & $0.68 \pm 0.03$ & $2.49 \pm 0.70$ \\
\hline
\end{tabular}

\begin{tabular}{|c|c|c|}
\hline Treatment 3 & $t=-1$ day & $\mathrm{t}=5$ days \\
\hline$P M M$ & $0.02 \pm 0.00$ & $0.06 \pm 0.00$ \\
\hline$P M M$ & $0.02 \pm 0.00$ & $0.06 \pm 0.00$ \\
\hline$S U B$ & $0.05 \pm 0.00$ & $0.24 \pm 0.01$ \\
\hline$S U B$ & $0.05 \pm 0.00$ & $0.36 \pm 0.13$ \\
\hline$S U B$ & $0.05 \pm 0.00$ & $0.48 \pm 0.29$ \\
\hline$T S$ & $0.05 \pm 0.00$ & $0.26 \pm 0.09$ \\
\hline$T S$ & $0.05 \pm 0.00$ & $0.81 \pm 0.72$ \\
\hline$T S$ & $0.05 \pm 0.00$ & $0.08 \pm 0.00$ \\
\hline$T S$ & $0.05 \pm 0.00$ & \multirow{3}{*}{ N.D. } \\
\hline$T S$ & $0.05 \pm 0.00$ & \\
\hline$T S$ & $0.05 \pm 0.00$ & \\
\hline$T S$ & $0.05 \pm 0.00$ & $0.08 \pm 0.01$ \\
\hline TOTAL & $0.53 \pm 0.03$ & $2.41 \pm 0.61$ \\
\hline
\end{tabular}

\begin{tabular}{|c|c|c|}
\hline Treatment 4 & $t=-1$ day & $\mathrm{t}=\mathbf{5}$ days \\
\hline$F F M$ & $0.07 \pm 0.00$ & $0.19 \pm 0.00$ \\
\hline$F F M$ & $0.07 \pm 0.00$ & $0.21 \pm 0.01$ \\
\hline$S U B$ & $0.05 \pm 0.00$ & $0.27 \pm 0.03$ \\
\hline$S U B$ & $0.05 \pm 0.00$ & $0.27 \pm 0.01$ \\
\hline$S U B$ & $0.05 \pm 0.00$ & $0.8 \pm 0.57$ \\
\hline$T S$ & $0.05 \pm 0.00$ & $0.39 \pm 0.23$ \\
\hline$T S$ & $0.05 \pm 0.00$ & $0.19 \pm 0.11$ \\
\hline TS & $0.05 \pm 0.00$ & $0.07 \pm 0.00$ \\
\hline TS & $0.05 \pm 0.00$ & \multirow{3}{*}{$N . D$. } \\
\hline$T S$ & $0.05 \pm 0.00$ & \\
\hline$T S$ & $0.05 \pm 0.00$ & \\
\hline$T S$ & $0.05 \pm 0.00$ & $0.07 \pm 0.01$ \\
\hline TOTAL & $0.63 \pm 0.03$ & $2.46 \pm 0.73$ \\
\hline
\end{tabular}

\begin{tabular}{|c|c|c|}
\hline Treatment 5 & $t=-1$ day & $t=5$ days \\
\hline$P M M$ & $0.03 \pm 0.00$ & $0.02 \pm 0.00$ \\
\hline$P M M$ & $0.03 \pm 0.00$ & $0.03 \pm 0.01$ \\
\hline$S U B$ & $0.12 \pm 0.00$ & $0.14 \pm 0.04$ \\
\hline$S U B$ & $0.12 \pm 0.00$ & $0.19 \pm 0.08$ \\
\hline$S U B$ & $0.12 \pm 0.00$ & $0.44 \pm 0.33$ \\
\hline LOS & $0.08 \pm 0.00$ & $0.07 \pm 0.02$ \\
\hline $\operatorname{LOS}$ & $0.08 \pm 0.00$ & $0.06 \pm 0.00$ \\
\hline LOS & $0.08 \pm 0.00$ & $0.08 \pm 0.01$ \\
\hline LOS & $0.08 \pm 0.00$ & \multirow{3}{*}{ N.D. } \\
\hline $\operatorname{LOS}$ & $0.08 \pm 0.00$ & \\
\hline $\operatorname{LOS}$ & $0.08 \pm 0.00$ & \\
\hline LOS & $0.08 \pm 0.00$ & $0.10 \pm 0.03$ \\
\hline TOTAL & $0.93 \pm 0.02$ & $1.13 \pm 0.27$ \\
\hline
\end{tabular}

\begin{tabular}{|c|c|c|}
\hline Treatment 6 & $t=-1$ day & $\mathrm{t}=\mathbf{5}$ days \\
\hline$F F M$ & $0.11 \pm 0.00$ & $0.29 \pm 0.19$ \\
\hline$F F M$ & $0.11 \pm 0.00$ & $0.21 \pm 0.11$ \\
\hline$S U B$ & $0.12 \pm 0.00$ & $0.11 \pm 0.01$ \\
\hline$S U B$ & $0.12 \pm 0.00$ & $0.25 \pm 0.14$ \\
\hline$S U B$ & $0.12 \pm 0.00$ & $0.19 \pm 0.05$ \\
\hline$L O S$ & $0.08 \pm 0.00$ & $0.08 \pm 0.01$ \\
\hline LOS & $0.08 \pm 0.00$ & $0.07 \pm 0.00$ \\
\hline LOS & $0.08 \pm 0.00$ & $0.09 \pm 0.01$ \\
\hline LOS & $0.08 \pm 0.00$ & \multirow{3}{*}{ N.D. } \\
\hline$L O S$ & $0.08 \pm 0.00$ & \\
\hline LOS & $0.08 \pm 0.00$ & \\
\hline$L O S$ & $0.08 \pm 0.00$ & $0.09 \pm 0.01$ \\
\hline TOTAL & $1.10 \pm 0.03$ & $1.38 \pm 0.08$ \\
\hline
\end{tabular}

\begin{tabular}{|c|c|c|}
\hline Treatment 7 & $t=-1$ day & $\mathrm{t}=5$ days \\
\hline$P M M+F$ & $4.27 \pm 0.09$ & $0.03 \pm 0.00$ \\
\hline$P M M$ & $0.03 \pm 0.09$ & $0.03 \pm 0.00$ \\
\hline$S U B$ & $0.12 \pm 0.00$ & $0.11 \pm 0.01$ \\
\hline$S U B$ & $0.12 \pm 0.00$ & $0.17 \pm 0.07$ \\
\hline$S U B$ & $0.12 \pm 0.00$ & $0.29 \pm 0.18$ \\
\hline LOS & $0.08 \pm 0.00$ & $0.07 \pm 0.01$ \\
\hline LOS & $0.08 \pm 0.00$ & $0.08 \pm 0.02$ \\
\hline LOS & $0.08 \pm 0.00$ & $0.08 \pm 0.01$ \\
\hline $\operatorname{LOS}$ & $0.08 \pm 0.00$ & \multirow{3}{*}{ N.D. } \\
\hline LOS & $0.08 \pm 0.00$ & \\
\hline LOS & $0.08 \pm 0.00$ & \\
\hline LOS & $0.08 \pm 0.00$ & $0.08 \pm 0.01$ \\
\hline TOTAL & $5.17 \pm 0.20$ & $0.94 \pm 0.23$ \\
\hline
\end{tabular}

\begin{tabular}{|c|c|c|}
\hline Treatment 8 & $t=-1$ day & $\mathrm{t}=5$ days \\
\hline$F F M+F$ & $5.02 \pm 0.06$ & $0.29 \pm 0.04$ \\
\hline$F F M$ & $0.11 \pm 0.06$ & $0.10 \pm 0.00$ \\
\hline$S U B$ & $0.12 \pm 0.00$ & $0.15 \pm 0.05$ \\
\hline$S U B$ & $0.12 \pm 0.00$ & $0.14 \pm 0.03$ \\
\hline$S U B$ & $0.12 \pm 0.00$ & $0.35 \pm 0.24$ \\
\hline $\operatorname{LOS}$ & $0.08 \pm 0.00$ & $0.06 \pm 0.00$ \\
\hline LOS & $0.08 \pm 0.00$ & $0.06 \pm 0.00$ \\
\hline LOS & $0.08 \pm 0.00$ & $0.10 \pm 0.02$ \\
\hline LOS & $0.08 \pm 0.00$ & \multirow{3}{*}{ N.D. } \\
\hline LOS & $0.08 \pm 0.00$ & \\
\hline LOS & $0.08 \pm 0.00$ & \\
\hline $\operatorname{LOS}$ & $0.08 \pm 0.00$ & $0.08 \pm 0.00$ \\
\hline TOTAL & $6.01 \pm 0.14$ & $1.34 \pm 0.24$ \\
\hline
\end{tabular}

Peer-reviewed, unedited version of the manuscript of Rees et al. (2020) published by Applied Geochemistry: 
Fig. S18: $0.5 \mathrm{M} \mathrm{K}_{2} \mathrm{SO}_{4}$ extractable fertilizer-derived mineral $\mathrm{N}\left(\mathrm{g} \mathrm{m}^{-2}\right)$ in Treatments 7 and 8, initially applied prior to leaching $\left(\mathrm{t}=-\mathbf{- 1}\right.$ day) and experimentally determined from ${ }^{15} \mathrm{NO}_{3}$ measurements after a 4-h intense rainfall and a resting period of 5 days $(t=5$ days). PMM: peat-mineral mix; PMM $+F$ : peat-mineral mix with fertilizer; FFM: forest floor mineral material; FFM + F: forest floor mineral material with fertilizer; SUB: blended B/C horizons of sandy subsoil; LOS: lean oil sand. N.A.: Not applicable. N.D: Not determined. Results are presented as mean \pm standard error ( 3 replicates). A color code is used to display the values: the higher the mean value, the darker the background of the cell.

\begin{tabular}{|c|c|c|}
\hline Treatment 7 & $t=-1$ day & $t=5$ days \\
\hline$P M M+F$ & $5.0 \pm 0.0$ & $3.3 \pm 0.0$ \\
\hline$P M M$ & $0.0 \pm 0.0$ & $1.3 \pm 0.2$ \\
\hline$S U B$ & $0.0 \pm 0.0$ & $0.0 \pm 0.0$ \\
\hline$S U B$ & $0.0 \pm 0.0$ & $0.0 \pm 0.1$ \\
\hline$S U B$ & $0.0 \pm 0.0$ & $0.0 \pm 0.2$ \\
\hline LOS & $0.0 \pm 0.0$ & $0.0 \pm 0.0$ \\
\hline LOS & $0.0 \pm 0.0$ & \multirow{6}{*}{ N.D. } \\
\hline LOS & $0.0 \pm 0.0$ & \\
\hline LOS & $0.0 \pm 0.0$ & \\
\hline LOS & $0.0 \pm 0.0$ & \\
\hline LOS & $0.0 \pm 0.0$ & \\
\hline LOS & $0.0 \pm 0.0$ & \\
\hline TOTAL & $5.0 \pm 0.0$ & $4.6 \pm 0.3$ \\
\hline
\end{tabular}

\begin{tabular}{|c|c|c|}
\hline Treatment 8 & $t=-1$ day & $t=5$ days \\
\hline$F F M+F$ & $5.0 \pm 0.0$ & $2.4 \pm 0.2$ \\
\hline$F F M$ & $0.0 \pm 0.0$ & $1.3 \pm 0.1$ \\
\hline$S U B$ & $0.0 \pm 0.0$ & $0.0 \pm 0.0$ \\
\hline$S U B$ & $0.0 \pm 0.0$ & $0.0 \pm 0.1$ \\
\hline$S U B$ & $0.0 \pm 0.0$ & $0.0 \pm 0.2$ \\
\hline LOS & $0.0 \pm 0.0$ & $0.0 \pm 0.1$ \\
\hline $\operatorname{LOS}$ & $0.0 \pm 0.0$ & \multirow{6}{*}{ N.D. } \\
\hline LOS & $0.0 \pm 0.0$ & \\
\hline LOS & $0.0 \pm 0.0$ & \\
\hline LOS & $0.0 \pm 0.0$ & \\
\hline LOS & $0.0 \pm 0.0$ & \\
\hline LOS & $0.0 \pm 0.0$ & \\
\hline TOTAL & $5 \pm 0$ & $3.7 \pm 0.4$ \\
\hline
\end{tabular}




\section{Rate of organic matter mineralization}

Fig. S19: Evolution of the rate of organic matter mineralization (respired $\mathrm{CO}_{2}$ related to the initial soil organic carbon content) over the course of the 25-day incubation experiment, with peat-mineral mix without (PMM) or with (PMM + F) initial fertilizer addition and forest floor mineral material without (FFM) or with (FFM + F) initial fertilizer addition. Error bars represent standard errors (2 to 4 replicates). It is assumed that the $\mathrm{CO}_{2}$ accumulated in the incubation jars came from the mineralization of organic matter and not from the dissolution of soil carbonate.

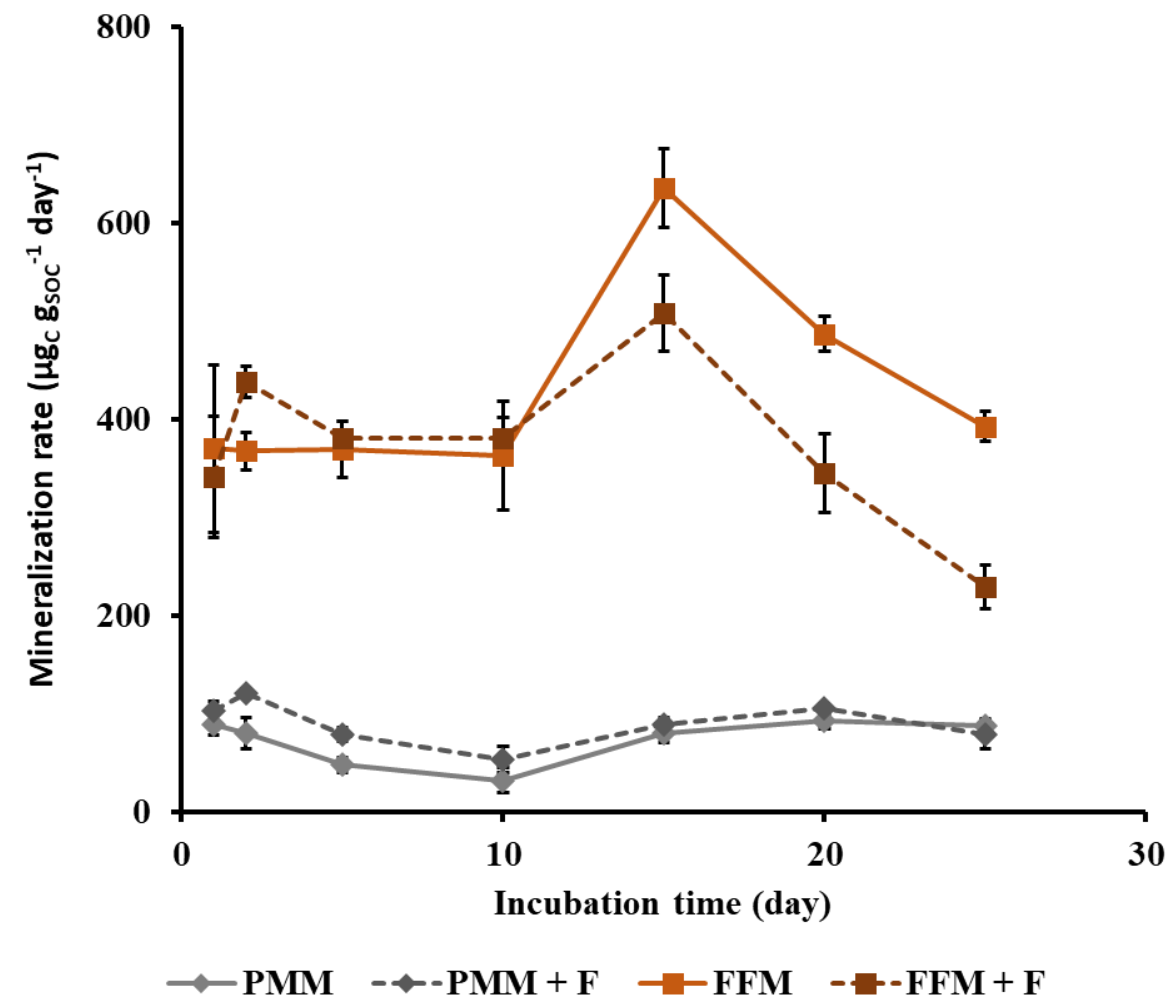




\section{Experimental and modelled distribution of water and nutrients in soil profiles}

Fig. S20a: Comparison between experimental and simulated data describing the amount of water present $\left(1 \mathrm{~m}^{-2}\right.$, i.e. $\left.\mathrm{mm}\right)$ in the different soil profiles at the start $(\mathrm{t}=-1 \mathrm{~d})$ and at the end $(\mathrm{t}=+5 \mathrm{~d})$ of the column leaching experiment. Error bars represent standard errors (3 replicates). Simulation 1: no possibility of nutrient exchange between the liquid phase and the solid phase. Simulation 2: possibility of nutrient sorption/desorption, as determined in the nutrient sorption experiment. Simulation 3: possibility of nutrient mobilization/immobilization in PMM and FFM, based on the results of the incubation experiment.

Treatment 1

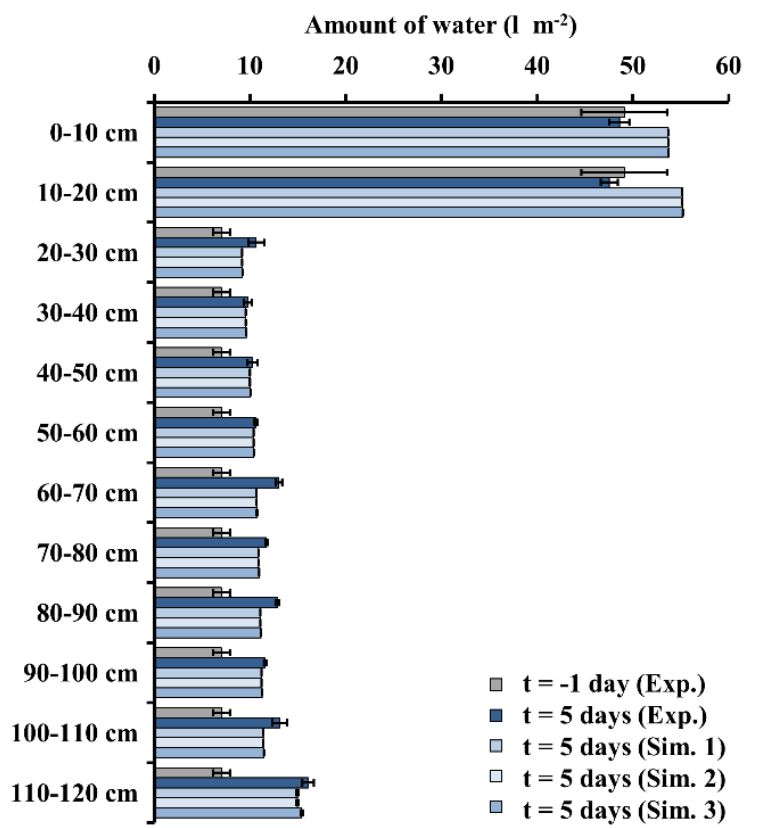

Treatment 3

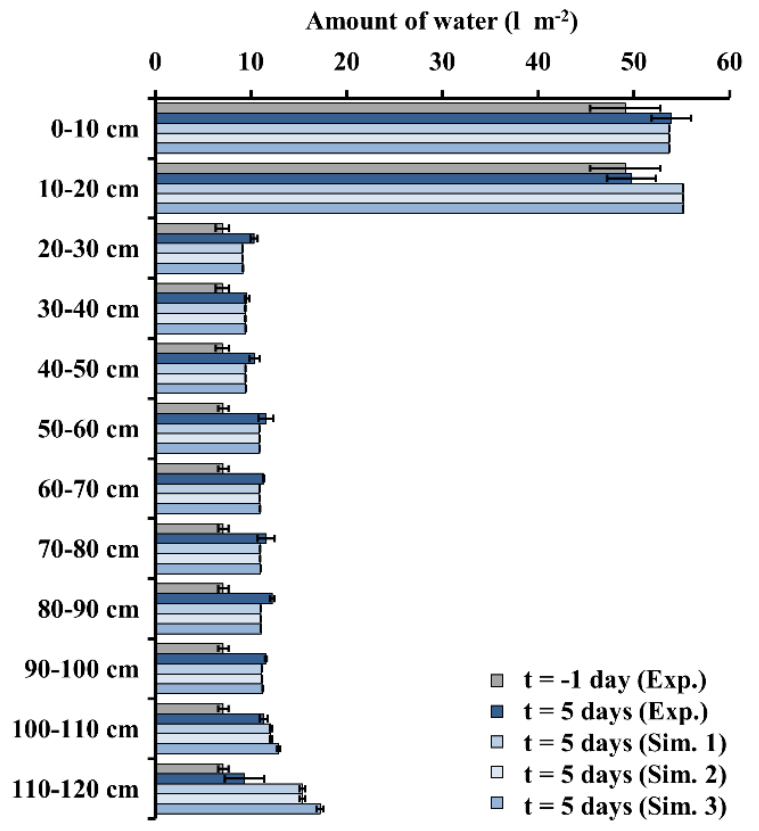

Treatment 2

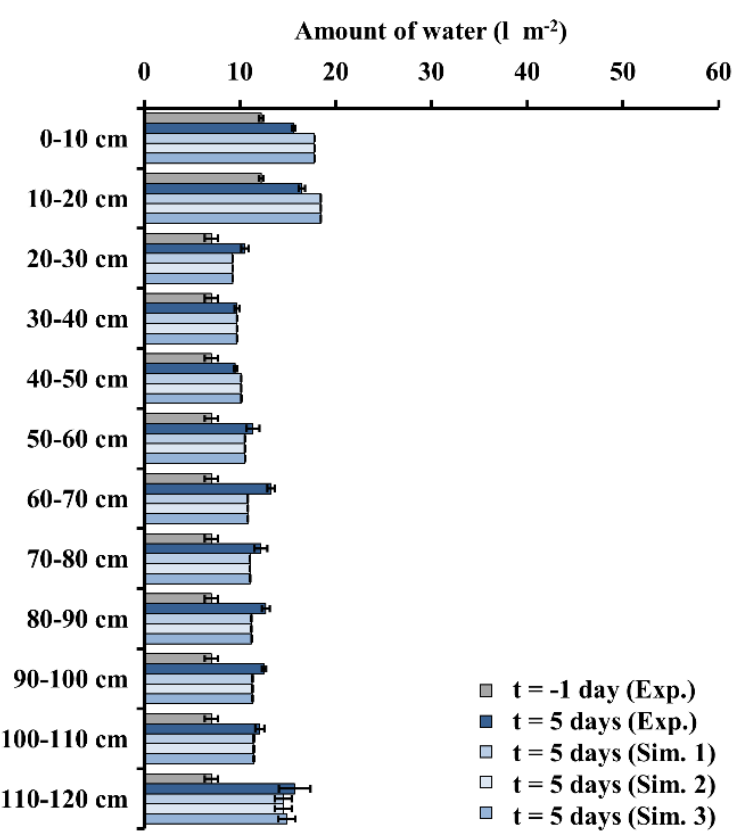

Treatment 4

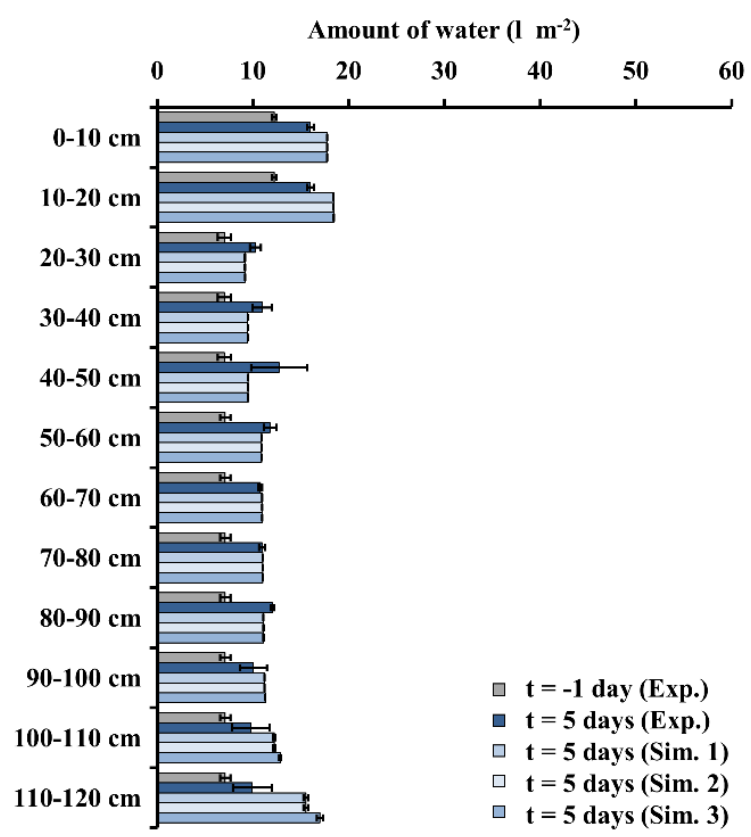


Treatment 5

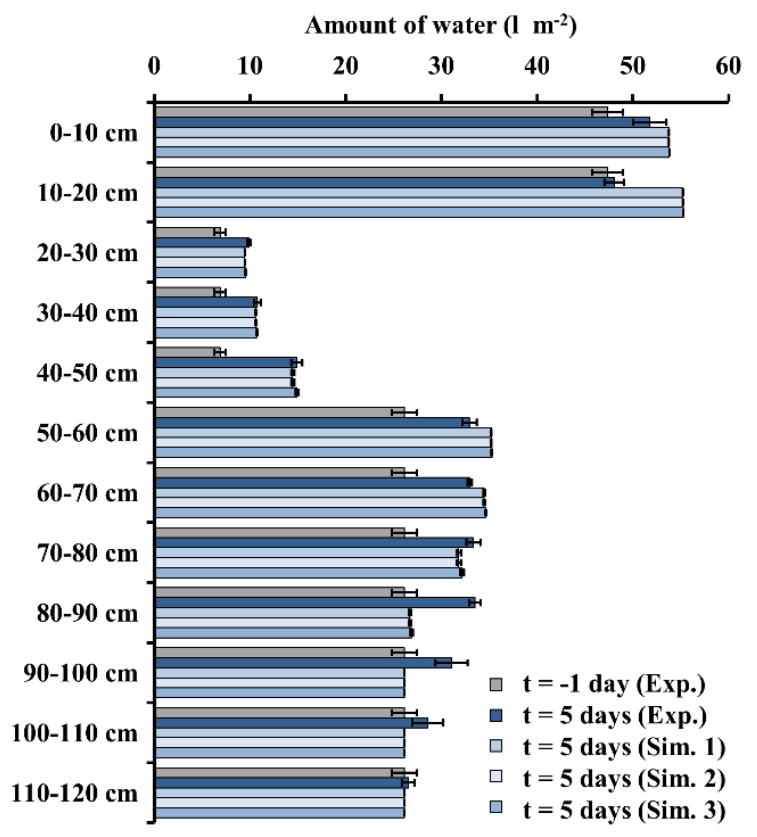

Treatment 7

Amount of water $\left(1 \mathrm{~m}^{-2}\right)$

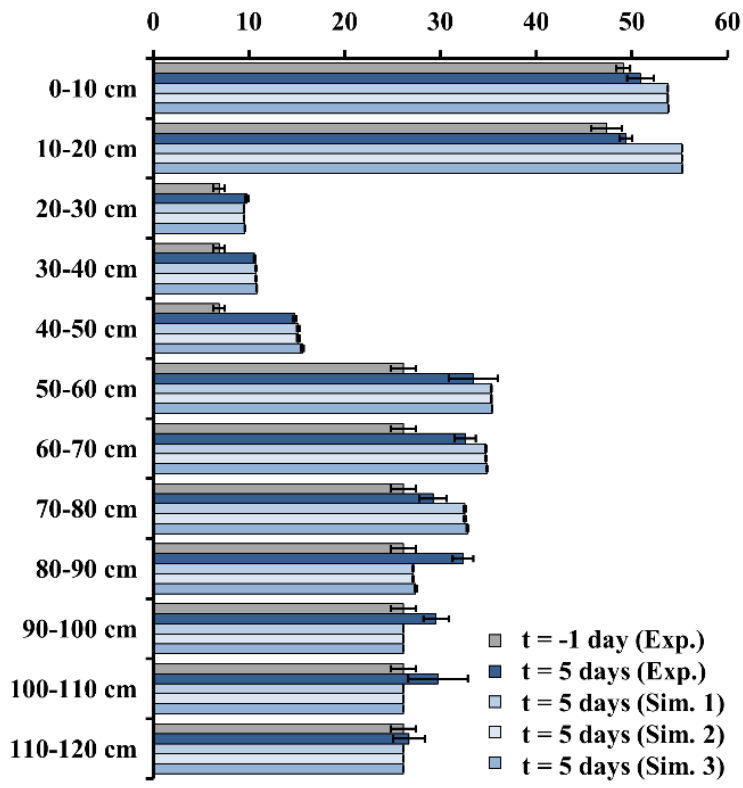

Treatment 6

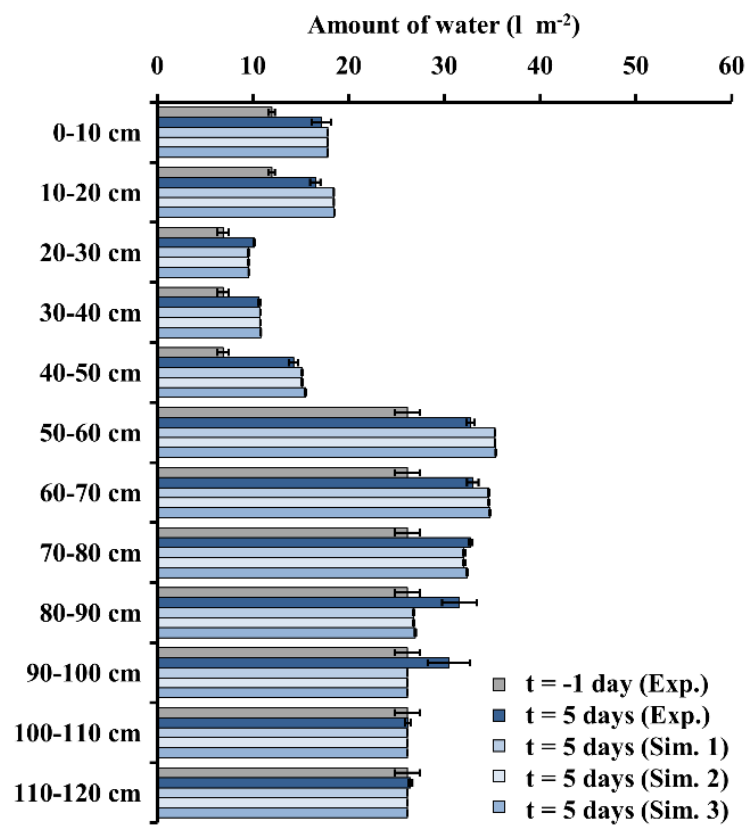

Treatment 8

Amount of water $\left(\mathrm{l} \mathrm{m}^{-2}\right)$

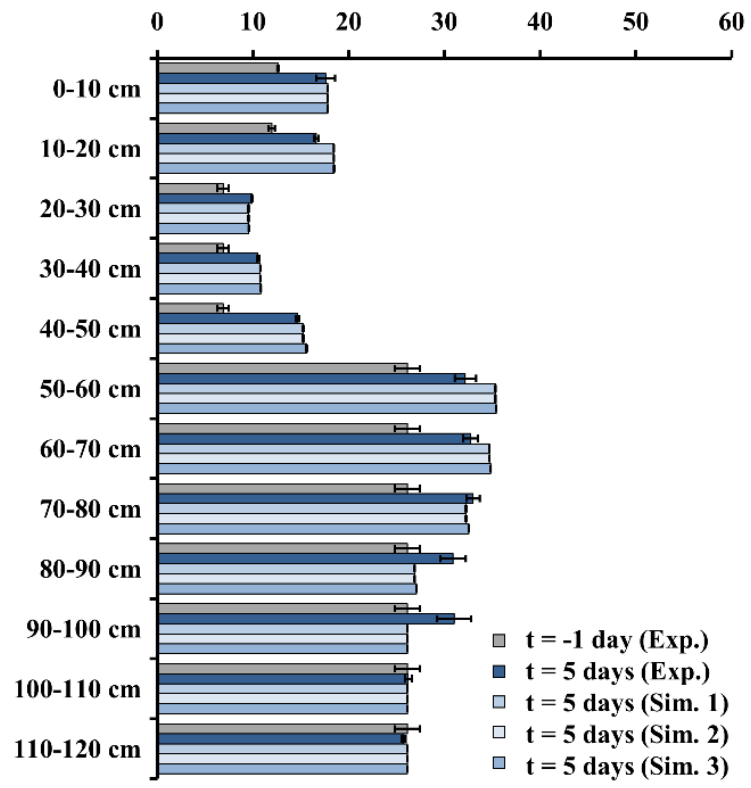


Fig. S20b: Comparison between experimental and simulated data describing the amount of $0.5 \mathrm{M} \mathrm{K} \mathrm{K}_{2} \mathrm{SO}_{4}$ extractable mineral $N$ present in the different soil profiles at the start $(t=-1 d)$ and at the end $(t=+5 d)$ of the column leaching experiment. Data at $+5 \mathrm{~d}$ between 80 and $110 \mathrm{~cm}$ were not experimentally determined. Error bars represent standard errors ( 3 replicates). Simulation 1: no possibility of nutrient exchange between the liquid phase and the solid phase. Simulation 2: possibility of nutrient sorption/desorption, as determined in the nutrient sorption experiment. Simulation 3: possibility of nutrient mobilization/immobilization in PMM and FFM, based on the results of the incubation experiment.

Treatment 1

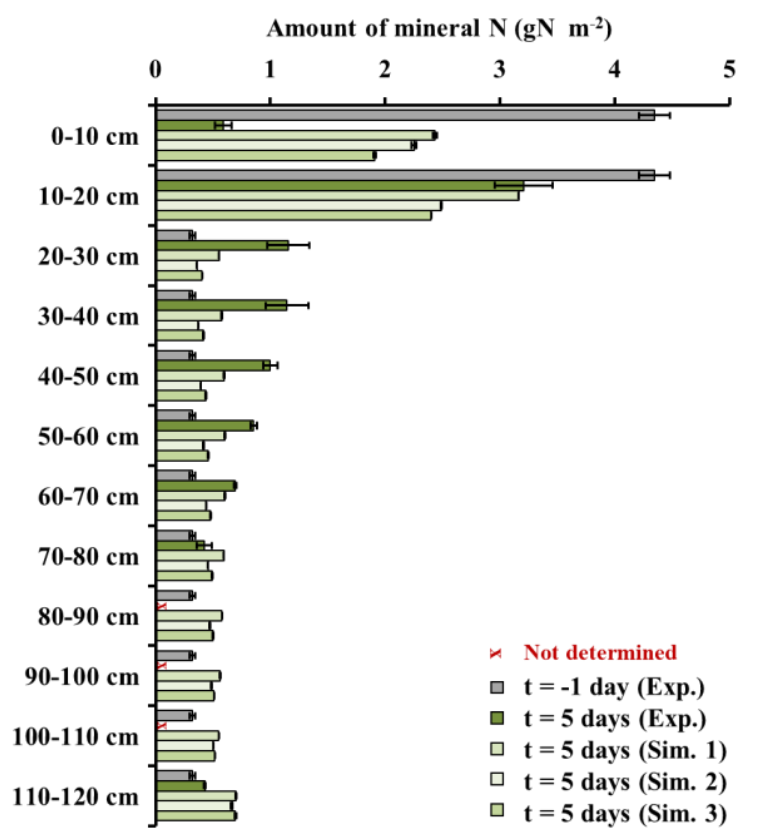

Treatment 3

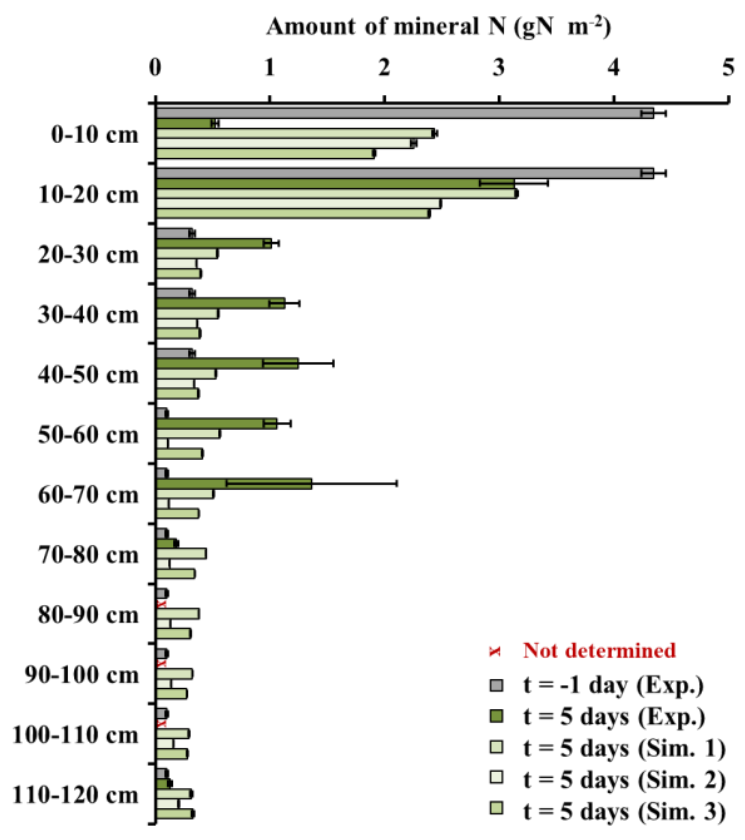

Treatment 2

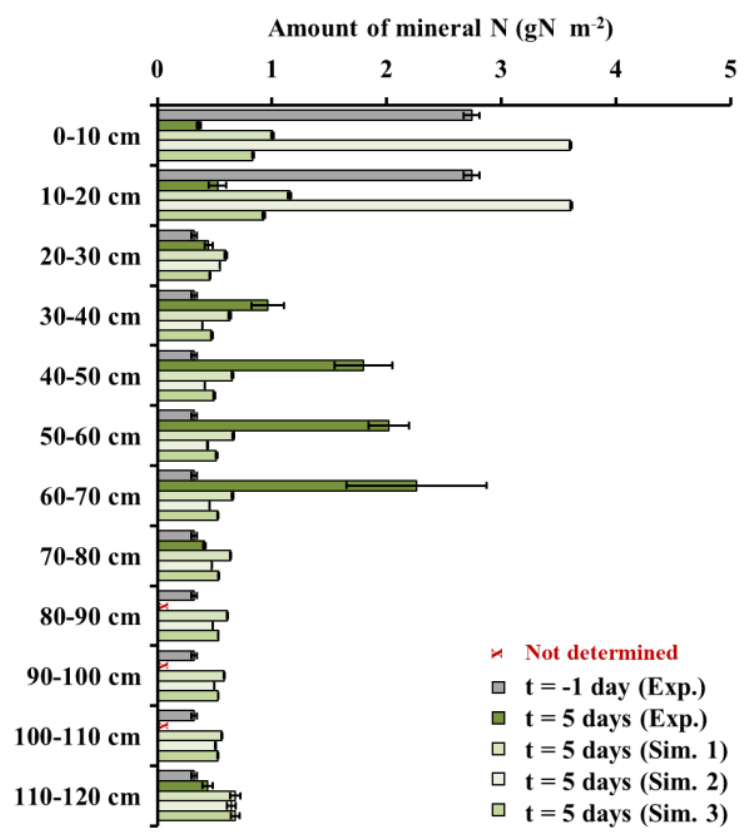

Treatment 4

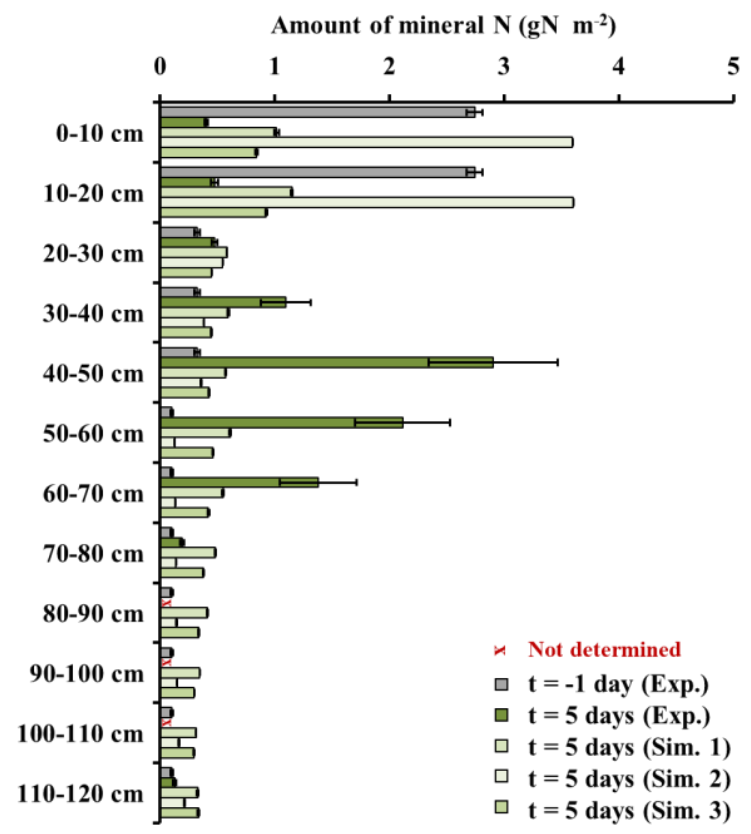


Treatment 5

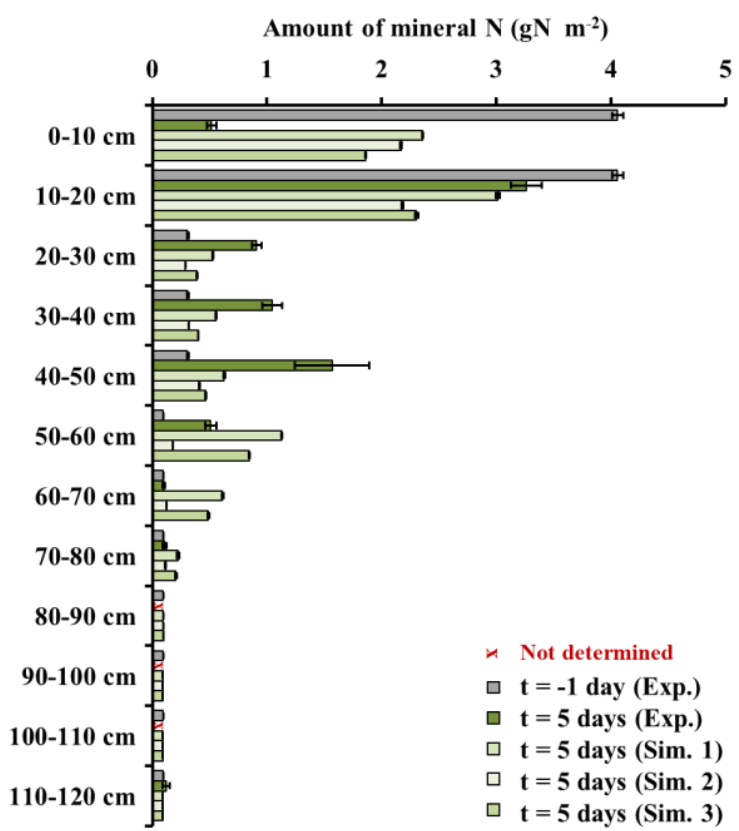

Treatment 7

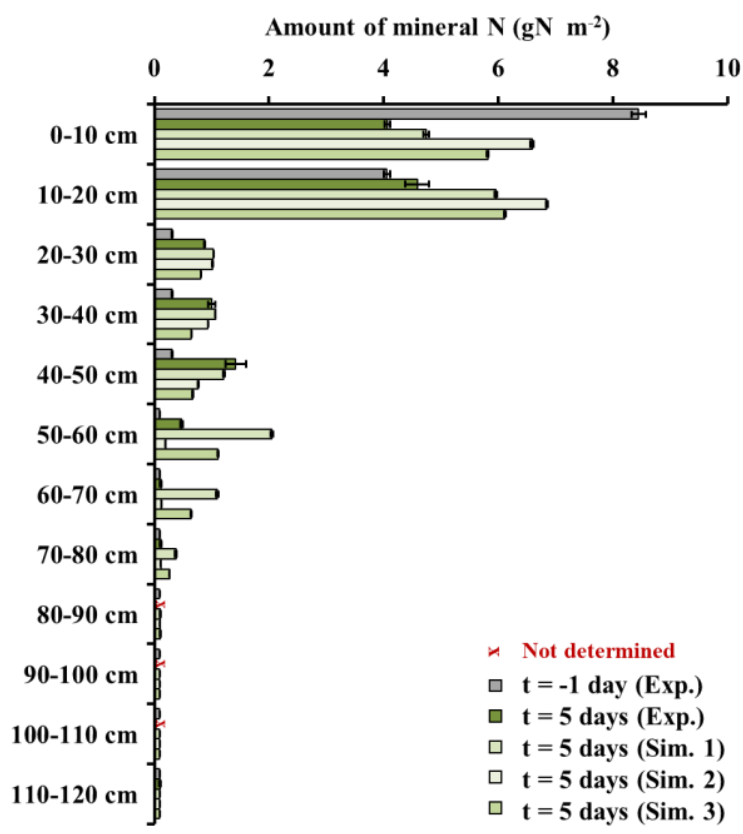

Treatment 6

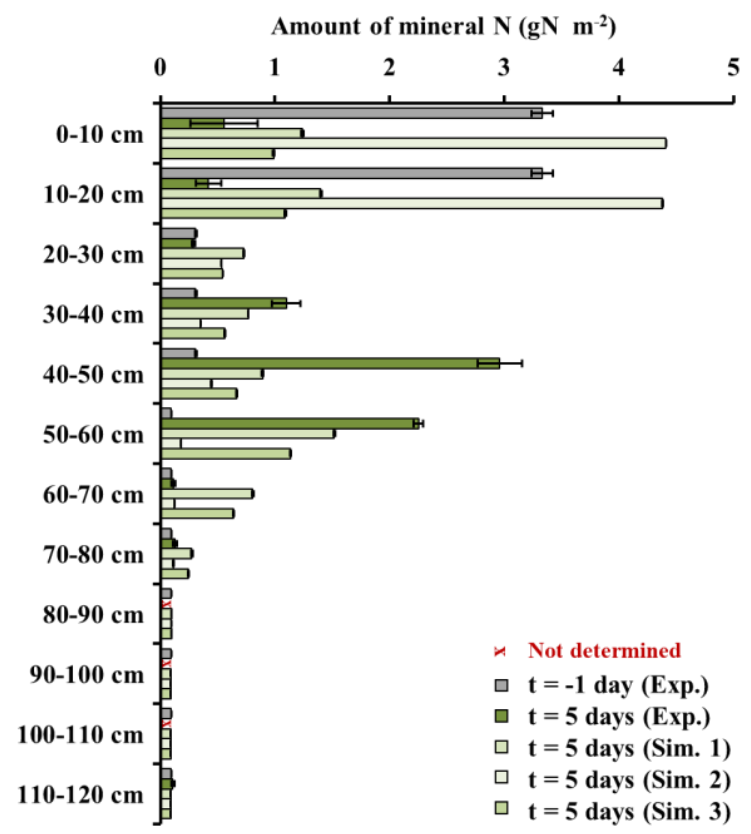

Treatment 8

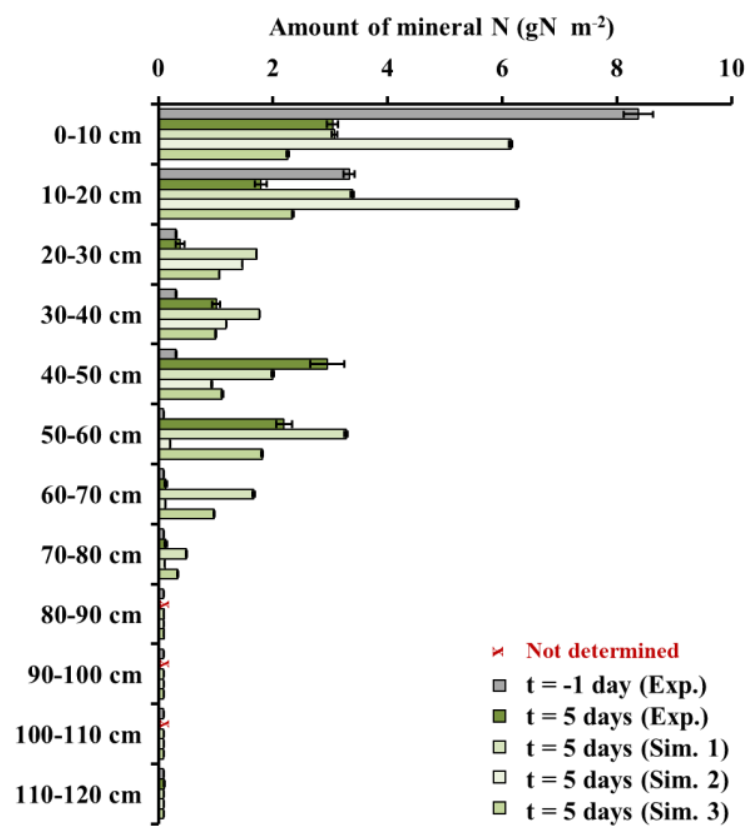


Fig. S20c: Comparison between experimental and simulated data describing the amount $0.5 \mathrm{M} \mathrm{K}_{2} \mathrm{SO}_{4}$ extractable $P$ present in the different soil profiles at the start $(t=-1 d)$ and at the end $(t=+5 d)$ of the column leaching experiment. Data at $+5 \mathrm{~d}$ between 80 and $110 \mathrm{~cm}$ were not experimentally determined. Error bars represent standard errors (3 replicates). Simulation 1: no possibility of nutrient exchange between the liquid phase and the solid phase. Simulation 2: possibility of nutrient sorption/desorption, as determined in the nutrient sorption experiment. Simulation 3: possibility of nutrient mobilization/immobilization in PMM and FFM, based on the results of the incubation experiment.

Treatment 1

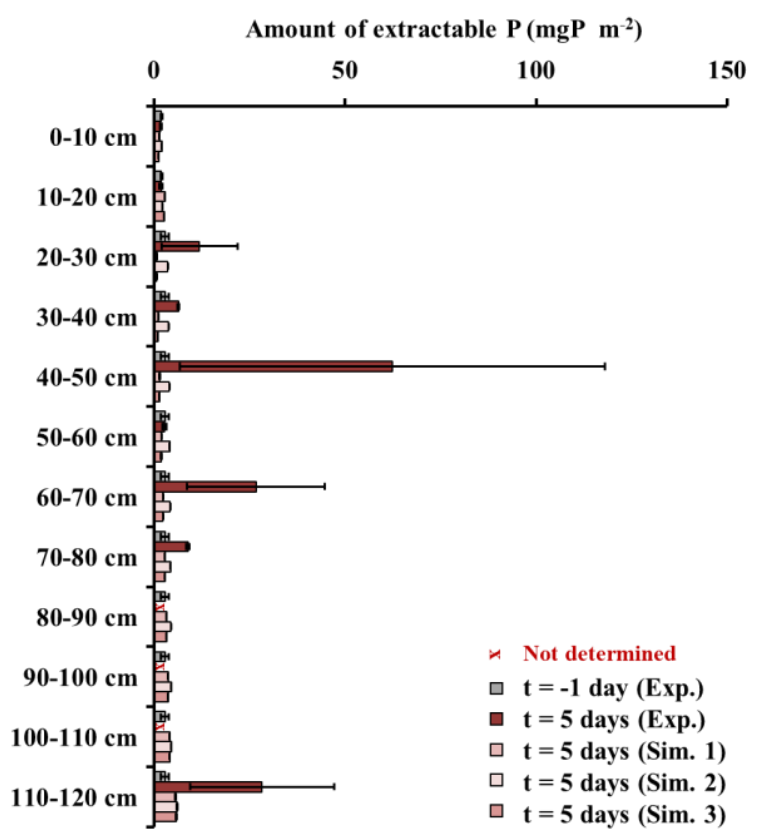

Treatment 3

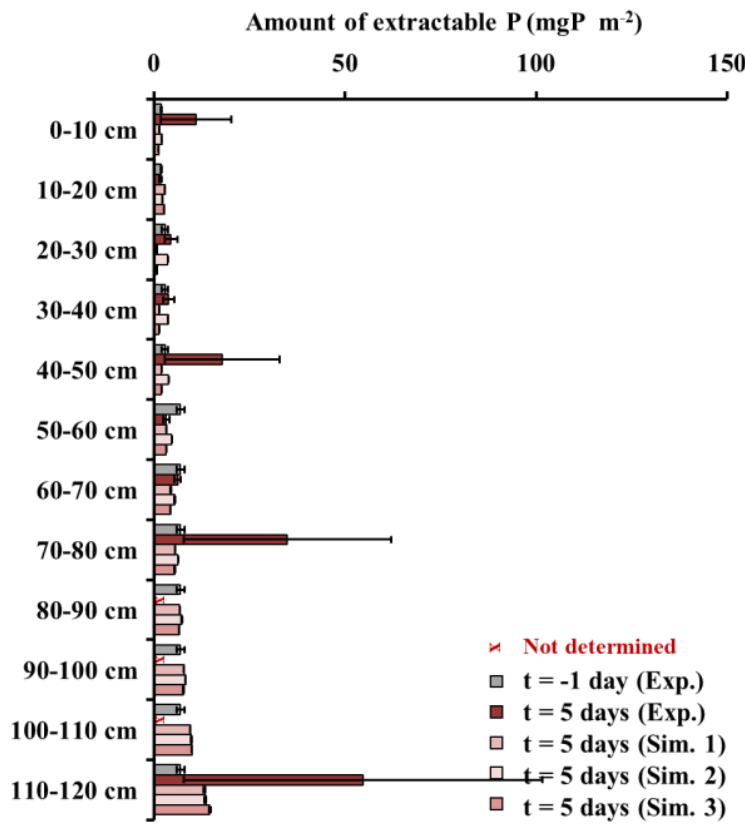

Treatment 2

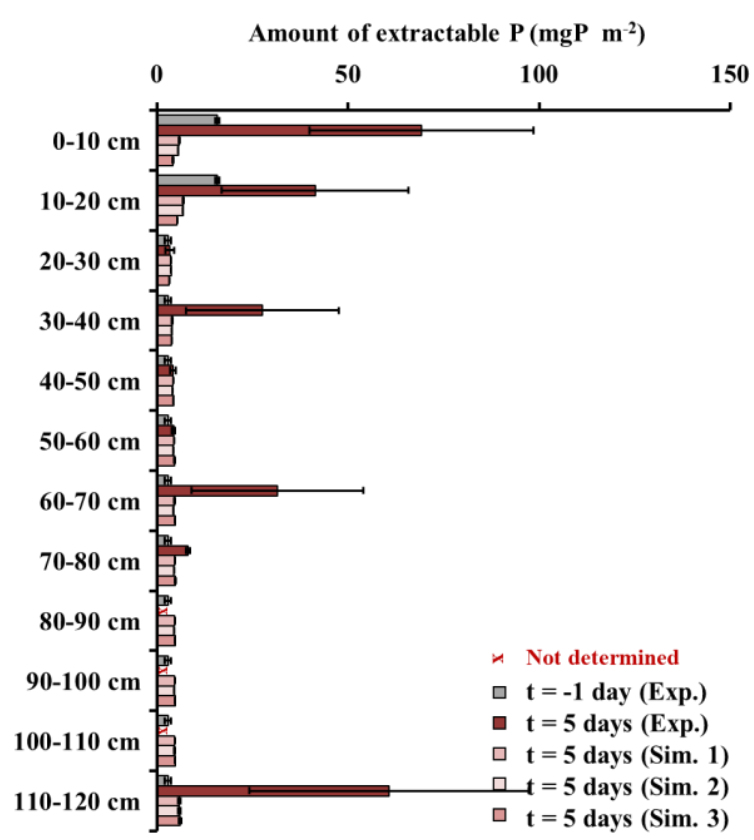

Treatment 4

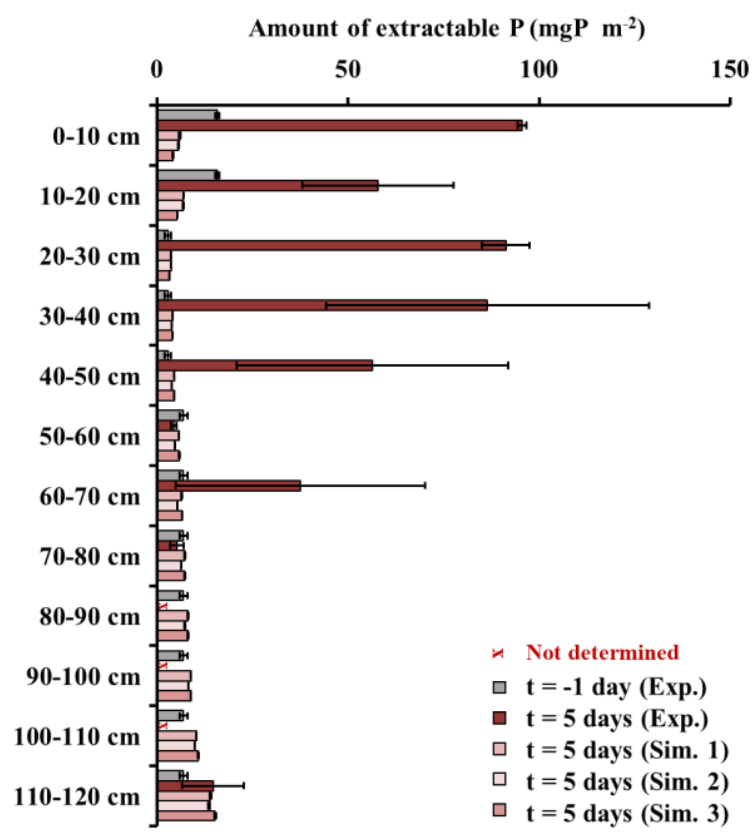


Treatment 5

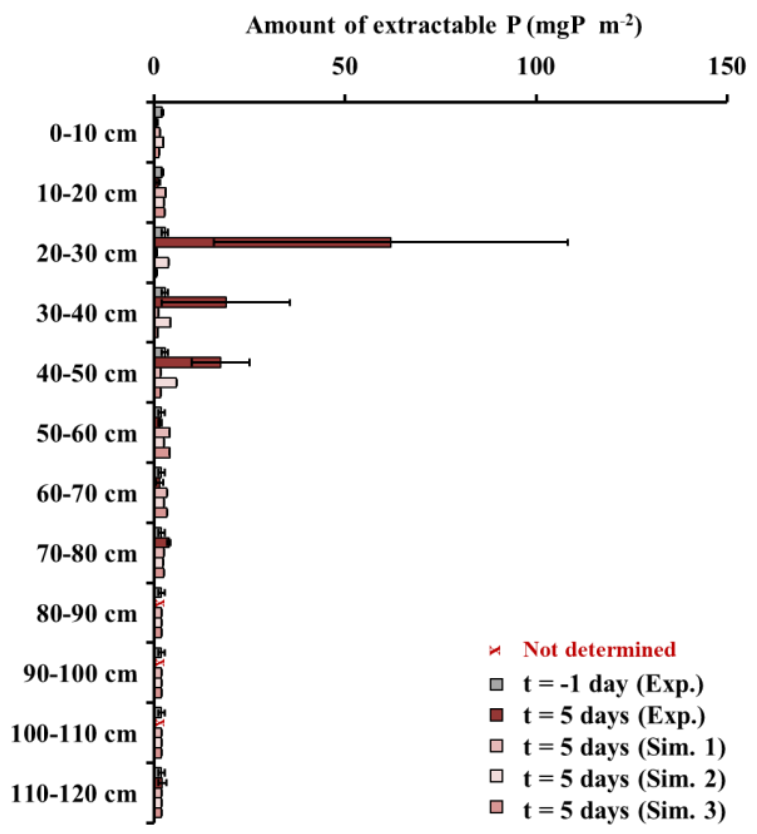

Treatment 7

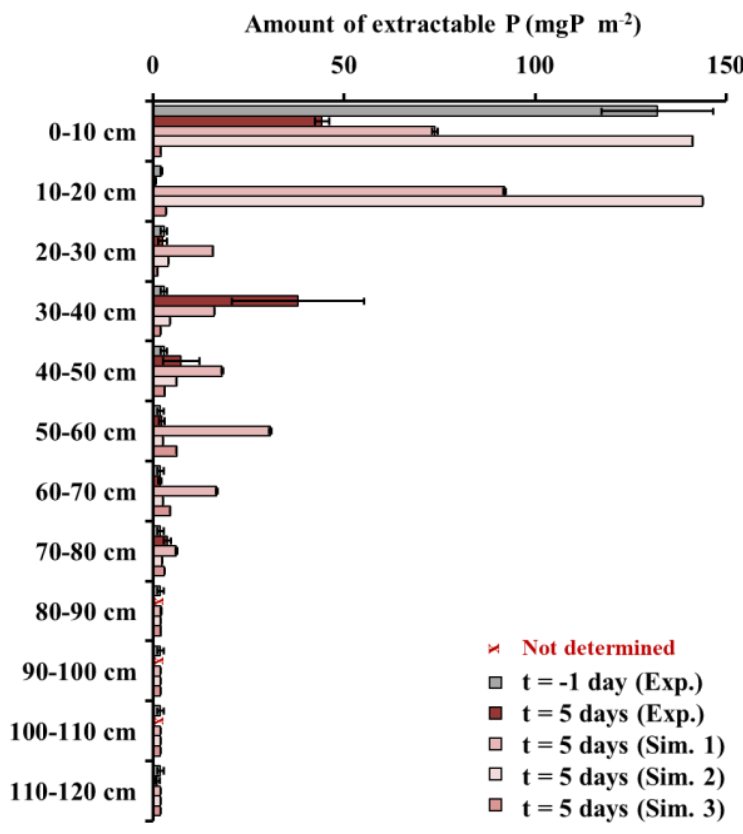

Treatment 6

Amount of extractable $\mathrm{P}\left(\mathrm{mgP} \mathbf{m}^{-2}\right)$

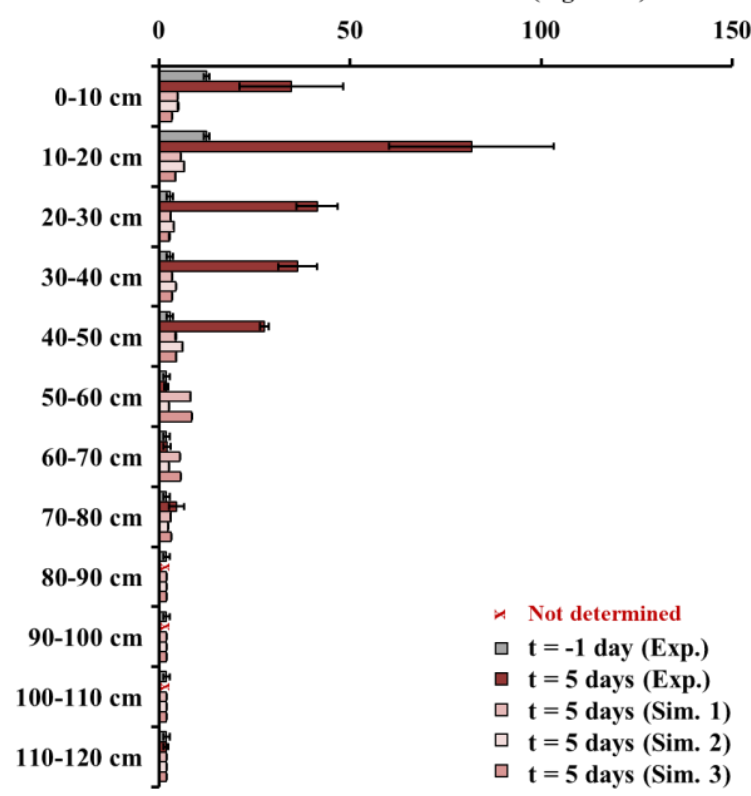

Treatment 8

Amount of extractable $\mathrm{P}\left(\mathrm{mgP} \mathbf{~ m}^{-2}\right)$

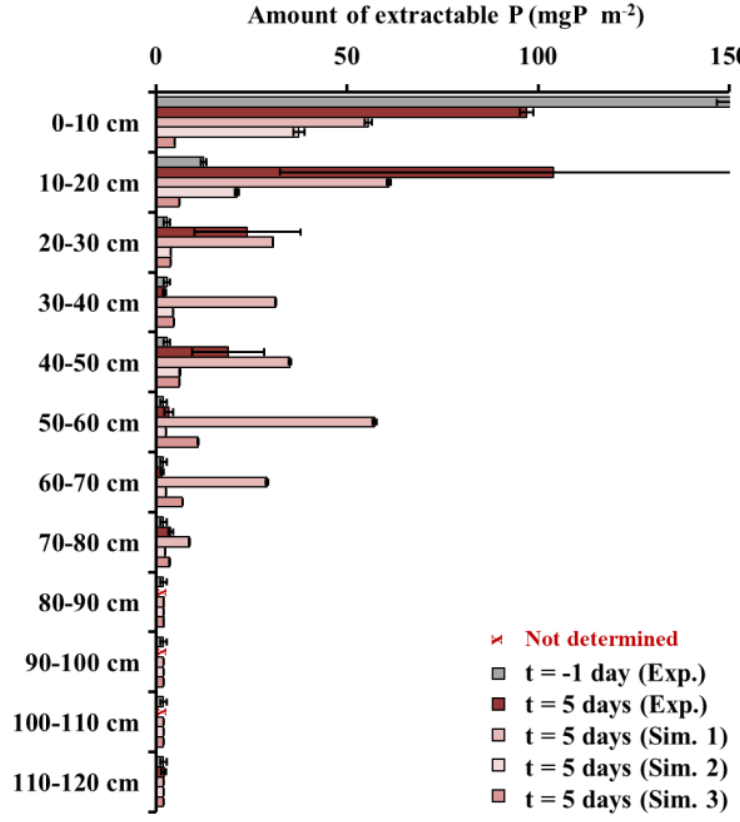




\section{Estimations of possible water and nutrient losses by leaching}

Fig. S21: Simulations of soil mineral $N$ distribution and calculations of the net losses of water and mineral $\mathrm{N}$ at $120 \mathrm{~cm}$ depth for various times between $\mathbf{0}$ and 100 days following the start of the rainfall for each reclaimed soil profile.

- Test 1 corresponds to the experimental conditions set in the column leaching experiment.

- Test 2 is similar to Test 1, but allows free drainage at the bottom of the columns.

- Test 3 is similar to Test 2, but distributes the rainfall event over a period 10 times longer (35h instead of $3.5 \mathrm{~h}$ ), which corresponds to the actual rate of precipitation from the average maximal annual rainfall event recorded in Fort McMurray's weather station between 2001 and 2015. 


\section{Treatment 1}

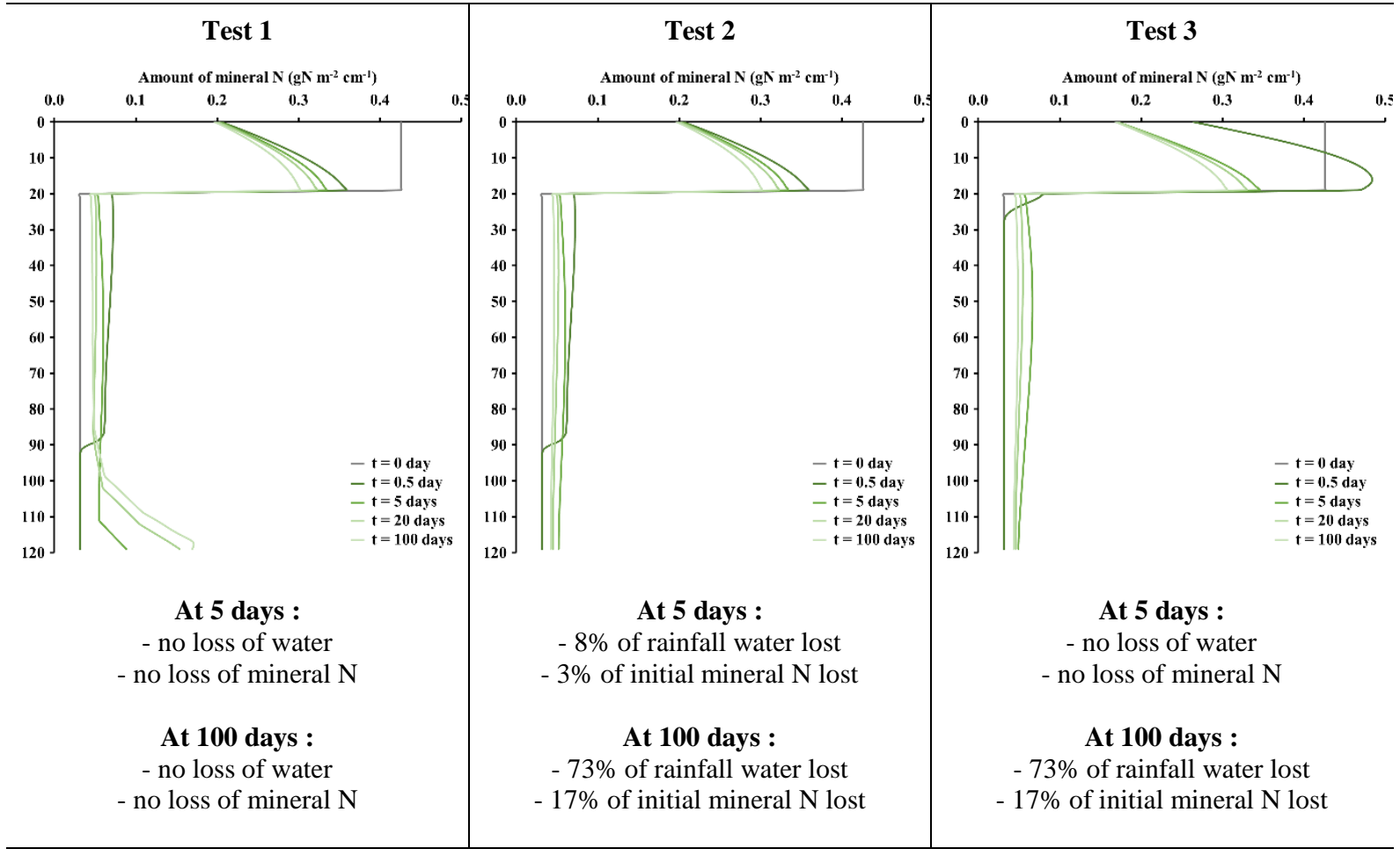

\section{Treatment 2}

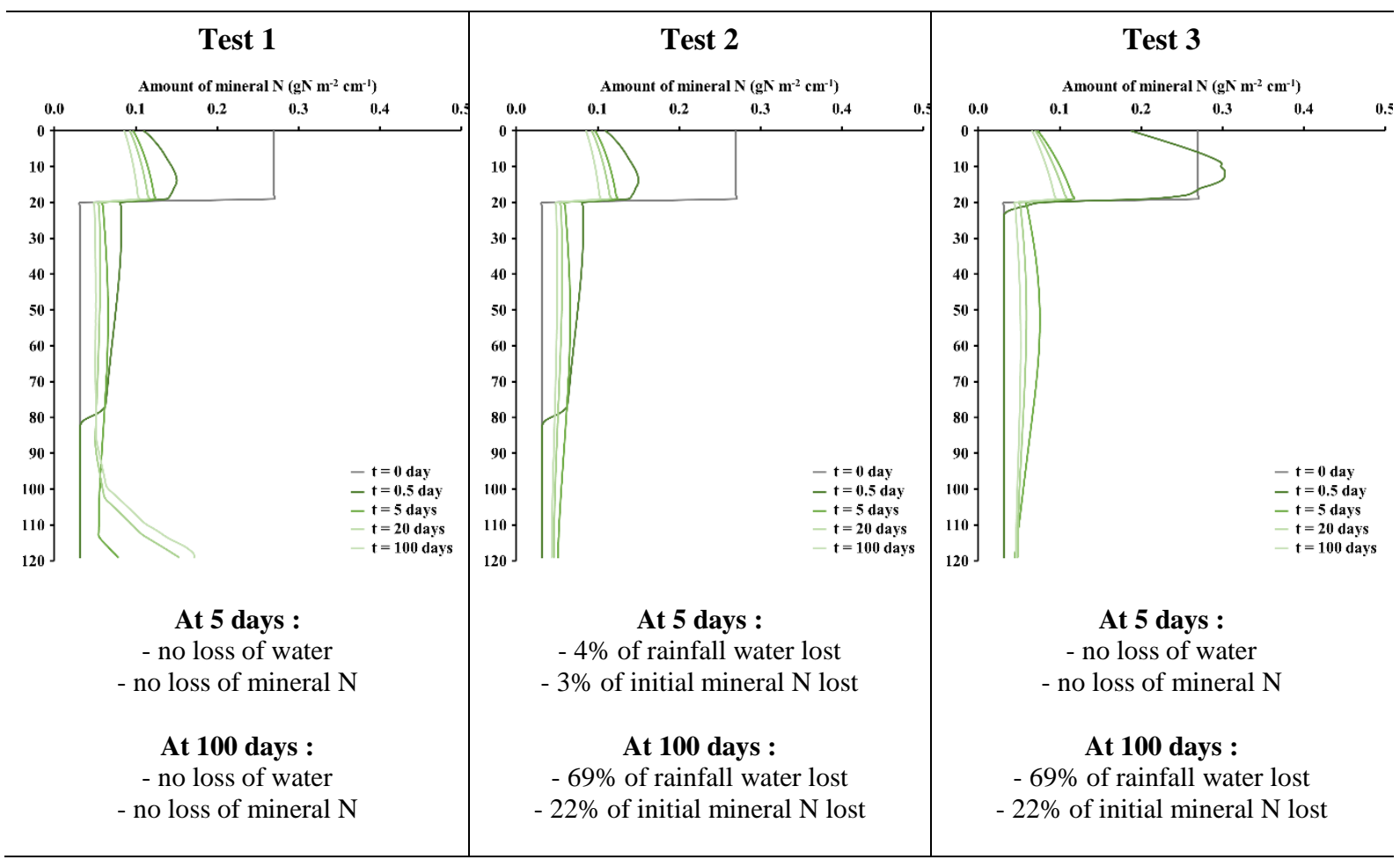

Peer-reviewed, unedited version of the manuscript of Rees et al. (2020) published by Applied Geochemistry: 


\section{Treatment 3}

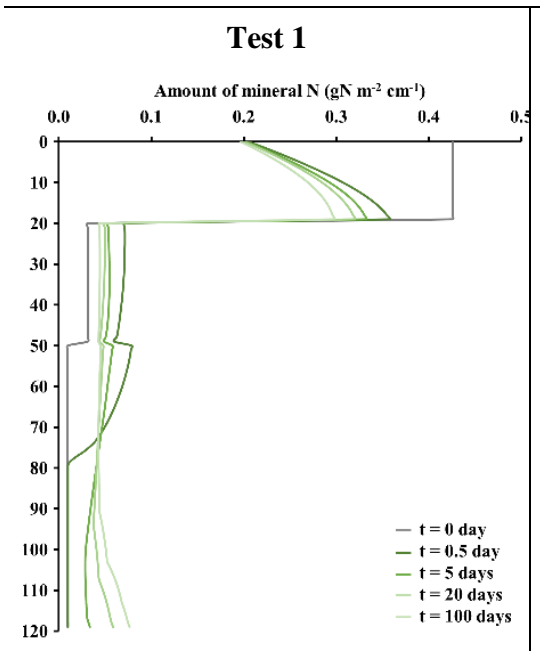

At 5 days :

- no loss of water

- no loss of mineral N

At 100 days :

- no loss of water

- no loss of mineral $\mathrm{N}$

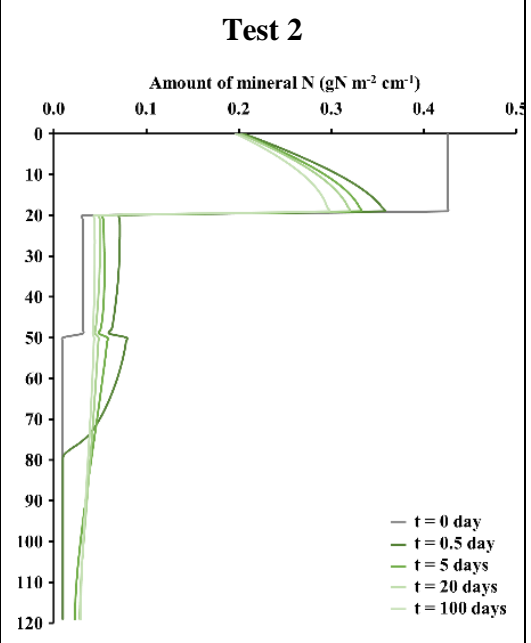

At 5 days :

$-8 \%$ of rainfall water lost

$-2 \%$ of initial mineral $\mathrm{N}$ los

At 100 days :

$-75 \%$ of rainfall water lost

$-11 \%$ of initial mineral $\mathrm{N}$ lost
Test 3

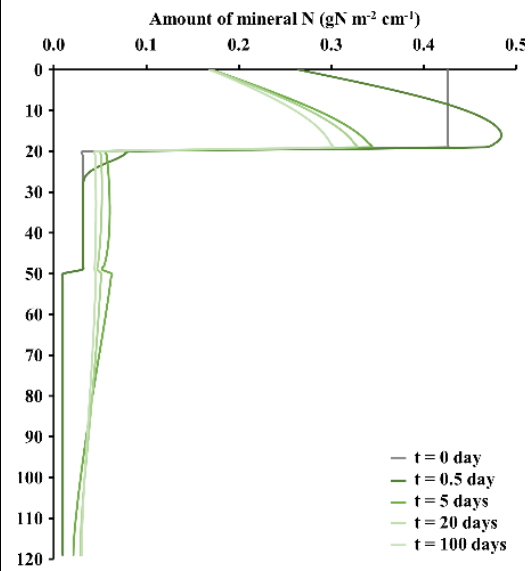

At 5 days :

- no loss of water

- no loss of mineral $\mathrm{N}$

\section{At 100 days :}

$-75 \%$ of rainfall water lost $-11 \%$ of initial mineral $\mathrm{N}$ lost

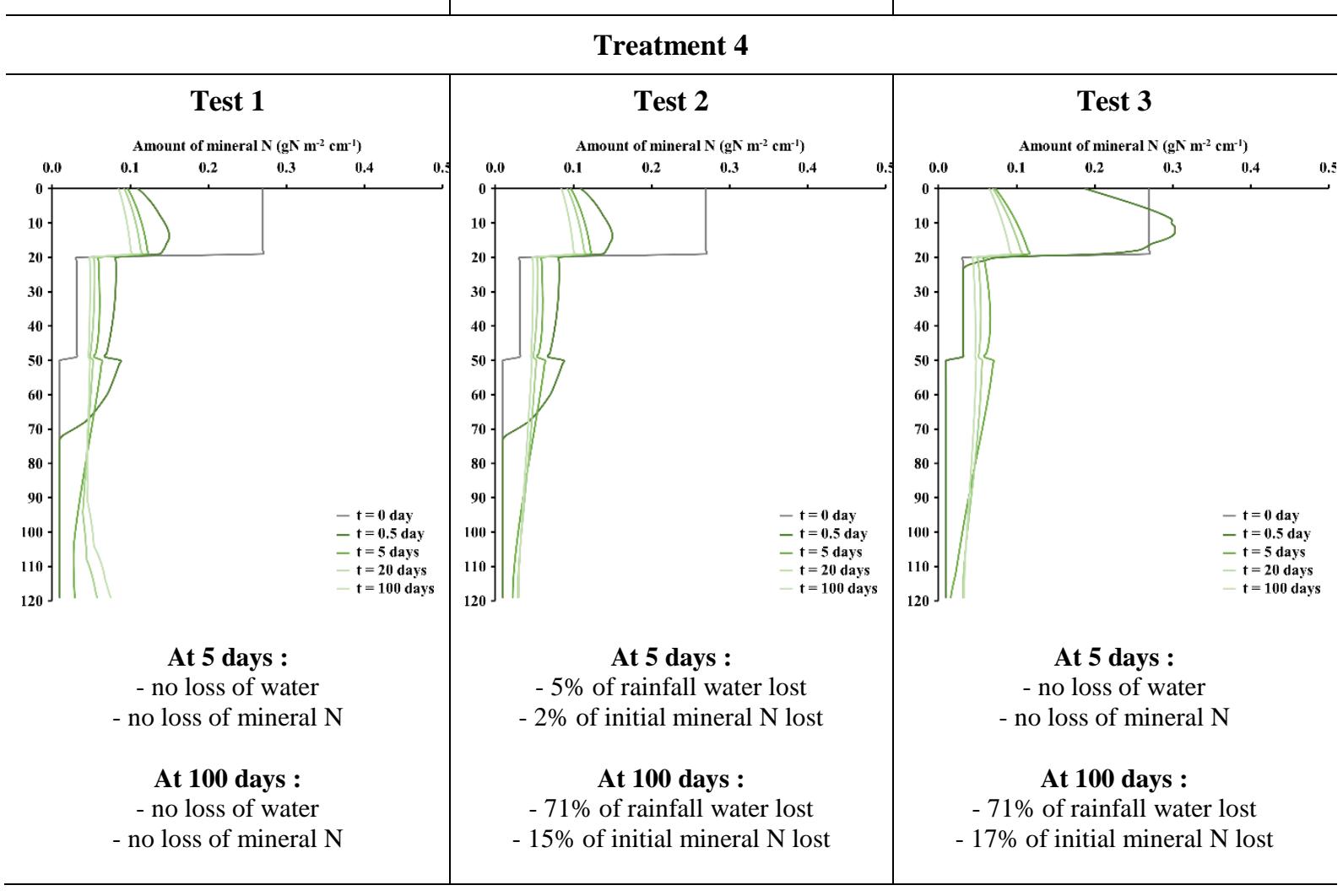

Peer-reviewed, unedited version of the manuscript of Rees et al. (2020) published by Applied Geochemistry: 


\section{Treatment 5}

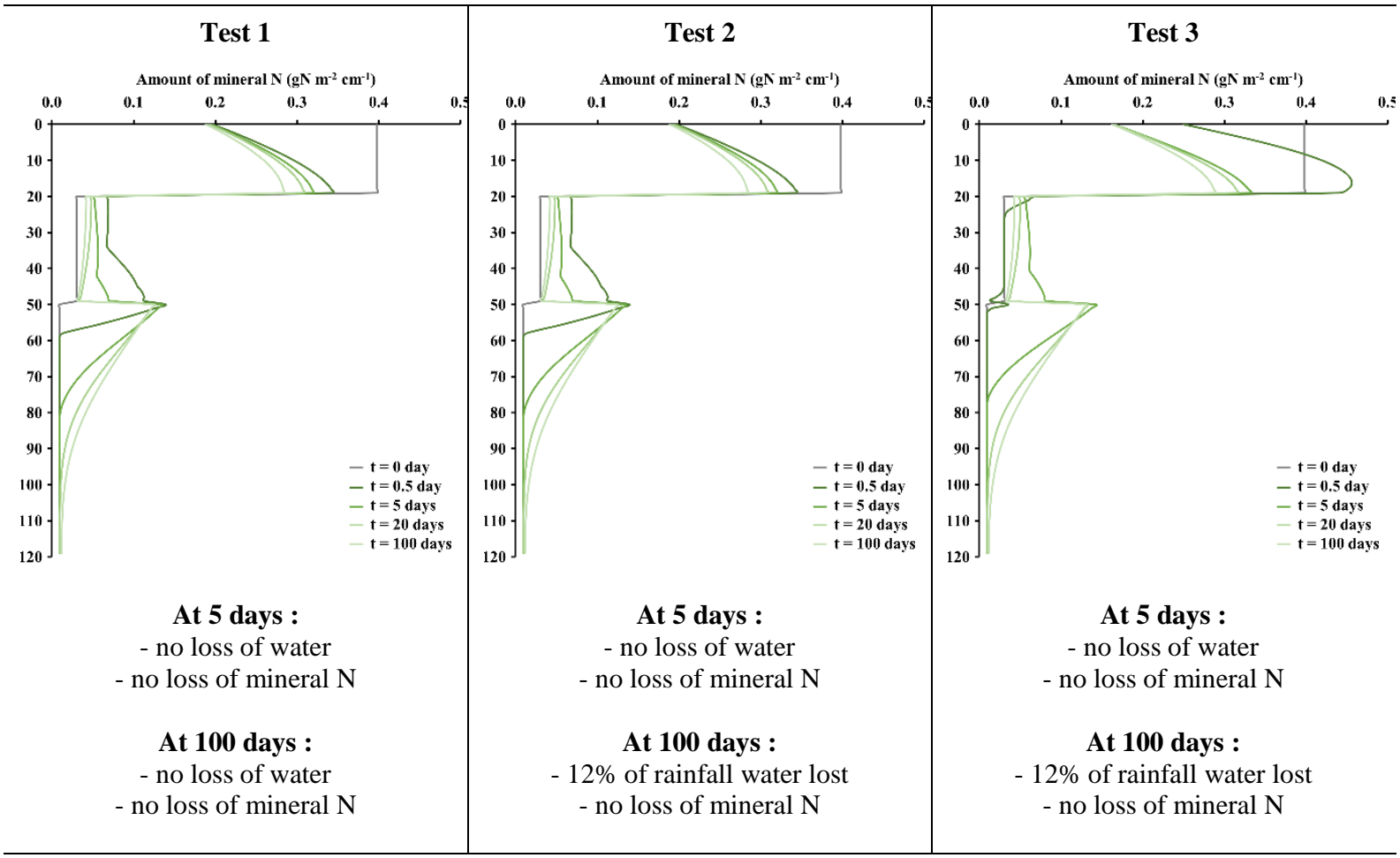

\section{Treatment 6}

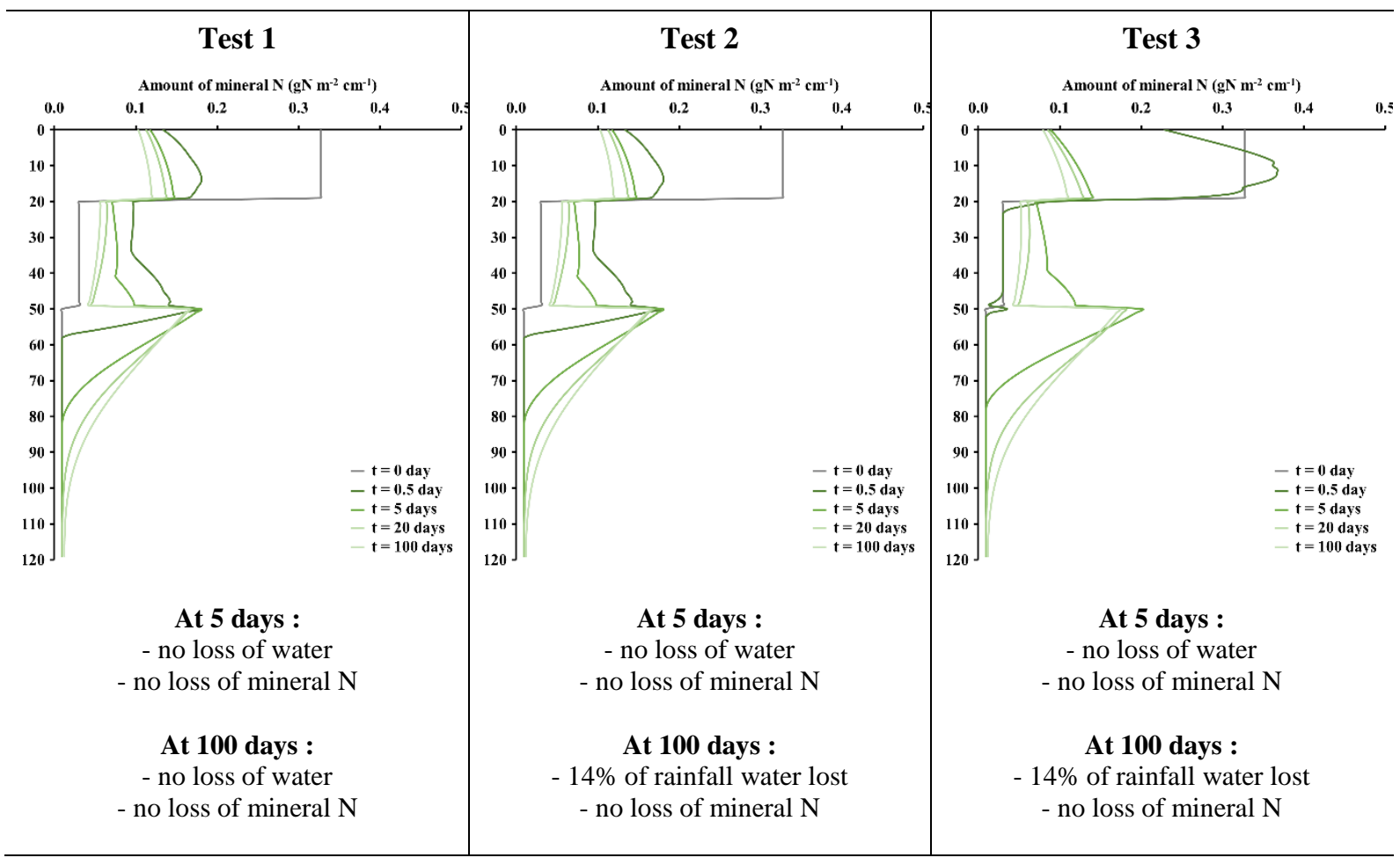

Peer-reviewed, unedited version of the manuscript of Rees et al. (2020) published by Applied Geochemistry: 


\section{References}

Durner, W., 1994. Hydraulic conductivity estimation for soils with heterogeneous pore structure. Water Resources Research 30, 211-223. https://doi.org/10.1029/93WR02676

Šimůnek, J., van Genuchten, M.T., Šejna, M., 2008. Development and Applications of the HYDRUS and STANMOD Software Packages and Related Codes. Vadose Zone Journal 7, 587-600. https://doi.org/10.2136/vzj2007.0077 